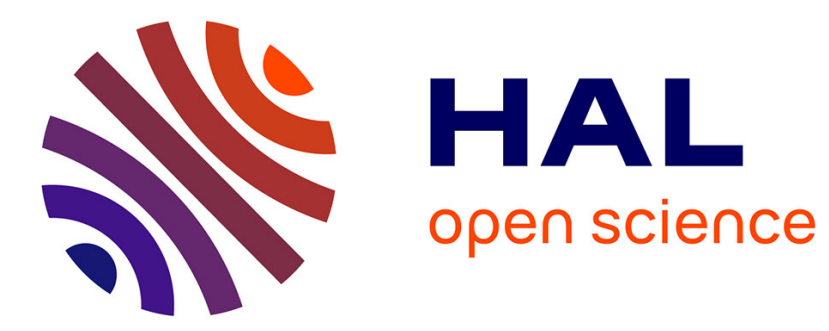

\title{
Drug releasing nanoplatforms activated by alternating magnetic fields
}

Damien Mertz, Olivier Sandre, Sylvie Begin-Colin

\section{To cite this version:}

Damien Mertz, Olivier Sandre, Sylvie Begin-Colin. Drug releasing nanoplatforms activated by alternating magnetic fields. Biochimica et Biophysica Acta (BBA) - General Subjects, 2017, 1861 (6), pp.1617-1641. 10.1016/j.bbagen.2017.02.025 . hal-01476632

\section{HAL Id: hal-01476632 \\ https://hal.science/hal-01476632}

Submitted on 25 Oct 2018

HAL is a multi-disciplinary open access archive for the deposit and dissemination of scientific research documents, whether they are published or not. The documents may come from teaching and research institutions in France or abroad, or from public or private research centers.
L'archive ouverte pluridisciplinaire HAL, est destinée au dépôt et à la diffusion de documents scientifiques de niveau recherche, publiés ou non, émanant des établissements d'enseignement et de recherche français ou étrangers, des laboratoires publics ou privés. 


\title{
Drug releasing nanoplatforms activated by alternating magnetic fields
}

\author{
Damien Mertz ${ }^{1,}{ }^{*}$, Olivier Sandre ${ }^{2}$, Sylvie Begin-Colin ${ }^{1}$
}

\author{
${ }^{1}$ Institut de Physique et Chimie des Matériaux de Strasbourg, Université de Strasbourg, UMR 7504 CNRS, 23, \\ rue du Loess, 67034 Strasbourg, France.E-mail: damien.mertz@ipcms.unistra.fr \\ ${ }^{2}$ Laboratoire de Chimie des Polymères Organiques (LCPO), CNRS UMR 5629, Université de Bordeaux, Bordeaux- \\ INP, Pessac 33607 Cedex, France
}

\begin{abstract}
The use of an alternating magnetic field (AMF) to generate non-invasively and spatially a localized heating from a magnetic nano-mediator has become very popular these last years to develop magnetic hyperthermia $(\mathrm{MH})$ as a promising therapeutic modality already used in the clinics. AMF has become highly attractive this last decade over others radiations, as AMF allows a deeper penetration in the body and a less harmful ionizing effect. In addition to pure $\mathrm{MH}$ which induces tumor cell death through local T elevation, this AMF-generated magneto-thermal effect can also be exploited as a relevant external stimulus to trigger a drug release from drug-loaded magnetic nanocarriers, temporally and spatially. This review article is focused especially on this concept of AMF induced drug release, possibly combined with $\mathrm{MH}$. The design of such magnetically responsive drug delivery nanoplatforms requires two key and complementary components: a magnetic mediator which collects and turns the magnetic energy into local heat, and a thermoresponsive carrier ensuring thermo-induced drug release, as a consequence of magnetic stimulus. A wide panel of magnetic nanomaterials/chemistries and processes are currently developed to achieve such nanoplatforms. This review article presents a broad overview about the fundamental concepts of drug releasing nanoplatforms activated by AMF, their formulations, and their efficiency in vitro and in vivo.
\end{abstract}

\section{Introduction}

Today, it is admitted that the combination of therapies is a way to considerably increase the efficacy of a treatment, for instance in the case of anti-cancer treatments. Besides, the follow-up of therapy by imaging is reported of paramount importance because it brings precious information spatially and in real-time to improve and optimize the therapy efficacy.[1,2] To face these challenges, nano-platforms based on nanoparticles (NPs) are very promising because NPs bring key features to overcome the major drawbacks of conventional medicines, namely poor bioavailability, insufficient target specificity, and significant side effects. There are various types of therapies offered by NPs that are mainly : drug delivery[3], gene therapy[4], photodynamic therapy (PDT) [5], photothermal therapy (PTT) [6] and magnetic hyperthermia (MH) [7]. Considering the blossoming growth of nanotechnology which has brought challenging innovations in the synthesis of such multifunctional nano-objects for therapeutic applications, the targeted and local drug delivery controlled by an external stimuli using nanoparticulate systems has emerged as a very promising strategy for nanomedicine. The concept of NP-mediated-drug delivery systems (DDS) or "nanodevices" (medical devices having simplified 
regulatory route towards authorization in clinics as compared to medicines) involves the incorporation of a drug within nanoparticulate carriers via encapsulation, absorption, adsorption, or conjugation, for safe and stable administration in the body. Besides, an enhanced delivery and controlled release at target sites can be envisioned with such carriers through the incorporation of a cocktail of drugs aimed at combination therapy of complex diseases, such as cancer, where a single drug is rarely effective.[8,9]

For nanoplatforms used in intravenous injection, controlling the drug transport in the blood flow but also the cell targeting and the cell internalization in organs (biodistribution) are key issues.[10-12] It is now admitted and demonstrated that nanocarriers allow improving the delivery of chemotherapeutics whereas for drug alone, there are various issues such as poor water solubility of drugs, their rapid drug clearance, nonspecific biodistribution, toxicity to healthy tissues, etc... Indeed, as stated by Ulbrich et al., "It has been reported that about $40 \%$ of the drugs being developed by the pharmaceutical industry are poorly water soluble molecules."[13] Furthermore, surface functionalization of the NPs is needed to impart blood circulation and carry the drugs to the targeted tissues/cells. In addition, there are several other issues to overcome with the intravenous injections: opsonization i.e. the adsorption of plasma proteins followed by subsequent RES uptake; suitable cell internalization (i.e. cytoplasm or nucleus entry); and the relevance of active vs. passive cell targeting.

Regarding nanocarrier design, a further issue is controlling the drug release with biological or externally applied stimuli. The triggering of drug release can be achieved either by local biological stimuli $(\mathrm{pH}$, redox, enzymes) or by externally applied radiation (light/electromagnetic fields, focused ultrasound).[14-16] Local triggers are encountered in various biological environments e.g. acidic pH tumor, lysosomal compartments, reductive cytosol, however in such environments there is no possibility of remote activation or dose control over drug release as the parameters are defined by the biological environment. Here only a burst or "one shot" release may be envisioned in this case. The triggering of drug release was also developed recently from polymer films by the use of mechanical forces [17-19]. The external or remote triggers present advantages to achieve drug release with spatiotemporal control. The nanoplatforms can be also designed to ensure pulsatile release i.e. the drug can be released several times on demand with control over the diffusion rates and the times of drug release. However, this requires a specific, well-controlled and/or sophisticated design.

Among the various external stimuli such as electromagnetic or acoustic waves, the use of an alternating magnetic field (AMF) is becoming highly attractive over others, as it allows a deeper penetration in the body compared with near infrared (NIR) light, that is comparable to ultrasound (US), and a less harmful ionizing effect compared with X-ray radiations. Since two decades, the conversion of the magnetic induction energy AMF into a non-invasively and spatially localized heating from a magnetic mediator is investigated to develop $\mathrm{MH}$, a therapeutic modality which acts in inducing tumor apoptotic cell death through local controlled T elevation and "thermal dose" deposition. This nevertheless must be achieved within a certain range of frequency and field strength, which is called Brezovitch criterion.[20,21] Indeed, in 1988, to consider as negligible the effects due to nonspecific heating and nervous system activation by the electric field associated to the AMF, Atkins and Brezovich proposed a safety limit where the product of magnetic field and amplitude 
frequency $\left(\mathrm{H}_{0} \times \mathrm{f}\right)$ should not exceed $4.85 \times 10^{8} \mathrm{~A} \mathrm{~m}^{-1} \mathrm{~s}^{-1}$ to avoid parasitic eddy current effects on the organism. Since recent years, this AMF-generated magneto-thermal effect can also be exploited as a relevant external stimulus to trigger a drug release from drug-loaded magnetic nanocarriers, temporally and spatially. This magnetically induced drug release [22-24]sometimes called "magneto-chemotherapy" can be thus envisioned as a complementary promising therapeutic modality to pure $\mathrm{MH}$. In any case, the drug release is activated by an AMF-generated local heating (at $\mathrm{nm}$-scale) which may be mutualized with $\mathrm{MH}$ if macroscopic $\mathrm{T}$ elevation is reached above a threshold, typically $43^{\circ} \mathrm{C}$. In other words, magnetically induced drug release can also occur without macroscopic T elevation, provided that the local T can generate a high local structural change of the carrier, triggering the drug release from the nanoplatform. Hence this requires loading the drug in a nanoplatform composed of two key components: a magnetic mediator which collects and turns the magnetic energy into local heat, and a thermoresponsive carrier/binder ensuring thermo-induced drug release, as a consequence of magnetic stimulus. A wide panel of magnetic nanomaterials / chemistries and processes are currently developed to achieve magnetically activated drug releasing platforms.

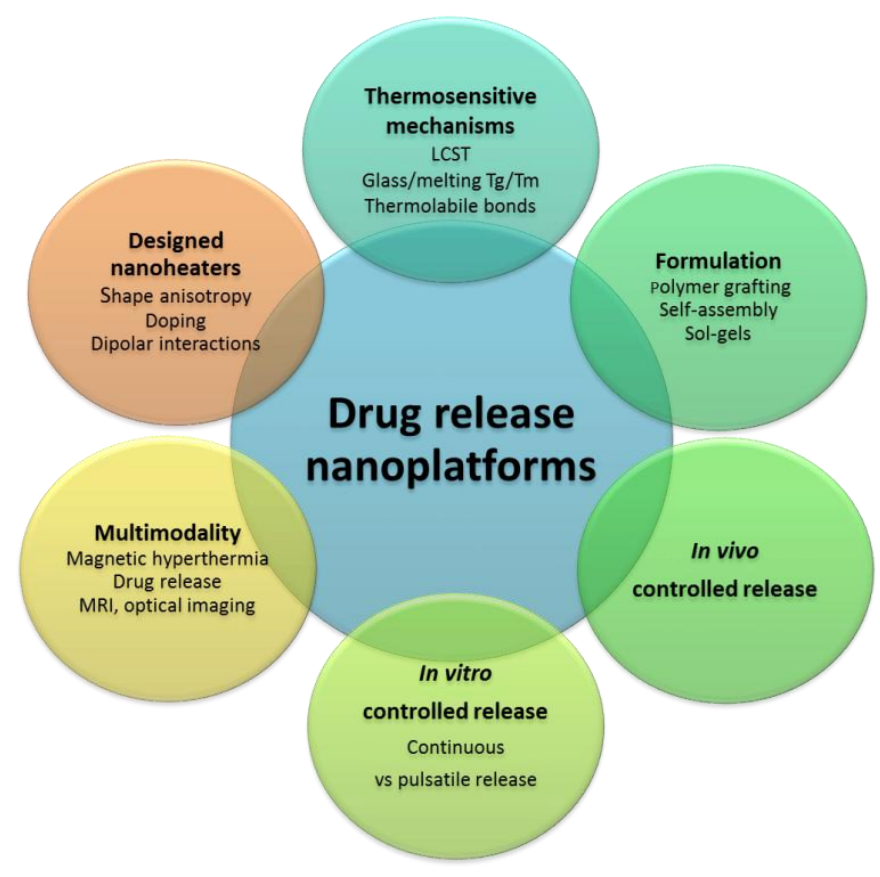

Figure 1. Concepts and challenges for the design of drug releasing nanoplatforms under AMF.

This review deals with the design of drug releasing magnetic nanoplatforms activated by external AMFs. In Part 2, we detail the fundamental concepts and the design of magnetic nanoheaters, the main mechanisms of thermo-responsive nanocarriers, the synthesis methods of thermoresponsive nanoplatforms loaded with magnetic NPs and hydrophobic or hydrophilic drugs (or both), and the experimental implementation of the in vitro assay of drug release activated upon AMF with a standardized set-up. These elements are conceptually and experimentally crucial to ensure the rational design and applications of suitable magnetic nanoplatforms displaying an efficient drug release upon AMF. Then, in Part 3, we provide a broad overview of the currently existing systems which were reported efficient to release drugs upon AMF application. For the sake of clarity, these magnetic nanoplatforms or nanomaterials are divided into four types : i) magnetic core-polymer shells, 
ii) hollow aqueous core filled shells including vesicles (liposomes, polymersomes, hybrids...) and double emulsion or templated polymer capsules, iii) polymer-based nanoparticles including nanogels, micelles and hydrophobic NPs, and iv) hybrid inorganic nanocomposites that are essentially made of a mesoporous silica matrix. The efficiency of AMF-induced drug release and the main in vitro results with cells are presented in this part to highlight the significance of the drug release combined with hyperthermia effect. In Part 4 , a focus on in vivo AMF-induced drug release is provided and the results all along this decade (since 2010) are reviewed. Indeed, this review aims at providing to the readers the main concepts of the topic but also the main performances with in vitro and in vivo results that were gathered and summarized (Figure 1). Hence, we expect that this review will hopefully provide a comprehensive and up-to-date overview of the field which may serve for future (pre)clinical purposes to chemists, physicians, biologists or clinicians. Drug releasing nanoplatforms upon AMF were never reviewed as an alone review as to date, the remote release by AMF especially in vivo being very recent (within last five years). There are reviews dealing partially with this topic or associated with other connected topics such as: Remotely Triggerable Drug Delivery Systems [25], Magnetoresponsive polymerbased materials [26,27], Remotely triggered nanovehicles actuated by the use of electromagnetic and acoustic waves [14,28], Chemothermotherapy[29], Iron oxide for magnetic resonance imaging (MRI) and therapy [2931], and Thermoresponsive carriers [33,34], Design of organic macrocycle modified iron-oxide nanoparticles for drug delivery.[35]

\section{Criteria and challenges for the design of magnetically drug releasing nanoplatforms}

This part aims at describing how magnetic hyperthermia (MH) is provided (through the design of nanoheaters), how AMF-induced MH may be the trigger of controlled release (thermoresponsive mechanisms), and how MH may be combined with both drug and nanoheater encapsulation (dual loading formulation).

\subsection{Mechanisms and challenges of MH: design of the magnetic nanoheaters}

Iron oxide based nanoparticles (IONPS) are widely used for biological applications thanks to their outstanding balance between superpara- or ferrimagnetic properties, surface-to-volume ratio suitable for efficient functionalisation and proven biocompatibility. Their development for MRI or MH concentrates much of the attention as these nanomaterials are already used within the health system as contrast agents or iron supplement (e.g. Ferumoxytol) and heating mediators.

Indeed IONPs are commercially used as $\mathrm{T}_{2}$ (i.e. negative) contrast agents (CAs) for MRI [36,37] and are of particular interest as biodegradable and non-toxic nano-objects compared to other CA families. To be used as in vivo MRI CAs, NPs should exhibit a high saturation magnetization and be functionalized with molecules leading to biocompatible stable suspensions in physiological media with average hydrodynamic sizes smaller than $50 \mathrm{~nm}$ for ensuring a good in vivo pharmacokinetics (e.g. for angiography) and biodistribution (for tumor labeling).

IONPs are also developed for MH. When exposed to AMF of appropriate amplitude and frequency, these NPs release heat locally (where they are concentrated), which reduces the viability of cancer cells through apoptotic or necrotic pathways. The MH potential is demonstrated with the favorable recent results of the "nanothermotherapy" study in clinical phase II ended in 2011 led by a German company MagForce ${ }^{\mathrm{TM}}$ 
Nanotechnology (hospital Charité in Berlin) which has led to a European market authorization [38-41]. MH has been demonstrated to enhance the sensitivity of tumor cells to facilitate chemo- or radio-therapies $[38,39]$ and to act on cell membranes or to trigger a thermally-induced release of drugs.[42]

However one of the limitations of $\mathrm{MH}$ is the low heating power of usual magnetic NPs, requiring a local injection of NPs in large quantities (e.g. $160 \mathrm{~g} \cdot \mathrm{L}^{-1}$ iron oxide for MagForce ${ }^{\mathrm{TM}}$ ). Given the clinical importance of $\mathrm{MH}$ as therapy and also as possible local heater for drug release, there is thus currently a crucial need to design optimized NPs for efficient MH.[43-45] However optimization is not yet well-understood and experimental characterization methods and results on magnetic NPs vary widely. Indeed in $\mathrm{MH}$, very specific physical properties are required for an optimal conversion of the supplied magnetic energy into heat. Three independent mechanisms result in thermal energy upon stimulation: Néel relaxation (internal friction of the magnetic moment with respect to the crystal lattice of NPs), Brown relaxation (external friction of the NPs in the surrounding viscous medium) and hysteresis of the DC magnetization curve (shift of domain walls for multidomain NPs).[46,47] The relative contribution of each mechanism is strongly dependent upon size, shape, crystalline anisotropy and degree of aggregation or agglomeration of the NPs. Static hysteresis loss is encountered with large multi-domain particles. Single domain superparamagnetic NPs, which display smaller size than that of multi-domain particles, absorb much more power at biologically tolerated magnetic fields/frequencies and form more easily stable suspensions. For these small sized NPs, the Néel and Brown relaxations are the main mechanisms of magnetic moment relaxation, and their heating power is related to hysteresis of the AC magnetization curve: contrary to the static magnetization curve that is perfectly reversible for superparamagnetic NPs, AC magnetometry performed under a radiofrequency field evidences a delay between magnetization and magnetic field, ascribed to non-zero relaxation times. The heating efficiency is proportional to the surface area of this dynamic hysteresis.[48] Néel and Brown relaxation times are mainly governed by the magnetocrystalline anisotropy constant, i.e. an intrinsic property of the material which gives a preferred orientation of the magnetic moment called "easy axis", the volume of NPs and the viscosity of the medium. Brownian relaxation will tend to dominate at larger particle volume and lower viscosities while the Néel relaxation will at smaller volumes of NPs and in viscous solutions or when the magnetic NPs are physically blocked (in frozen solvent or intra-cellular compartments). However, these relaxation rates depend also strongly on the NP anisotropy energy, which is the product of the anisotropy constant $\mathrm{K}_{\mathrm{a}}$ (with materials, shape anisotropy and surface contributions) by the NP volume, $[43,44]$ and this is currently a key challenge to overcome in the design of NPs with magnetic properties specifically tailored for hyperthermia related applications.[30,37,46,49,50]

The heating efficiency of an ensemble of magnetic NPs depends not only on the structural and magnetic properties of NPs but also on the magnitude and frequency of the applied AMF. Indeed the heating performance is usually assessed by determining the specific absorption rate (SAR) which is the power dissipated by magnetic NPs per unit of mass of magnetic materials [51] : SAR $=\mathrm{C} / \mathrm{m} \times \mathrm{dT} / \mathrm{dt}$ with $\mathrm{C}$, the water (or medium) specific heat capacity per unit of volume, $m$ the iron oxide (or sometimes only the equivalent iron) concentration in suspension $\left(\mathrm{Fe}_{x} \mathrm{O}_{\mathrm{y}}\right.$ or $\left.\mathrm{Fe} \mathrm{g} \cdot \mathrm{L}^{-1}\right)$ and $\mathrm{dT} / \mathrm{dt}$ the initial increase rate of measured temperature. The best methodology for SAR measurement is still under debate, as experimental setups are rarely adiabatic and 
thermal losses are sources or error in the determination of SAR (in $W \cdot g^{-1}$ ), which values depend on the structure and composition of the NPs but also on the frequency (f) and the amplitude (i.e. the maximal value of the sine function) of the magnetic field strength $(H)$ applied during the measurements. $[43,44,47]$ For an efficient heat treatment with minimal invasiveness for the patient, the search for new magnetic nanomaterials which show the highest SAR values at the lowest NPs dose administered and at the lowest frequency and/or magnetic field amplitude applied is of paramount relevance.[52,53] For superparamagnetic NPs, SAR values usually increase by increasing either the frequency or the magnetic field amplitude (or both) applied during the measurements. However, the variation of SAR linear in frequency and quadratic in field amplitude predicted by the "linerar relaxation model" is only valid at low field values (typically below $5 \mathrm{kA} \cdot \mathrm{m}^{-1}$ ), and recent experiments and models rather show scaling laws of different exponents, and a saturation of SAR to plateau values at large field intensity. [48] For a safe application of hyperthermia to patients, it was proposed that the product of the frequency and the magnetic field amplitude $(\mathrm{H} \times \mathrm{f})$ should be smaller than $5 \times 10^{9} \mathrm{~A} \cdot \mathrm{m}^{-1} \cdot \mathrm{s}^{-1}$, i.e. ten times the Brezovich limit, although this criterion was quite arbitrary and still under debate.[52] However, many of the SAR values reported so far for magnetic NPs are measured at frequencies between 300 and $700 \mathrm{kHz}$ and fields between 10 and $30 \mathrm{kA} \cdot \mathrm{m}^{-1}$, resulting in $\mathrm{H} \times \mathrm{f}$ factors which are mostly largely above this limit (ca. 2-4 times higher). Furthermore, the lack of standard devices or established measurement protocols contributes to an increase of the variability of the SAR values reported in the literature for magnetic NPs. [39]

For frequencies of the magnetic field used in hyperthermia studies compatible with clinical use, the linear relaxation model indicates an optimal distribution of diameters centered around $14 \mathrm{~nm}$ for standard spherical NPs but, given the variation in the anisotropy of the different synthesized magnetite $\left(\mathrm{Fe}_{3} \mathrm{O}_{4}\right) \mathrm{NPs}$, the experimental optimal diameter appears to fall between a broad range between 12 and $20 \mathrm{~nm} .[43,44,49]$ Indeed magnetic properties of iron oxide NPs strongly depends on their synthesis way,[54-56] and SAR values depend strongly on the measurement parameters (field frequency and amplitude, viscosity, NP concentration) which strongly vary from one paper to another. This makes that the published SAR values are very difficult to compare. Among the highest SAR values for standard spherical NPs obtained in conditions compatible with clinical uses $\left(\mathrm{H} \times \mathrm{f}<5 \times 10^{9} \mathrm{~A} \cdot \mathrm{m}^{-1} \cdot \mathrm{s}^{-1}\right)$ found up to now in the literature are those obtained for IONPs with a diameter of $30 \mathrm{~nm}$ synthesized by chemical methods followed by a size selection process $\left(600 \mathrm{~W} \cdot \mathrm{g}^{-1}\right.$ at $400 \mathrm{kHz}$, $13 \mathrm{mT}$ ), or magnetite NPs produced by bacteria (magnetosomes $960 \mathrm{~W} \cdot \mathrm{g}^{-1}$ at $410 \mathrm{kHz}, 12.5 \mathrm{mT}$ ).[57,58] One may just conclude at this point that by imposing hyperthermia measurement conditions compatible with clinical uses $\left(\mathrm{H} \times \mathrm{f}<5 \times 10^{9} \mathrm{~A} \cdot \mathrm{m}^{-1} \cdot \mathrm{s}^{-1}\right)$, magnetocrystalline anisotropy, saturation magnetization and sizes of the NPs would be the key parameters to consider for optimizing the heating capability of NPs.

Doping of iron oxide with Co or Mn cations has been proposed as a way to improve SAR.[30,43] For example cobalt ferrite NPs were found to have very large SAR values (up to $720 \mathrm{~W} \cdot \mathrm{g}^{-1}$ ).[46] However, up to now most works were devoted to pure IONPs[23] because of their proven biocompatibility and ease of synthesis and of tuning of their size within a narrow size distribution. Despite their high potential, the development of doped ferrites was thus limited, their synthesis being generally more complex (chemical heterogeneities)[59$61]$ and their biocompatibility being discussed. 
Nevertheless, current progress in synthesis allows now synthesizing NPs with different shapes and coreshell structures that are highly promising to optimize heating efficacy. By playing on the NP shape e.g. via the synthesis of cubic iron oxide NPs[53,62] or cobalt ferrite nanocubes[61] or flower-shaped nanostructures which enable cooperative or frustrated (spin glass) magnetism[63-65], the heating power was recently considerably improved up to SAR values in the range $1000-2000 \mathrm{~W} \cdot \mathrm{g}^{-1}$. Besides, the capping of inorganic shells on magnetic core allows e.g. to shield non biocompatible doped-ferrites NPs by a protecting shell such as silica or to modify the magnetocrystalline anisotropy of the resulting core-shell systems (through exchange interaction between materials of different anisotropy constants $\mathrm{K}_{\mathrm{a}}$ ). Indeed, a very important anti-tumor effect induced by $\mathrm{MH}$ has been noticed with core-shell NPs consisting of a core with a high $\mathrm{K}_{\mathrm{a}}$ and of a shell with a low $\mathrm{K}_{\mathrm{a}}$ value.[45]

However, the heat released by magnetic NPs does not depend only on their intrinsic properties but also on dipolar magnetic interaction between individual NPs building up as the concentration increases. [66,67] The effect that dipolar interactions might have on SAR is not completely understood at present and has often not been properly addressed in the past years. $[62,68,69]$ Experimental studies reported either a decrease or an increase of SAR with interactions.[62,66-68,70,71] In fact, depending on the NP anisotropy $K_{a}$, dipolar interactions may act differently on the clustering/spatial arrangement of NPs under an applied magnetic field leading either to their aggregation or to their alignment in chains. A very recent evaluation of these interaction effects $[62,68]$ and studies on magnetosomes synthesized by bacteria[57,58] pointed out that chains of ferromagnetic NPs are ideal candidates for obtaining high SAR values, introducing a coercivity field and opening a "square hysteresis". Furthermore, the cubic shape of NPs would favor the NPs geometrical arrangement compared to the spherical shape. Indeed chains of nanocubes can form due to the existence of strongly anisotropic dipolar forces mediating nanoparticle attachment.[62,68] Serantes et al. reported the positive effect of oriented attachment of $44 \mathrm{~nm}$ NPs on hyperthermia properties.[71] The formation of chains with core-shell nanocubes at low concentration was observed by TEM without applying any magnetic field[72]. These observations may thus explain the high SAR values obtained at low concentration with these nanocubes by contrast to values obtained at high concentration. Indeed at high concentration, aggregates form due to enhanced dipolar interactions and then the benefit effects of the geometric arrangement is lost. Thus $\mathrm{MH}$ by using iron oxide based NPs is quite complex as it depends on NP materials properties but also on dipolar interaction between them, and on the magnitude and frequency of the applied AMF which are limited by the $\mathrm{MH}$ equipment. Nevertheless, there are currently designed magnetic NPs (nanocubes, nanoflowers, coreshells....) with optimized $\mathrm{MH}$ properties in conditions compatible with clinical uses. Therefore the existence of suitable magnetic nanoheaters is promising for the release of drug triggered by locally deposited heat, itself generated internally by $\mathrm{MH}$, a strategy sometimes referred to as "magneto-chemotherapy".

\subsection{Thermoresponsive bonds, polymers and nanocarriers: concepts and mechanisms}

Criteria for the design. The ideal thermo-responsive nanocarriers should be designed, on the one hand, to efficiently load a sufficient amount of drugs together with magnetic NPs for an efficient therapy, with neither burst nor sustained release at physiological $\mathrm{T}$, and on the other hand to achieve a timely and spatially controlled drug release through a rapid magnetothermal response. Indeed, the drug release has to be 
controlled in time, in location, and in dosage, with the possibility to perform sequential or pulsatile release. Designing thermosensitive carriers that can achieve such a degree of time and spatially-controlled response, i.e. at a specific upper hyperthermia temperature $T_{\max }$ not damaging the healthy tissues, requires a specific thermal response with well-defined structural characteristics. To face these challenges, nanocarriers with various mechanisms of thermo-responsiveness have been explored in recent literature:

i) Polymers or copolymers displaying a lower critical solution temperature (LCST)

ii) Thermosensitive lipid bilayers or polymer matrix presenting either a melting $\left(T_{m}\right)$ or a glass transition temperature $\left(\mathrm{T}_{\mathrm{g}}\right)$

iii) Thermolabile (non-covalent) and thermodegradable (covalent) bonds with the drug

i) LCST-polymers and nanocarriers. Probably the most reported approach involved in a broad range of thermoresponsive nanocarriers is to use the thermal response of polymers that display a dramatic volume change or coil-to-globule transition at a specific T called LCST. Below the LCST, the polymer chains are extended and fully hydrated in water through $\mathrm{H}$-bonds, and when the medium $\mathrm{T}$ is increased above the LCST, interactions with solvent are disrupted to the benefit of inter- or intra-chain bonds, and the polymer phase segregates through $\mathrm{H}$-bonds and hydrophobic interactions (Figure 2). There are various polymers or copolymers exhibiting a LCST in the physiological temperature range, which is an attractive feature for biomedical applications.[26,33,34] The main reported polymer is poly(N-isopropylacrylamide) (PNIPAM)[73] with a LCST of $32^{\circ} \mathrm{C}$, but other LCST amphiphilic polymers are also used such as poly(vinlycaprolactam) (PVCL, LCST $\left.25-35^{\circ} \mathrm{C}\right)[74]$, PEO- $b$-PPO- $b$-PEO i.e. triblock copolymers of ethylene oxide and propylene oxide (Pluronics ${ }^{\mathrm{TM}}$ F127, LCST of $c a$. $37^{\circ} \mathrm{C}$ ) $[75,76]$, hydroxypropyl cellulose (HPC, LCST $41^{\circ} \mathrm{C}$ ) $[77,78]$ or elastin-like polypeptides (ELPs) (LCST range of 10 to $70^{\circ} \mathrm{C}$ depending on the choice of guest residue $X$ in the repetition sequence of the -VPGXG- pentapeptide)[79,80].
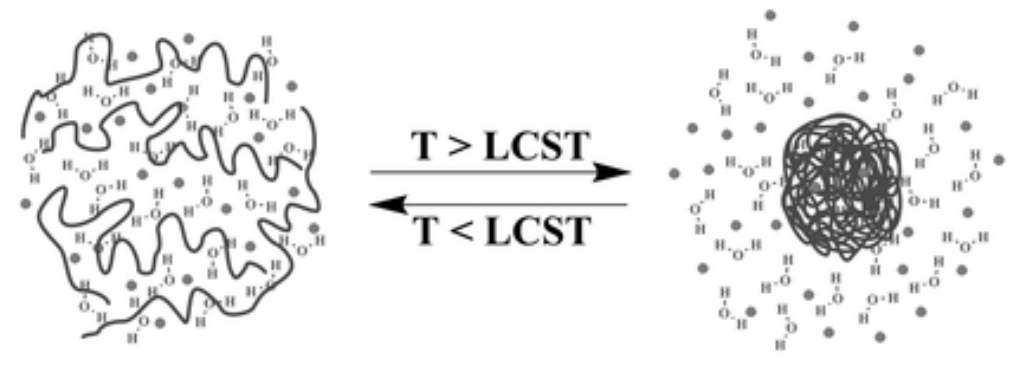

- Hydrophilic drug

Figure 2. Illustration of the volume phase transition obtained with LCST polymers leading to a coil-to-globule conformation change. Above LCST, the aqueous content (drug) is released through polymer chain collapse. [81] Reprinted with permission (Publisher name)

However to ensure a suitable drug release at a macroscopic temperature reachable by $\mathrm{MH}$ without damaging healthy surrounding tissues (typically $42^{\circ} \mathrm{C}$ ), the thermo-responsive polymer should be in a hydrated state at physiological T $\left(37^{\circ} \mathrm{C}\right)$ and its LCST should be above ca. $41-42^{\circ} \mathrm{C}$ but not higher than $43^{\circ} \mathrm{C}$. Co-polymerization methods especially controlled radical polymerizations (CRP) including atom transfer radical polymerization (ATRP)[82,83], ring opening polymerization (ROP)[84,85], reversible addition-fragmentation chain transfer (RAFT)[86,87] are particularly well-suited to adjust finely the required LCST. Indeed, the LCST will depend on 
the composition between the hydrophobic and the hydrophilic parts of the thermosensitive block copolymer.[13,28,33] Introducing a hydrophilic part allows shifting the LCST towards higher value while increasing the hydrophobic part favors lower LCST values. Furthermore, a narrow thermal transition requires copolymers with well-defined architecture rather than statistical copolymers that not only shift but also broaden the LCST range.

LCST polymers are key components in the design of various thermo-responsive nanocarriers and are used as polymer brushes, or coatings at the surface of inorganic NPs (preferentially as a dense brush rather than in dilute "mushroom" regime), or as building blocks of nanogels or micelles. Thus, LCST polymer shells can be anchored at the surface of IONPs, and be loaded with drugs via hydrophilic interactions and ensure the sneezing out of the drugs when T reaches the LCST, i.e. when the polymer becomes hydrophobic.[27,88] LCST polymers have also been grafted at the surface of mesoporous silica (MS), and play the role of thermoresponsive gatekeepers controlling the pore aperture of MS NPs with T and then the diffusion of the initially embedded drugs towards the outside medium of the silica NPs.[89] Thus, Liu, Yang et al. [90] have shown that Zn(II) phthalocyanine used as a PDT sensitizing drug could be efficiently loaded (drug loading content, $\mathrm{DLC}=18 \%$,) in magnetic MS cores coated with a thermo-sensitive P(NIPAM-co-NHMA)polymer shell that was copolymerized from the silica surface. The authors have shown that the LCST could be adjusted from 38 to $44^{\circ} \mathrm{C}$ with the composition of the copolymer, P(NIPAM-co-NHMA) acting as a gatekeeper. In a very recent work, Baeza, Vallet et al.,[91] grafted P(NIPAM-co-NHMA) copolymers at the surface of magnetic MS composite NPs loaded with fluorescein according to two different polymerization pathways: a cross-linked or a hairy P(NIPAMco-NHMA) copolymer shell. The triggered release of fluorescein was studied at 37 and $50^{\circ} \mathrm{C}$, and opposite controlled release behaviors were obtained according to the polymerization pathway. Indeed, the hairy polymer layer collapsed and blocked the drug diffusion upon T increase above LCST while the cross-linked polymer shell ensured an enhancement of the drug diffusion when it shrunk.

LCST polymers are also part of nanogels which are physically- or chemically-crosslinked systems in a hydrated or swollen state below the LCST that undergo an important volume phase transition (VPT) (i.e. gel shrinkage) above the LCST. Above the LCST, the important polymer shrinking effect ensures the diffusion of water out of the gel, together with its solubilized content. Hence in a work by Rubio-Retama et al.,[92] thermosensitive PNIPAM polymer was used to form monodisperse submicron microgels decorated with $\nu-\mathrm{Fe}_{2} \mathrm{O}_{3} \mathrm{NPs}$ through a surfactant-free radical polymerization. The authors have shown that a loading content of $18 \%$ IONPs allowed changing the LCST from 36 to $40^{\circ} \mathrm{C}$, and to induce a submicron gel size shrinking from ca. 600 to $300 \mathrm{~nm}$ indicating the broad potential of magnetic nanogels for drug delivery.

In another study by Zaher et al[93],composite membranes made of blends of ethyl cellulose or cellulose acetate, PNIPAM microgels and IONPs exhibited enhanced permeability by application of an AMF (62 mT, 50 $\mathrm{kA} \cdot \mathrm{m}^{-1}, 450 \mathrm{kHz}$ ). With a thickness around $20 \mu \mathrm{m}$, such membrane was used as magnetically controllable valve to tune the effusion rate of a drug model (rhodamine B) between the donor and acceptor chambers of an osmotic pump.

ii) Nanocarriers with melting $\left(T_{m}\right)$ or glass transition $\left(T_{g}\right)$ temperatures. Aside from the LCST polymer-based nanocarriers, there are also self-assembled vehicles that respond upon T variation by a change in their matrix 
permeability or membrane fluidity, associated with a thermal transition that can be $a T_{m}$ ( $1^{\text {st }}$ order transition) or a $\mathrm{T}_{\mathrm{g}}\left(2^{\text {nd }}\right.$ order or pseudo-transition). For instance, thermosensitive liposomes (TSLs) which were introduced almost forty years ago[94,95] usually respond upon T increase by a thermal destabilization of their hydrophobic bilayer membrane which becomes leaky /more permeable and allows the transfer of molecules from the inner aqueous core to the external solution. Various works and reviews reported that such effects were attributed to the main chain melting $\left(T_{m}\right)$ temperature transition where the lipid bilayer turns from a gel phase $\left(L_{\beta}\right)$ to a liquid crystalline state $\left(L_{\alpha}\right)$, the boundary line between the two phases coexisting at the transition $T_{m}$ acting as defects enhancing solute permeation trough the membrane. This phenomenon allows a reversible permeation of the bilayer membrane ensuring a time-controlled release of the drugs. Dipalmitoyl-sn-glycerophosphocholine (DPPC, $\mathrm{T}_{\mathrm{m}}$ of $41.5^{\circ} \mathrm{C}$ ), often combined with cholesterol was historically the first lipid to be used to form TSLs with a $T_{m}$ close to the clinically relevant hyperthermia T.[28,96,97] Other lipids e.g. distearoyl-sn-glycerophosphocholine (DSPC, $\mathrm{T}_{\mathrm{m}}$ of $55^{\circ} \mathrm{C}$ ) were used to improve the amount and rates of drugs released.[98] It is interesting to note that TSLs encapsulating doxorubicin in their lumen have been patented 20 years ago and commercialized under the brand name Thermodox ${ }^{\mathrm{TM}}$, leading to both pre-clinical [99] and clinical trials [100] on various cancers.

With much longer molecules than lipids like polymers, a soft and reversible temperature transition can arise either at a true $\mathrm{T}_{\mathrm{m}}$ for semi-crystalline polymers, typically short and stereo-regular chains, or at the glass transition $\mathrm{T}_{\mathrm{g}}$ also encountered for longer or more rigid chains. This is in particular the case with polymer vesicles named polymersomes [101,102], polymer emulsion nanocapsules $[27,103]$ or poly(D,L-lactide-coglycolide) (PLGA)-based NPs.[104,105] In these various works, a reversibly thermally controlled-permeability ensuring the drug release without structural alteration effects on the polymer matrix (3D) or membrane (2D) was achieved. Such a response is particularly suitable to ensure a pulsatile drug release. However, one main issue with such reversible $T_{m}$ or $T_{g}$ transitions which is also encountered with LCST-based nanosystems, is the non-negligible leakage of the drugs that often occurs in the absence of hyperthermia. Hence, tightest encapsulation/binding methods are thus required to ensure a "zero premature release".

iii) Thermolabile (non-covalent) and thermodegradable (covalent) bonds. A very limited and even zero premature release can be reached when drugs are bound via strong non-covalent or covalent thermosensitive bonds in nanocarriers. For instance, the H-bond pairing by DNA hybridization[106-109] affords a strong noncovalent pairing of complementary DNA strands in which the number of DNA base pairs determines the labile transition $\mathrm{T}$ in the range of $40-90^{\circ} \mathrm{C}$ depending on the AT/GC composition. Thermally responsive nanovalves made of pseudorotaxane complexes formed between cucurbituryl molecules complexed with grafted molecular thread at the surface of MS were also used as gatekeepers controlling the diffusion of embedded drugs.[110] The T of un-coordination was assumed to be around $52^{\circ} \mathrm{C}$.

Regarding thermo-degradable covalent bonds strategies: diazo-linkers cleavage and retro Diels-Alder (DA) decyclization and intramolecular lactamisation are the two strategies that were developed these last years. Hence, thermo-labile diazo group linkers have been used in some recent works either to directly conjugate polymer-coated IONPs with anti-tumoral drugs[111] or as thermo-degradable moieties composing PEG polymers gatekeeping the diffusion of embedded drugs in magnetic MS.[112] The thermo-reversible DA 
reaction was reported by N'Guyen et al.[113] in aqueous solution which involved maleimide-conjugated rhodamine, as a drug model, to furan group coupled to a phosphonated PEG grafted at IONPs surface. The local T ensuring the DA cycle opening being in the range of $90-110{ }^{\circ} \mathrm{C}$, it was hypothesized that such high temperature above water boiling point can nevertheless be reached upon AMF application, at least in the close (nanoscale) vicinity of the NPs (ascribed to huge Laplace pressure needed to nucleate gas bubbles). [113,114] Very recently a novel thermally responsive nanoparticle system was proposed and patented, by using a tethering approach linking an alcohol- or amine-terminated drug to an ester or amide group and responding to an AMF-generated local heating by an intramolecular lactamization cyclization reaction ensuring the drug release. [115] Worthy to note that contrary to nanoplatforms displaying LCST, $T_{m}$ or $T_{g}$ responses which occurred typically around mild hyperthermia $\mathrm{T}\left(42^{\circ} \mathrm{C}\right)$, thermo-labile bonds including DNA base pairing, pseudorotaxane nanovalves and thermodegradable covalent bonds respond at a higher local $\mathrm{T}\left(\mathrm{T} \geq 80-90^{\circ} \mathrm{C}\right)$. This means that to actuate these systems, a very high local T should be reached to ensure the efficient thermal cleavage of the bonds and efficient release of the drugs. This underlines also the importance of the nanoheater design and understanding the effect of heat diffusion at the nanoscale. Furthermore, a potential drawback associated with the covalent drug binding is the decrease of the colloidal stability of the NPs in the blood stream, and also of the biological activity of the drug.

\subsection{Formulation of drugs and magnetic NPs in thermally sensitive nanocarriers}

The development of suitable processes to formulate drug-loaded magnetic nanoplatforms is of paramount importance. Such methods should ensure the efficient assembly of the nanoplatforms and the dual loading of the $\operatorname{drug}(s)$ and of IONPs without premature release in the absence of AMF while promoting the destabilization of the drug-nanotplatform bond or interaction under AMF application. This is actually still even more challenging when considering interactions with biological media in vivo.

There are various classes of antitumoral drugs that can be loaded in such platforms. The most encountered anti-tumoral agents are hydrophilic such as the anthracycline doxorubicine (DOX, which is water-soluble at mild acidic and neutral $\mathrm{pH}$ ) or hydrophobic such as paclitaxel derivatives (e.g. Tamoxiphen ${ }^{\mathrm{TM}}, \mathrm{Taxol}^{\mathrm{TM}}$ ), camptothecin (CPT), curcumin... The hydrophobic/hydrophilic balance of these drugs will dictate their interactions within the magnetic carriers: payloads, location in the structure, and mechanism of thermal release. Key parameters characterizing the drug loading in a nanomedicine carrier are the drug loading efficiency (DLE) and the drug loading capacity or loading content (DLC). They are defined according to the following expressions, respectively:

$$
D L E(\%)=\frac{\text { weight of loaded drugs }}{\text { weight of fed drugs }} \quad D L C(\%)=\frac{\text { weight of loaded drugs }}{\text { weight of the nanocarrier }}
$$

Evaluation of DLC and DLE is usually measured by HPLC, UV visible or fluorescence methods after establishing an etalon-curve and measuring the amount of drug remaining in the supernatant. For instance, the extinction coefficient of DOX at $485 \mathrm{~nm}$ and $\mathrm{pH}=7.4$ is $6631 \mathrm{~cm}^{-1} \cdot \mathrm{M}^{-1}$ which corresponds to an absorbance value of only 0.0122 for a $1 \mu \mathrm{g} \cdot \mathrm{mL}^{-1}$ DOX solution $(1 \mathrm{~cm})$. [101]

The main chemical procedures to formulate magnetic carriers loaded with a drug are: 
i) Polymer grafting methods (grafting-to vs. grafting-from) at the surface of magnetic NPs

ii) Self-assembly methods involving the design of magnetic liposomes, micelles, capsules

iii) Sol-gel methods ensuring the synthesis of magnetic silica nanocomposites where drug is embedded in the carrier either by in situ sequestration or by impregnation and use of polymer or wax gatekeeping.

i) Polymer grafting methods. Surface modification of magnetic NPs with a polymer coating ensuring drug loading/release upon thermal response can be done using "grafting-to" and "grafting-from" methods. Graftingto strategies involve the functionalization of IONPs by polymers either by non-covalent interactions $[88,116]$ or by strong interactions (coordination/electro-covalent) using anchoring groups such as phosphonate[72,117,118], carboxylate[119] or alkoxysilane[120-123]. In these different cases of chemisorption, multivalency is an important way to increase the binding strength e.g. with bis- or triphosphonates[124,125] or with polyacids such as phosphonate end-terminated sidechains[126] or polyacrylates. The grafting-to method provides a great versatility of the surface modification as well with synthetic and natural polymers. One issue which is usually reported with the grafting-to method is the low polymer surface coverage density, not reaching the brush regime.[127-129] Alternatively, the grafting-from method is performed to create polymer brushes through a surface-initiated CRP polymerization such as ATRP, RAFT etc... In surface-initiated CRP[130], the initiator is usually grafted at the surface of the IONP and the monomers are brought in solution (together with an excess of "sacrificial initiator") to ensure an effective controlled polymerization from the NP surface. Such CRPs are suitable methods to design block copolymers with controlled growth, tunable chain length, high grafting density and an adjustable LCST response.[13,127] Additionally, free radical polymerization was also reported to produce tight and thick polymer shells around IONPs.[131,132] For both grafting-to/-from schemes to get polymer shells and brushes, the thermo-sensitive drug binding may be ensured by electrostatic or hydrogen bonds, hydrophobic interaction or covalent coupling. ii) Self-assembly methods. The design of drug-loaded magnetic liposomes, polymer capsules, polymer vesicles (polymersomes) and micelles involve various processes of self-assembly. The drug is usually held in these nanostructures via hydrophilic or hydrophobic non-covalent bonds as described above. The non-covalent encapsulation of drugs in such magnetic nanoplatforms is advantageous as it neither changes the original drug bioactivity, nor requires any extra lab-work chemical modification, and also it simplifies the regulatory approval for clinical use compared to drug conjugates.

Magnetoliposomes. For the formation of magnetoliposomes (MLs), there are two main techniques described: the reverse phase evaporation (RPE) and the thin film (TF) rehydration methods. In the RPE method, typically an aqueous solution of hydrophilic iron oxide NPs is added to the lipids dissolved in an organic solvent to form a reverse water in oil (w/o) micro-emulsion, and the MLs self-assemble upon solvent evaporation accelerated by sonication. The RPE is well suited to incorporate a high payload of IONPs in the aqueous core.[133-135] In the TF-rehydration process sometimes called "Bangham method", the lipids are first dispersed in a volatile organic solvent and a thin multi-lamellar lipid film is formed onto the walls of the container upon solvent evaporation under reduced pressure: the TF is subsequently rehydrated by an aqueous solution. The lipid TF method allows both the incorporation of hydrophilic IONPs in the aqueous core $[136,137]$ or hydrophobic NPs, yet limited in size to $\sim 5 \mathrm{~nm}$, inside or on (i.e. decorating) the liposome bilayer[138-141] To encapsulate 
hydrophilic drugs in the liposomes, the ammonium sulfate gradient method[142,143] is typically employed with a high efficacy as it was done for the formulation of Doxil' ${ }^{\text {m. }}$.[13] As found by Barenholz et al., DOX gets trapped inside the aqueous compartment because the molecule can cross membrane in its neutral (deprotonated) form while its sulfate salt inside the cavity precipitates (unlike its acidic DOX-HCl form that is water soluble), therefore avoiding the reverse crossing of the membrane.

Magnetic polymersomes. For the synthesis of magnetic polymersomes which can be seen as the equivalent of liposomes for the self-assembly of amphiphilic polymers, nanoprecipitation is the main reported method ensuring the self-assembly of vesicles of sub-micron vesicles. Also called "solvent-displacement" method, nanoprecipitation consists in adding progressively an aqueous solution to an organic solution of the block copolymer or the reverse, water acting as a selective solvent (i.e. good solvent for one block, bad solvent for the other one). Vesicles being out-of-equilibrium structures, their structural properties are very processdependent, and nanoprecipitation is a mean to orient towards preferred sizes and decrease size-dispersity as compared to direct dissolution (which is also impossible when the copolymers are glassy or semi-crystalline). The IONPs and the drugs depending on their hydrophobicity / hydrophilicity can be encapsulated within the polymersomes either in the polymer shell[101,102] or in the aqueous core.[144] The dual incorporation of the drugs and magnetic NPs can be done simultaneously during the self-assembly or the drugs can also be postloaded by permeation of through the membrane via electrostatic attraction.[144]

Magnetic polymer capsules. Magnetic polymer capsules are usually formed according to "soft templating" when using reverse micro-emulsion droplets as templates or "hard templating" when using rigid preformed colloids as templates. "Soft templating" allows forming polymer capsules typically by the double emulsion (DE) technique. In this technique, a first w/o reversed nanoemulsion stabilized by an amphiphilic polymer is added to a large volume of aqueous solution of a complementary polymer (PVA, proteins etc..) yielding to the formation of a w/o/w double emulsion. The polymer double emulsion capsules (DEC) are then formed after organic solvent evaporation. Synthetic polymers[103] or biomacromolecules[145] can be used to stabilize the capsule. Poly-addition reactions can also be applied at the emulsion interface[146] to create the DEC polymer shell. As for the liposomes and polymersomes, drugs and IONPs can be incorporated either in the core or within the shell during the self-assembly process depending on their hydrophobic / hydrophilic ratios. IONPs can be also formed in situ by co-precipitation in the aqueous core by initial loading of iron(II) and iron(III) ions followed by a basification step at $\mathrm{pH}=10$.

Magnetic capsules made by the "hard templating" approach involve the use of either inorganic colloidal templates such as calcium carbonate[147,148] or polymer rigid organic colloidal templates such as melamine formaldehyde.[149,150] The polymer shell is usually assembled on the template by the layer-by-layer (LbL) method via electrostatic interactions typically by the sequential layering of oppositely charged polyelectrolytes. It is however worth to note that there have been recently a wide range of "one pot" chemical processes used to assemble polymer or protein capsules through hard templating.[151-157] The magnetic NPs are incorporated in the shell either by adsorption during the film build-up or by in situ coprecipitation of ferric and ferrous ions at the surface the template. The magnetic capsules are then formed after dissolution of the 
templating core by the use of EDTA for carbonate calcium removal, or $\mathrm{HCl}$ for melamine formaldehyde removal.

Magnetic micelles. Regarding the preparation of magneto-micelles, it is usually performed by mixing together the hydrophobic magnetic NPs (typically oleic acid-coated 10 nanocrystals), hydrophobic drugs with the blocks amphiphilic copolymer. In the case of doxorubicin which is an amphipathic base (i.e. its protonated form is water soluble), its incorporation in the hydrophobic core of copolymer micelles can be achieved by the Kataoka method [158] consisting in fist deprotonating DOX overnight in a 1:2 mixture of triethylamine (TEA) and DMSO. The resulting drug loaded magnetic micelles are formed by the self-assembly of the amphiphilic species and the drug and IONPs are concomitantly held via hydrophobic interactions within the hydrophobic micelle core; There are different procedures allowing to prepare self-assembled magnetic micelles (i) emulsion-solvent evaporation, (ii) nanoprecipitation, (iii) dialysis, and (iv) thin film rehydration.[13] For LCST thermo-responsive polymer micelles, these are usually made by the self-assembly of di-block copolymers containing a LCST polymer moiety especially PNIPAM[159-162] In such thermo-responsive micelles, the hydrophobic part of the copolymer self-assembles into a reservoir core for the loading of hydrophobic drugs and the hydrophilic part of the copolymer forms an outer hydrophilic shell ensuring colloidal stability in physiological media. As such, the thermal stability of the micelle is mainly determined by the LCST response of the di-block copolymer, shifting from a hydrophilic to a hydrophobic state upon temperature change past the LCST. Magnetic polymer micelles were first introduced quite concomitantly by Ai et al.[163] for poly( $\varepsilon$-caprolactone)- $b$-poly(ethylene glycol) and by Lecommandoux et al. [164] for poly(butadiene)-b-poly(L-glutamic acid) (PB-b-PGA). Later on, magnetic polymer micelles with a thermosensitive shell were designed e.g. with the rod-coil copolymer poly $(\gamma$-benzyl-Lglutamate)- $b$-poly[2-(dimethylamino)ethyl methacrylate] (PBLG- $b$-PDMAEMA, LCST=39²).[165]

iii) Sol-gel methods. Sol-gel methods are the most encountered processes allowing the formulation of magnetic nanocomposites. There are mainly two ways to prepare drug loaded-magnetic nanocomposites. A first approach is the direct encapsulation of the drugs (and the magnetic NPs or their precursors) within the silica matrix network during the sol-gel process. Previously, Barbé et al.[166] shown for silica that Orange II, rhodamine dyes and DOX could be co-encapsulated during a sol-gel process. The sustained drug release over 20 days from the silica xerogel was explained by the combination of dye diffusion and silica dissolution processes in aqueous solutions. Later Hu, Liu et al.[167] reported the synthesis of ibuprofen-loaded silica magnetic composites NPs (size 50-60 nm) through a one step process by reacting the drugs, iron salts and silica precursors during the sol-gel process reaching a $D L C=1 \%$ and a $D L E=23 \%$. In another report in the same group[168], the authors have tightly encapsulated a fluorescent dye in a PVP-coated silica core during a sol-gel process. They surrounded the dye-loaded silica core by a further layer of iron oxide on the surface as a way to provide magneto-thermal response upon AMF and a zero release in the absence of the magnetic field. In these examples, the tight magnetic silica matrix structure requires a very high local $\mathrm{T}$ to induced drug release by local de-structuration. The performances upon AMF for these two latter examples are described in Part 3.4.

The second approach is the formation of porous silica shells at the surface of single or multicore magnetic NPs followed by drug impregnation/adsorption within the porous matrixes. Such porous shells act as efficient reservoirs with high loading capacity. The drug release can be controlled by a further wax, polymer or 
supramolecular capping ensuring drug gatekeeping as described in the previous paragraph in Part 2.2 Mesoporous silica (MS) shells are usually formed at the surface of hydrophilic or hydrophobic magnetic NPs by reacting a silica source precursor (TEOS) in the presence of a surfactant (e.g. CTAB) assembled in micelles.[169172] The surfactant acts as a pore structuring templating agent by the formation of micelles arranged in hexagonal phase and also ensures the water-phase transfer in the case of hydrophobic IONPs. The silica hence polymerizes in aqueous basic conditions around the magnetic core and the micelles, to form the magnetic ordered MS structures. After the sol-gel process, the surfactant is extracted from the pores by an acidic treatment or by the use of ammonium nitrate solutions. [173,174] The drug loading in MS porosity (whether magnetic or not) depends on several parameters: the nature of drugs (hydrophilic vs. hydrophobic), type of solvents (protic/polar/apolar) or the internal surface modification.[89] For instance, a high drug loading is typically achieved by electrostatic interactions between DOX, positively charged in water at $\mathrm{pH} 6$ and the negatively charged bare MS.[175] DOX can also be adhered at the surface of bare MS in polar solvent such as ethanol by H-bonds.[176] Loading of hydrophobic drugs such as camptothecin (CPT) or paclitaxel were also achieved on bare MS in DMSO yet lower DLC were obtained compared with DOX.[177,178] Modifications of MS surface either with charged polymers $[8,179]$ or aromatic hydrophobic molecules[180] have been also reported to influence the loading capacity by increasing respectively the electrostatic or hydrophobic interactions with the drugs.

\subsection{Releasing drugs upon magnetic field: the experimental set-up}

The typical setup for studying an in vitro drug release triggered by an applied AMF comprises the high power current generator feeding an application coil of sufficient diameter to hold the IONP-doped drug carrier sample (1-5 mL). The IO NPs /drug carrier sample is contained inside a dialysis bag itself immersed inside a much larger volume (at least 10 times) of buffer. The molecular weight cut-off (MWCO) of the dialysis membrane is chosen as large as possible (yet not letting the NPs go through) so that the drug release kinetics is limited by the permeability of the nanocarriers, not by the membrane porosity. Such set-up is sketched on Figure 3.

The follow-up and quantification of the drug release is performed by picking up at successive times aliquots of buffer in the reservoir, every time filling back the tank with the same volume of fresh buffer in order to maintain "sink boundary conditions". The drug within each aliquot is titrated compared to a calibration curve using the most appropriate analysis method (by UV-visible absorbance, fluorescence or HPLC), and the result is converted into a "cumulative release amount", the asymptotic value of $100 \%$ being obtained by disruption of the nanocarriers (e.g. with a surfactant or a solvent for liposomes). It is recommended also to record the temperature curve all along the process using a fiber optics T probe rather than a metallic thermocouple that would heat up by itself under application of the AMF. Most biological buffers having high salinity, the parasitic heating of water in the reservoir under the $A C$ magnetic field by eddy current should also be recorded (without magnetic sample). 


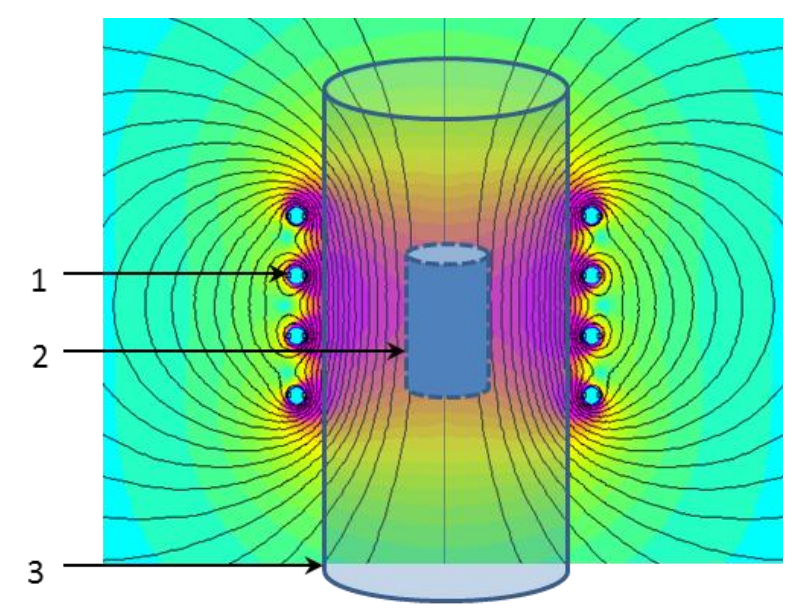

Figure 3. Setup for model drug release experiment through drug diffusion across semi-permeable membrane. 1: Solenoid and calculated magnetic field lines; 2: Dialysis bag (e.g. Spectra/Por Float-A-Lyzer ${ }^{\text {TM }}, 50000$ g.mol ${ }^{-1}$ MWCO, $10 \mathrm{~mm}$ diameter, $5 \mathrm{~mL}$ volume); 3: Cylinder $(50 \mathrm{~mL}$ ) filled with aqueous buffer. Usually the drug is titrated in the outer medium, in "sink" and thermostatic $\left(37^{\circ} \mathrm{C}\right)$ conditions.

Most experiments published so far present cumulative drug release profiles measured manually. One drawback is the limited number of data points, with blanks in the kinetics ascribed to the overnight periods. The magnetic field must also be switched off when pipetting the aliquots (especially when using metallic needles!). In pharmaceutical sciences, the release curves can be much more precise by a continuous "on-line" automatic measurement during many hours. Most pharmaceutical companies use indeed the Sotax ${ }^{\mathrm{TM}}$ USP-4 flow-through system initially developed for tablet dissolution kinetics. This system was adapted to monitor drug release from nanocarriers by incorporation of a $2 \mathrm{~mL}$ volume dialysis bag in the loop and validation on liposomal formulation of dexamethasone.[181] Instead of taking aliquots at discrete times, it would be very benefic for data interpretation and modelling of AMF-induced drug release to monitor the drug release profile continuously, while keeping the intensity of the magnetic field ON (or applying pulsatile ON/OFF magnetic field profiles). However there is no commercial device yet coupled to $\mathrm{MH}$, although several providers of $\mathrm{MH}$ generators are currently working on such a product. Another advantage of the Sotax ${ }^{\mathrm{TM}}$ USP-4 flow-through system is that the buffer is not static as sketched on Figure 3, but it circulates around the dialysis bag, thanks to peristaltic pump beating at $120 \mathrm{rpm}$, mimicking to some extents blood circulation. The optimal design of in vitro drug release experiments also requires that the nanocarriers are maintained at physiological temperature during all the process (whatever the increased local temperature, in close vicinity to the IONPs), e.g. with a cylindrical reservoir that is made of a double-wall jacket with water circulating through a controlled temperature bath at $37^{\circ} \mathrm{C}$.

One has to remember indeed that the aim of the in vitro release curve measurements is to assess the potential of a nanoparticle-drug formulation to respond significantly to a stimulus, here the application of an AMF, whereas only preclinical in vivo assays can give truly relevant pharmacokinetic data (like halftime in blood circulation). Nevertheless, the experimental release profiles (measured manually or continuously) can be fitted to semi-empirical laws like a power law (Korsmayer-Peppas), Higuchi model for highly water insoluble drugs, or Weibull law (sigmoid profile),[182] and the resulting kinetic parameters can be compared with or without 
applied AMF, in order to evidence "proof-of-concept" results. Ideally, these in vitro release data need to be completed by cellular experiments (internalization in relevant biological cells and cytotoxicity assays at drug concentration below the IC50) and/or in vivo data (bio-distribution, pharmacokinetics, tumor regression...). In that case the in vitro drug release profiles with model diffusion experiments under AMF can help choosing the appropriate parameters (magnetic field strength, frequency, and application time), although other physical parameters like the IONP concentration and the spatial distribution of the sample need also to be chosen as close as possible to the case of a real tumor in order to be truly biologically relevant.

\section{Efficacy of magnetic nanoplatforms releasing drugs upon AMF and in vitro biological results}

This part 3 is an overview of the current magnetic nanoplatforms that were used to trigger drug release upon AMF. For sake of clarity, we have divided the nanosystems into four types:

i) Magnetic core-polymer shells

ii) Polymer or lipid vesicles having hollow aqueous compartments

iii) Polymer nanospheres (NS) including hydrophilic nanogels, hydrophobic NSs and nanomicelles

iv) Inorganic nanocomposites mainly with silica matrix

For each example of nanosystem described, we provide briefly the structural properties and focus on the salient features and efficacy of the AMF-induced drug release along with the in vitro data gathered on biological cells. A broad updated overview of in vivo results will be presented in Part 4.

\subsection{Activable magnetic core-polymer shells}

Such nanoplatforms consist in a magnetic core surrounded by a polymer shell. As seen in Part 2, there are different ways to trigger the drug release from the polymer matrix by an applied AMF: via LCST response, noncovalent thermolabile bonds or thermodegradable covalent bonds.

\subsubsection{Magnetothermal release by the LCST response of a polymer coating}

The drugs are released through the thermoresponsive LCST behavior of grafted polymer on IONP surface via a mechanism which is detailed in Part 2. For instance, Yao et al. [131] used an emulsion free polymerization to form a dense and thick P(NIPAAM-co-Am) shell (85\% wt) at the surface of IO cores which was thus loaded with the hydrophilic vitamin B12 (DLE=65\%) in the copolymer shell. The authors applied an AMF $\left(H=6.5 \mathrm{kA} \cdot \mathrm{m}^{-1}, \mathrm{f}=60\right.$ $\mathrm{kHz}$ ) either continuously (6h) or intermittently $(6 \times 1 \mathrm{~h}$ every $3 \mathrm{~h}$ on $24 \mathrm{~h})$. They showed a better cumulative AMFinduced drug release in the intermittent application (almost 100\%) vs. the continuous regime (69 \%). For both AMF regimes, they measured a $\mathrm{T}$ rise of the solution up to $46^{\circ} \mathrm{C}$ after $1 \mathrm{~h}$ AMF application and the LCST of P(NIPAAM-co-Am) shell was measured at $42^{\circ} \mathrm{C}$ from the UV-vis transmittance, explaining such magnetically induced release behaviors.

The 'grafting-from' and 'grafting-to' methods detailed in Part 2 are most importantly developed to prepare magnetic core-polymer shell nanostructures exhibiting AMF-induced drug release. Very recently, Kakwere, Pelegrino et al.[183] formed at the surface of IO nanocubes (19-22 nm) PNIPAAM-co-PEGA brushes by RAFT living radical polymerization with a LCST of $52^{\circ} \mathrm{C}$ (Figure 4.A). High DOX loading content (23\%) was reached by simple impregnation $24 \mathrm{~h}$ at room T. Application of an AMF $\left(\mathrm{H}=20 \mathrm{kA} \cdot \mathrm{m}^{-1}, \mathrm{f}=220 \mathrm{kHz}, 240 \mathrm{~min}\right)$ ensured the 
efficient DOX in vitro release (ca. 25\%) whereas a negligible release was found at $37^{\circ} \mathrm{C}$ without applying $A M F$. The authors have shown that during AMF application, $\mathrm{T}$ of the solution rose up to $80^{\circ} \mathrm{C}$ in $15 \mathrm{~min}$. Cell viability studies (without AMF) performed on KB cells showed cell uptake and no toxicity up to $1 \mathrm{~g} \cdot \mathrm{L}^{-1}$ iron of the incubated core-shell NPs. In a recent study, Hervault, Thanh et al.[122] used a 'grafting to' approach where a concomitant $\mathrm{pH}$ and thermoresponsive copolymer was priory synthesized and then attached by trimethoxysilane anchoring endgroup onto the surface of the 10 cores formed by microwave-assisted coprecipitation. Polymer grafting was estimated up to $8.1 \%$ weight relatively to IO by TGA. The DOX loading (DLC $=7.6 \%, \mathrm{DLE}=82.3 \%$ ) in the polymer shell was done by the formation of the $\mathrm{pH}$-responsive covalent imine bond between the amine group of DOX and the aldehyde group of the copolymer. Concomitant effect of $\mathrm{pH}$ in media mimicking acidic tumor $\mathrm{pH}(5.7)$ and $\mathrm{MH}\left(\mathrm{T} \sim 50^{\circ} \mathrm{C}\right)$ allowed $85.2 \%$ of DOX release over $48 \mathrm{~h}$ while a lower DOX amount was released $(39.4 \%)$ at $37^{\circ} \mathrm{C}$ within the same period.

A

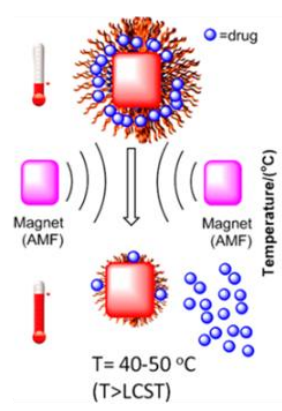
$T=40-50$
$(T>L C S T)$

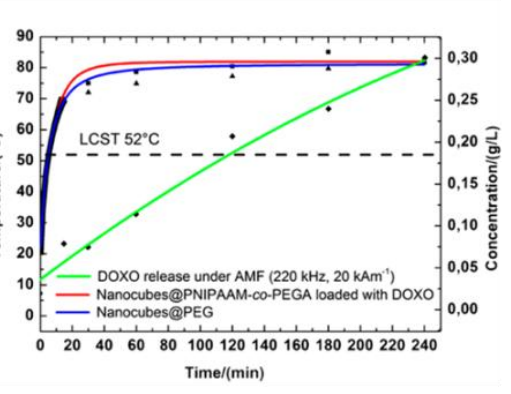

B

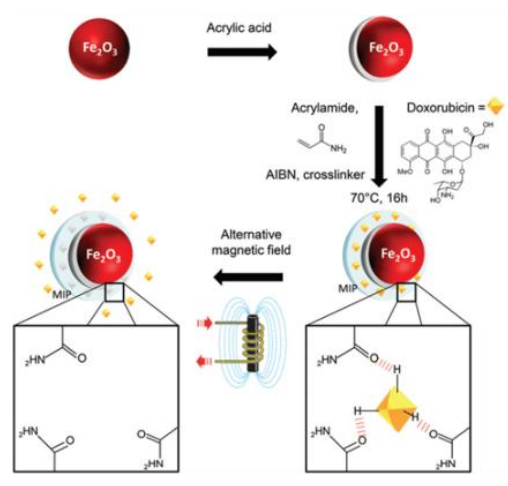

C

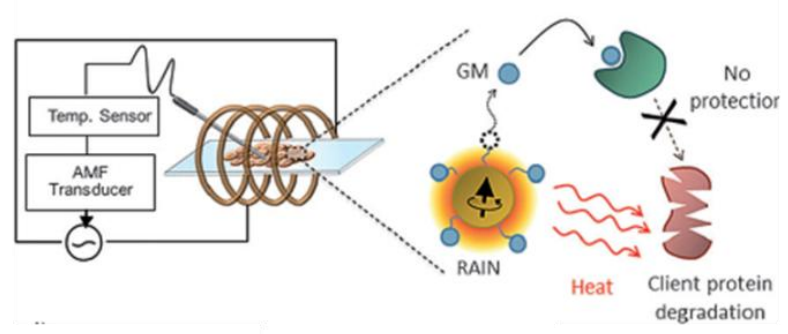

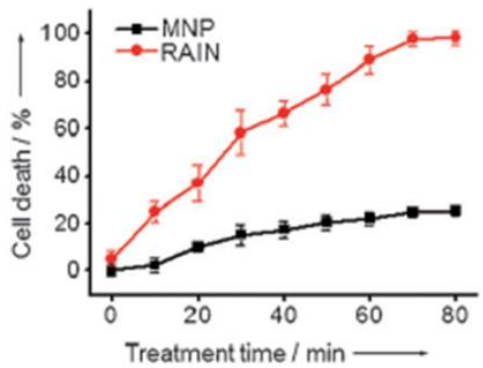

Figure 4. A. PNIPAAM-Co-PEGA brushes grafted on 10 nanocubes $(19-22 \mathrm{~nm})$ by RAFT living radical polymerization. Reprinted with permission from ref. [183]. Copyright 2015 American Chemical Society B. Preparation and DOX loading in MIP $\mathrm{Y}-\mathrm{Fe}_{2} \mathrm{O}_{3}$ NPs. Reproduced from ref. [184] with permission of The Royal Society of Chemistry. C. In vitro release of geldanamycine with cells upon AMF application. Reproduced from ref. [185] with permission of Wiley.

\subsubsection{Magnetothermal release by $\mathrm{H}$ bonds and $\pi$-stacking disruption}

The magnetothermal release of drugs bound by weak interactions ( $\mathrm{H}$-bonds, electrostatic, $\pi-\pi$ stacking) is also reported. As underlined in Part 2, an advantage is that the required thermal energy is often lower compared with the one needed for the cleavage of thermo-sensitive covalent bonds. However the molecules are more loosely attached and hence they may experience more premature release in the absence of AMF. H-bonds are mostly exploited to bind drugs to a polymer shell matrix. Hence, Fluorouracyl (5-FU) drugs could be efficiently 
loaded in PolyA15 polynucleotide grafted to poly(styrene-alt-maleic acid) coated $\mathrm{Fe}_{3} \mathrm{O}_{4}$ core (22 $\mathrm{nm}$ ) through 5FU/adenine H-bond interactions (5425 FU molecules per NP).[186] A cell targeting function was added to the thermally responsive core-shell NPs by grafting anti-HER2 monoclonal antibody to target overexpressed human epidermal growth factor receptor (HER) receptors in mouse bladder tumor (MBT2) cells. The authors have shown that the combination of cell targeting and application of $A M F\left(H=33 \mathrm{kA} \cdot \mathrm{m}^{-1}, \mathrm{f}=1.3 \mathrm{MHz}, 15 \mathrm{~min}\right)$ on the MBT-2 cells allowed to reduce efficiently the cell viability at $50 \%$, whereas the same treatment but with a nonspecific targeting ligand (IgG) or a free 5FU treatment did not reduce as much the cell viability.

The magnetothermal H-bond release of DOX was also performed with molecularly imprinted poly(acrylamide) shell around $\gamma-\mathrm{Fe}_{2} \mathrm{O}_{3}$ core further cross-linked with ethyleneglycoldimethacrylate (EGDMA) [184]. The DOX was loaded in situ during the polymerization process and was held via $\mathrm{H}$-bonding by the poly(acrylamide) mesh.

(Figure 4.B) The authors investigated the "athermal" AMF induced drug released by performing AMF pulsatile sequences $(B=9 \mathrm{mT}, \mathrm{f}=335 \mathrm{kHz}, 5 \times 2$ min separated by $30 \mathrm{~s}$ intervals) on regular points over 8 hours and compared it with the drug release at a macroscopic T maintained at $37^{\circ} \mathrm{C}$. They have shown that 4 times higher drug quantity was released with applied AMF compared to the externally applied $\mathrm{T}$ at $37^{\circ} \mathrm{C}(60 \% \mathrm{vs}$. $15 \%$ cumulative release respectively). PC 3 cancer cells internalized these core-shell NPs and were treated at higher field parameters $(700 \mathrm{kHz}, \mathrm{B}=25 \mathrm{mT})$ in isothermal conditions for $\mathrm{t}=30 \mathrm{~min}, 1 \mathrm{~h} 30 \mathrm{~min}$, and $2 \mathrm{~h} 30 \mathrm{~min}$ AMF treatment. The results indicated a $40 \%$ cell viability reduction after $1 \mathrm{~h} 30$ of AMF treatment compared with a negligible toxicity without AMF.

DNA hybridization is also a relevant way to tune the thermal response as the base pair (bp) length and thus the force of the $\mathrm{H}$-bonds between the complementary DNA strands can be tuned. Thus Derfus, Bhatia et al.[106] hybridized simultaneously fluorescently labelled 12 and 24 bp single strands DNA on a 30 bp single strand DNA conjugated to a dextran shell coated at the surface of IONPs. They investigated the respective thermal response according to the power of the AMF applied ( $400 \mathrm{kHz}, \mathrm{P}=0.55-3 \mathrm{~kW}, 5 \mathrm{~min}$ pulses every $40 \mathrm{~min}$ ). They showed that low power at $0.55 \mathrm{~kW}$ allowed the selective release of only the $12 \mathrm{bp}$ DNA whereas a higher power at $3 \mathrm{~kW}$ allowed the simultaneous release of both 12 and $24 \mathrm{bp}$ DNA demonstrating the possibility to modulate the thermal release response through DNA hybridization approaches.

Recently, an original approach was developed by Xu, Biris et al.[187] by binding aromatic drugs to iron NPs coated with a graphitic surface. DOX anthracycline and Erlotinib inhibitor drugs were bound (respectively at 0.07 and $0.11 \mathrm{mg}$ per $\mathrm{mg}$ of $\mathrm{Fe}$ ) by $\pi$-stacking to the carbon shell of NPs. These drugs could be efficiently released by rupturing the non-covalent bond with the carbon-coated IONPs. The AMF application (350 kHz, $\mathrm{P}=1.2 \mathrm{~kW}, 10 \mathrm{~min}$ ) treatment in PBS at $\mathrm{pH} 7.4$ was shown to enhance the DOX and Erlotinib release rates in the first hour. The release was at about 4.8 and 1.8 fold higher respectively compared to the release without AMF treatment. Trypan blue viability assays on Panc1 cells was also studied. Overall, application of the AMF was shown to decrease the cell viability of Panc-1 cells incubated with both DOX- and Erlotinib-bound C/Fe NPs. For instance, Erlotinib-bound C/Fe NPs reduced the cell viability from 50.4\% to $25.4 \%$ upon AMF application.

\subsubsection{Magnetothermal release of drugs by covalent bond cleavage.}

One of the most suitable ways of releasing drugs 'on demand' from a magnetic core and with zero premature release in the absence of AMF consists in grafting the drug to the NP with a covalent thermo-cleavable bond. In 
a recent work, Yoo Cheon et al.[185] grafted geldanamycin, a heat shock protein (HSP) inhibitor to $\mathrm{Zn}_{0.4} \mathrm{Fe}_{2.6} \mathrm{O}_{4}$ zinc ferrite MNPs (15 nm) modified with amine groups using a thermo-labile diazo linker. The authors showed an impressively high magneto-thermal control of geldanamycin release upon AMF $\left(37.4 \mathrm{kA} \cdot \mathrm{m}^{-1}, \mathrm{f}=500 \mathrm{kHz}, 80\right.$ $\min )\left(100 \%\right.$ complete release) whereas only $7 \%$ was released in a water bath at $43^{\circ} \mathrm{C}$. The authors hypothesized a high local $\mathrm{T}$ increase above $90^{\circ} \mathrm{C}$ ensuring the efficient bond cleavage of the diazo bond. Incubation of these core-shells NPs with MDA-MB breast cancer cells allowed an efficient cell killing (up to $100 \%$ toxicity) by AMF application while only $25 \%$ of cancer cells were killed upon MH with NPs not grafted to geldanamycine. (Figure

4.C) Moreover, the authors demonstrated also in this work that the treatment induced preferably the apoptosis vs. the necrosis pathways. The in vivo aspects of this study will be detailed in Part 4.

\subsection{Magnetic vesicles : liposomes, polymersomes, capsules}

\subsubsection{Magnetoliposomes}

Within the same vein than the ThermoDox ${ }^{\mathrm{TM}}$ liposomal formulation patented by Needham at Durham University and Dewhirst from the Celsion company,[188] and pioneering work by Yatvin et al. on thermosensitive liposomes, [94] Babincova et al. [189] first associated gel phase liposomes with IONPs to envision a drug release triggered by AMF-induced magnetic hyperthermia. Although brief and lacking of structural details, their coating of IONPs with a phospholipid bilayer (as DeCuyper's 'magnetoliposomes' $[190,191])$ and their use of $\mathrm{pH}$ gradient method introduced by Mayer [192] (internal core more acidic than outer medium), let us infer that these authors managed co-encapsulating DOX and IONPs within the aqueous lumen of the liposomes (in particular due to the magnetic core size around $8 \mathrm{~nm}$ of their co-precipitated IONPs, which is twice the thickness of a phospholipid membrane). The idea of $\mathrm{MH}$-induced drug release from thermosensitive liposomes was actually already mentioned at the first edition of the international conference on Scientific and Clinical Applications of Magnetic Carriers held in 1996 in Rostock, but the DOX release curve under an AMF (reproduced on Figure 5.A) appeared to be the first convincing realization. Later on, other groups developed magnetoliposomes with this goal. Zhu et al. [133] obtained by the RPE method DPPC magnetoliposomes encapsulating methotrexate (MTX) and hydrophilic IONPs that liberate 80\% of MTX after 1 hour at $41^{\circ} \mathrm{C}$ but they did not measured the release under an applied AMF. In another study, Chen, Bose and Bothun managed to decorate multi-lamellar liposomes (dML)s with hydrophobic IONPs capped by an oleic acid (OA) monolayer: thanks to their ultra-small diameter $(5 \mathrm{~nm})$, these were supposedly embedded within lipid bilayers as shown by a shift of the Tm of DPPC by few ${ }^{\circ} \mathrm{C}$, yet authors evidenced also pinning of adjacent membranes by the IONPs (thus favoring multi-lamelarity). Applying an AMF caused twice increase of carboxyfluorescein (CF) leakage after $20 \mathrm{~min}$ and an optimal feeding rate of IONP compared to lipid corresponding to $0.5 \%$ volume fraction in the membrane.

Aiming at designing both magneto-thermosensitive and targeting liposomes, Pradham et al. [137] formulated them with DPPC/Cholesterol (80:20) as main lipid composition with also $4.5 \%$ of PEGylated lipid (DSPE-PEG2k) and $0.5 \%$ of folate functionalized PEGylated lipid, in order to combine stealth and targeting properties towards folate receptor overexpressed by cancer cell lines (KB/HeLa). Having proven the thermosensitivity on $\mathrm{CF}$ release at $43^{\circ} \mathrm{C}$, the authors employed two equivalent concentrations $(20$ and $30 \mu \mathrm{M})$ of encapsulated DOX at which a fraction of KB cells survived (respectively 70 and $21 \%$ ), while the survival rate 
decreased by more than two after 1 hour application of an AMF that raises temperature macroscopically (respectively to 42.5 and $43.5^{\circ} \mathrm{C}$ ).

Later the study by Katagiri et al.[139] was original because instead of the enhanced permeability of liposomes formed by gel-phase phospholipid at the main chain melting transition, they incorporated $4 \%$ of copolymer exhibiting LCST behavior around $30^{\circ} \mathrm{C}$, namely Poly[(2-ethoxy)ethoxyethyl vinyl ether- $b$-octadecyl vinyl ether] (PEOEOVE-b-PODVE) in a fluid phase lipid composition (egg yolk phosphocholine EYPC with also 7\% DSPE-PEG5k for stealthiness). As a further development of thermosensitive magnetoliposomes (TMLs), the study by Amstad et al. [140] showed that the bilayer disruption effect by $5.5 \mathrm{~nm}$ sized IONPs with a standard oleic acid coating can be suppressed by using palmityl nitrodopamine ligands that anchor much more strongly onto the IONPs, thereby avoiding to be replaced by the phospholipid head-groups leading to bilayer wrapping. They showed also that this system is much more efficient in AMF-induced calcein release than with TMLs obtained with OA-coated IONPs in the membranes or with hydrophilic PEGylated IONPs in their aqueous lumens, suggesting correlation of nanoscale heat transfer with true embedment of the IONPs in the bilayers.

As an alternative to TMLs, Hanus et al. [193] described non-magnetic thermosensitive liposomes (DPPC/cholesterol 2:1) encapsulating carboxyfluorescein (CF) trapped simultaneously with hydrophilic IONPs inside the hydrogel mesh of alginate microbeads: being magnetic, these beads around $50 \mu \mathrm{m}$ in diameter can be concentrated up to close-packing fraction by attraction by a permanent magnet: after two times dilution, they exhibited a CF release profile (as measured by fluorescence de-quenching) perfectly controlled by the application of AMF pulses. The authors pointed out that the proximity of the beads was necessary to reach macroscopic heating above the $T_{m}$ of the lipids and enhanced diffusion of CF through their membrane.

Finally, we would like to mention in that section a work of magnetically induced triggering of drugrelease with magnetoliposomes that are not thermosensitive, and that does not imply any increase of temperature. This was achieved by Guo et al. [194] who encapsulated DOX by the ammonium sulfate gradient method within soybean phospholipid/cholesterol liposomes containing a fraction (1/100 molar corresponding 10 wt.\% relatively to lipid) of an amphiphilic polymer obtained by grafting oleylamine onto carboxymethyl dextran (CMD, derived from T-10 dextran). The authors reported DOX release profiles on long durations (up to $80 \mathrm{~h}$ ) showing higher release rates when the CMD-decorated MLs were submitted to a low frequency AMF at $50 \mathrm{~Hz}$ (LF-AMF) for 10, 20 or $30 \mathrm{~min}$ at the beginning of the experiment, suggesting that the membrane structure and resulting permeability were profoundly altered in a non-reversible way, i.e. even after switching off the AMF. This phenomenon of release under LF-AMF by MLs had been reported early by Nappini et al. [141] with CF dye, but at 100 times higher frequency $(f=5.2 \mathrm{kHz})$ and with cobalt ferrite magnetic NPs known to exhibit higher anisotropy energy than pure IONPs. In the case of CMD-decorated MLs, the amphiphilicity of CMD-derived polymer could destabilize the membrane of the vesicles under magnetic field even and maintain a de-structured and leaky membrane even when the AMF gets switched off.

\subsubsection{Magnetic polymersomes}

Introduced less than two decades ago by Bates, Discher and Hammmer, vesicular structures based on amphiphilic block copolymers were called "polymersomes" [195] by analogy to liposomes. Such self- 
assemblies provide multiple opportunities, e.g. to be dually loaded with hydrophilic cargos in the aqueous lumen, as well as hydrophobic ones embedded in the vesicle membrane, which thickness can be tuned from 5 $\mathrm{nm}$ close to lipid bilayers to $15-20 \mathrm{~nm}$, scaling like the square root of the molar mass.[196] Hydrophobicallycoated IONPs have been loaded in polymersomes of various natures of the hydrophobic block: poly(butadiene) [164], poly(isoprene) and poly(2-vinylpyridine) [197], poly(styrene) [198], and poly(trimethylene carbonate).[101] In other cases, the IONPs are most likely decorating the membrane rather than being fully embedded within the hydrophobic leaflet, like with vesicles made of poly(acrylic acid)-statpoly(terbutylacrylate)[199] or poly(styrene)-b-poly(methacrylic acid)-b-poly(oligoethyleneglycol methacrylate).[200] The thumb rule to obtain polymersomes being that the amphiphilic copolymer should exhibit $30 \pm 5 \mathrm{wt}$. \% hydrophilic weight ratio [195], one or two hydrophilic blocks or grafted chains are linked to the hydrophobic backbone, usually chosen among poly(ethylene oxide) (PEO), poly(L-glutamic acid) (PGA) or poly(acrylate) (PAA). In the case of PTMC-b-PGA, the free chain end-group can be post-modified with relevant ligands (e.g. low molecular weight compounds like NIR dyes, peptides[201], antibodies,[202] aptamers, etc.) for endowing the polymersomes with specific properties. In the work by Sanson et al. [101], PTMC $24-b-\mathrm{PGA}_{19}$ self-assembly by nanoprecipitation enabled obtaining dual-loading polymersomes membrane of hydrophobic thickness $10 \mathrm{~nm}$ with both DOX (DLC of $12 \%$ ) and IONPs of $7 \mathrm{~nm}$ coated with a phosphonate hydrophobic ligand (at a payload of $50 \mathrm{wt}$ \%). The authors who observed an increase by a factor 2 of the release rate of DOX under an $A M F B=2.65 \mathrm{mT} / \mathrm{H}=2.1 \mathrm{kA} \cdot \mathrm{m}^{-1}$ at $\mathrm{f}=500 \mathrm{kHz}$ introduced the term of "magnetochemotherapy" to describe such effect of magnetically induced drug-release. Later on, the same group demonstrated the corresponding effect on cell toxicity on HeLa cells,[102] treating them by a more powerful $A M F(B=14$ $\mathrm{mT} / \mathrm{H}=10.2 \mathrm{kA} \cdot \mathrm{m}^{-1}$ at $\mathrm{f}=750 \mathrm{kHz}$ ) for $10 \mathrm{~min}$ thrice a day (Figure 5.B). Another example of polymersomes for magnetically triggered drug delivery was described by Chiang et al. [144] who developed vesicles made of poly(acrylic acid-co-distearin acrylate) (poly(AAc-co-DSA) encapsulating DOX and citrated-IONPs. To impart them better mechanical toughness and tumor-targeting capability, they were decorated with multiple layers of oppositely charged polyelectrolytes, respectively chitosan and a PGA backbone grafted by $\mathrm{N}$ hydroxysuccinimide (NHS) activation with a heterodifunctional $\mathrm{H}_{2} \mathrm{~N}$-PEG-maleimide for coupling to folic acid$\mathrm{SH}$. These polyelectrolyte gel "outlayered" polymersomes exhibited DOX enhanced release (up to 100\%) under an AMF applied for $20 \mathrm{~min}$, and a survival rate of HeLa cells decreased by more than 2 compared to free DOX at the same concentration $(10 \mu \mathrm{M})$.

To conclude on this part, magnetic polymersomes have been less studied until now than their liposome forerunners, but their higher membrane thickness (tunable by the polymer molar mass) enabling to embed larger IONPs thus more efficient for $\mathrm{MH}$, going with higher toughness and lower passive permeability open new horizons. Therefore one can envision their rapid development for magnetically induced drug delivery systems, as deduced also from their chemical versatility authorizing further bio-functionalization (e.g. with targeting ligands) to design optimal drug carriers and medical devices.

\subsubsection{Double emulsion capsules (DEC)}


Magnetic polymer hollow capsules with aqueous cores prepared by double-emulsion techniques were reported these last years as powerful nanovesicles to load and release efficiently drugs upon AMF. Main works on these magnetic DEC were achieved by Chen and co-workers. In a first work, the authors have incorporated Vitamin B12 and IONPs formed by co-precipitation in a covalently cross-linked thermoresponsive polymer shell made of PEO- $b$-PPO- $b$-PEO (Pluronic ${ }^{\mathrm{TM}}$ )/Gelatin mixture. [145] The thermosensitive polymer shell exhibited a hydrophilic-to-hydrophobic T transition around $40^{\circ} \mathrm{C}$. A limited leakage of the drugs was found at $25^{\circ} \mathrm{C}$ while upon application of an AMF (2.5 kA. $\left.{ }^{-1}, 50-100 \mathrm{kHz}\right)$, an important burst drug release was observed in few minutes, which was attributed to an irreversible capsule shell disruption.

Later on, the same team has developed water in oil in water (w/o/w) DEC capsules made of PS- $b$-PAA copolymer and amphiphilic poly(vinyl alcohol) PVA) having ca. $260 \mathrm{~nm}$ diameter with tunable payloads of IONPs ranging from 3.7 to $30 \%$ vs. polymer weight.[103] The PS- $b$-PAA/PVA DEC capsules were shown efficient to simultaneously load hydrophilic content: PEG coated-QDs, and DNA ${ }^{\text {FITC }}$ in the aqueous core and hydrophobic payloads: pyrene and IONPs in the hydrophobic shell. Upon AMF application $\left(H=0.8-2 \mathrm{kA} \cdot \mathrm{m}^{-1}\right.$ at $\left.\mathrm{f}=50 \mathrm{kHz}\right)$, the authors showed that DNA ${ }^{\text {FITC }}$ from the core and pyrene from the shell could be released in a controllable pulsatile fashion via ON/OFF sequential AMF pulses. Moreover, the amount of released content for both DNA and pyrene was shown to depend on the amplitude of the magnetic field varied from 0.8 to $2 \mathrm{kA} \cdot \mathrm{m}^{-1}$. The authors reported that the mechanism of the reversible shell permeability ensuring the pulsatile release was attributed to a membrane destabilization upon $\mathrm{T}$ increase which resembles to the transition $\mathrm{T}$ encountered in thermo-responsive polyelectrolyte capsule or polymer gel. These PS- $b$-PAA/PVA nanocapsules were also modified with RGD peptide sequence to target the integrin receptors of MCF-7 cells. Upon application of an AMF $\left(H=2 \mathrm{kA} \cdot \mathrm{m}^{-1}\right.$ at $\left.\mathrm{f}=50 \mathrm{kHz}\right)$ during $2 \mathrm{~min}$, they were shown efficient to release encapsulated DNA ${ }^{\mathrm{FITC}}$ within the MCF-7 cells as visualized by confocal laser scanning microscopy (CLSM).

The same authors have also developed similar DEC polymer capsules (ca. $150 \mathrm{~nm}$ size) that were however only made of PVA shell with embedded IONPs. [203] They used this approach to co-encapsulate DOX in the aqueous core $(\mathrm{DLE}=60 \%, \mathrm{DLC}=2.4 \%)$ and PTX within the hydrophobic shell (DLE= 90\%, DLC=3.6\%). Upon AMF (H= 16 $\mathrm{kA} \cdot \mathrm{m}^{-1}$ at $\mathrm{f}=50 \mathrm{kHz}, 10 \mathrm{~min}$ ) they demonstrated a cumulative release $\geq 50 \%$ for DOX and PTX. The capsules were then modified with IVO ligand targeting HeLa and MCF-7 cells. Upon 2.5 min AMF application, for both cell lines, the cancer cell viability was reduced to $2 \%$ for the DEC capsules combining the 2 drugs while controls in the absence of magnetic field or in the absence of drugs have shown cell viability of 10 and $20 \%$ respectively. These capsules were applied efficiently in vivo and results are described in Part 4.

Alternatively to the use of synthetic non degradable polymers like butyl, styrene or acrylic polymers, Xia and co-workers developed micron size capsules made of the hydrolysable Poly(D,L-lactide-co-glycolide) (PLGA) by the double emulsion (DE) method with hydrophobically coated IONPs loaded in the PLGA shell and DOX loaded in the aqueous core.[104] The authors demonstrated the fine control over the drug release by applying repeated ON/OFF AMF pulses $\left(50-100 \mathrm{kHz}, 2.5 \mathrm{kA} \cdot \mathrm{m}^{-1}\right.$ ) (Figure 5.C). A pulsatile drug release was then performed with a continuous amount of drug released in the PBS buffer. Cumulative drug release upon the sequence of 9 AMF regular pulses reached $90 \%$ of the initially loaded drug content. Such strategy shows the 
possibility to use biodegradable capsules with a drug releasing pulsatile behavior which, after being emptied, can be further degraded and metabolized by the biological environment.
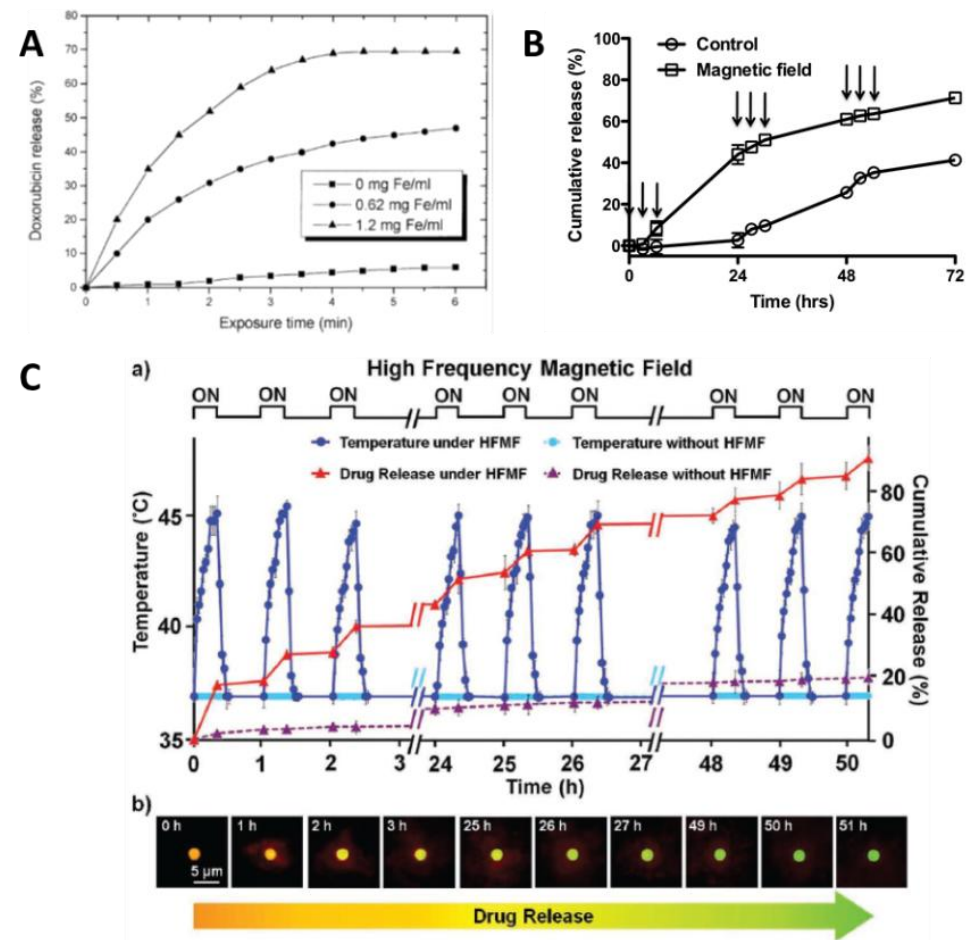

Figure 5. Examples of DOX cumulative release profile under AMF from vesicular or hollow shell structures of different types: A. Magnetoliposomes. Reprinted from ref. [189], Copyright 2002, with permission from Elsevier. B. Magnetic polymersomes. Reprinted from ref. [102] Copyright 2013, with permission from Elsevier and C. DEC capsules. Reproduced from ref. [104] with permission of Wiley.

\subsubsection{LbL capsules}

The colloidal templating technique on hard inorganic microparticles (MPs) was used this last decade to form magnetoresponsive capsules releasing dyes or drugs upon AMF. The capsule walls were usually formed by the layer-by-layer ( $\mathrm{LbL}$ ) technique ensuring a polymer/magnetic NP assembly at the surface of the template. Hu et al.[147] have been the first group to design LbL microcapsules having a drug delivery controlled by an AMF. In this work, the authors built poly(allylamine hydrochloride) (PAH) capsules stuffed with $\mathrm{Fe}_{3} \mathrm{O}_{4} \mathrm{NPs}_{\text {from }}$ a porous carbonate calcium template (4.6 $\mathrm{mm}$ diameter) initially loaded with FITC-dextran. They applied an AMF $\left(50 \mathrm{kHz}, 2.5 \mathrm{kA} \cdot \mathrm{m}^{-1}, 30 \mathrm{~min}\right)$ to the capsule suspensions to release the fluorescent content which was analyzed by spectroscopic/fluorimetric methods. In this work, the authors loaded DOX within the $\left(\mathrm{Fe}_{3} \mathrm{O}_{4} / \mathrm{PAH}\right)$ capsules through a pH-dependent mechanism of capsule wall opening/closing. At $\mathrm{pH} 5$, the enhanced capsule wall permeability ensured DOX entry within the capsules, whereas at pH7.4 the pores closed and the DOX was encapsulated with a limited release. Application of the AMF upon 30 min showed a 67\% DOX release whereas the control without AMF indicated a DOX release of $9 \%$ only. TEM and CLSM investigations performed on the capsule walls showed that the drug diffusion was ensured by capsule degradation as assessed by the formation of nanocavities and cracks/crevices on the capsule wall. To explain this, it was proposed that $\mathrm{Fe}_{3} \mathrm{O}_{4} \mathrm{NPs}(5-8$ 
$\mathrm{nm}$ ) upon AFM generate mechanical vibrations and rotations which induced mechanical stresses in the polymer capsule walls and also a moderate magneto-thermal energy conversion by Néel/Brown relaxations.

Recently, Carregal Romero et al.[204] have also addressed a very similar concept of magnetically induced dye releasing LbL capsules with optimized polymer matrixes and magnetic NPs for improved heating efficiency. The authors formed PAH/PSS (polystyrene sulfonate) capsules bearing in the capsule wall a cationic poly(acrylamide-co-diallyl-dimethylammonium chloride) $\mathrm{P}(\mathrm{Am}-\mathrm{DDA})$ random copolymer ensuring the efficient adsorption of highly uniform gallol- modified PEG iron oxide nanocubes (18 nm size). Such nanocubes were previously reported as one of the most efficient nanoheaters having high SAR values. [44,53] Fluorescent Cascade blue dextran was post-loaded in such magnetic capsules and encapsulated through the thermal annealing at $65^{\circ} \mathrm{C}$ of the LBL capsule wall. Release of the dye and T-profile upon AMF $\left(300 \mathrm{kHz}, 24 \mathrm{kA} \cdot \mathrm{m}^{-1}, 90\right.$ $\min$ ) were assessed with different formulations. Results showed that capsules with $1.5,2.7$ and $4.8 \mathrm{~g} \cdot \mathrm{L}^{-1}$ iron content displayed T profile reaching respectively 40,62 and $90{ }^{\circ} \mathrm{C}$ demonstrating thus the possibility of tuning the thermal response with the 10 nanocube concentration. The results emphasized that above $2.7 \mathrm{~g} \cdot \mathrm{L}^{-1}$ iron, the capsule walls were damaged by the AMF applications ensuring the rapid release of the capsule content.

Despite its high efficiency for remote AMF-induced drug release, the previous systems were limited by the irreversibility of the magneto-thermal response. Indeed, the design of a capsule wall that can be opened reversibly through AMF could be of high interest for pulsatile release. For this, Katagiri et al. [149] added a lipid bilayer to PAH/PSS/magnetite microcapsules with the aim at ensuring a soft thermal response and avoid capsule wall degradation upon thermal effect. The capsules were formed by LbL-templated assembly of the polyelectrolytes and magnetite NPs on a sacrificial melamine formaldehyde template that was further dissolved in $\mathrm{HCl} 0.1 \mathrm{M}$. Given their permeability to small molecules ( $\leq 500 \mathrm{Da}$ ), the PAH/PSS capsules were loaded with low MW dye molecules such as calcein or phenol red and a didodecylammonium chloride (DDAC) lipid bilayer membrane was added to control the permeability of the capsules. Indeed, the DDAC bilayer has a phase transition temperature $\left(T_{m}\right)$ of $45^{\circ} \mathrm{C}$ and is not permeable to the dyes below this $T$, ensuring the tight encapsulation within the PAA/PSS capsules at ambient or physiological T. Application of an AMF ( $\mathrm{f}=360 \mathrm{kHz}$, $B=23.4 \mathrm{mT}, 30 \mathrm{~min}$ ) reaching a macroscopic $\mathrm{T}$ of $58^{\circ} \mathrm{C}$, allowed then to trigger the diffusion of both dyes from the capsules to the solution. TEM investigations did not evidence capsule wall rupture, thereby confirming the mechanism of lipid bilayer phase transition above their $\mathrm{T}_{\mathrm{m}}$ of $45^{\circ} \mathrm{C}$.

\subsection{Magnetic polymer-based nanospheres}

In the following paragraphs, we review polymer-based nanospheres (NSs) which consist in several different polymer architectures:

i) Cross-linked (chemical) or entangled (physical) nanogel polymer matrixes

ii) Hydrophobic biodegradable polyester (e.g. PLGA or PCL) NSs well suited for the loading of hydrophobic drugs

iii) Micelles made by self-assembly of an amphiphilic block copolymer

\subsubsection{Magnetic micro and nanogels for hydrophilic drug loading and release}


As seen in Part 2, thermoresponsive micro- and nanogels are typically made of copolymers which present a volume phase transition temperature (VPPT) or a LCST close to the optimal hyperthermia $\mathrm{T}\left(41-42^{\circ} \mathrm{C}\right)$. Triblock copolymers made of poly(ethylene oxide) and poly-(propylene oxide) blocks $\left(\mathrm{PEO}_{100}-b-\mathrm{PPO}_{65}-b-\mathrm{PEO}_{100}\right)$ also known by the tradename Pluronic ${ }^{\mathrm{TM}} \mathrm{F} 127$, have been also reported for various biomedical applications including thermogelling injectable scaffolds. In a work by Liu et al.[205] magnetic thermo-sensitive F127 NSs were loaded with DOX and IONPs formed in situ by alkaline co-precipitation. Upon AMF application (50-100 $\mathrm{kHz}, \mathrm{P}=15 \mathrm{~kW}, 30 \mathrm{~min}$ ), a strong burst release of DOX followed by a slowest continuous regime ensured the efficient release of $c a$. $70 \%$ DOX, whereas an external heating at $35^{\circ} \mathrm{C}$ led to only $c a .30 \%$ release. Thus the higher amount of released DOX with AMF application was not only attributed to a thermo-induced shrinkage (F127-NSs which size showed a strong decrease from $37.8 \mathrm{~nm}$ at $15^{\circ} \mathrm{C}$ to $16.2 \mathrm{~nm}$ at $35^{\circ} \mathrm{C}$ ) but also to a matrix porosity enhancement generated specifically upon AMF application.

The same group recently designed thermosensitive PEO-PPO-PEO (F127) triblock-copolymer nanogels bound with a PVA polymer and loaded both with magnetic NPs and Ethosuximide (ETX), a Ca ${ }^{2+}$ channel blocker for anti-epilepsy applications.[206] Nanogels were interpenetrated with PVA chains to increase their colloidal stability and to reduce the drug leakage. The authors showed that the LCST of the PVA/F127 nanogels could be tuned from $25^{\circ} \mathrm{C}$ to $47^{\circ} \mathrm{C}$ according to the polymer blend composition. Upon AMF applied $\left(2.5 \mathrm{kA} \cdot \mathrm{m}^{-1}, 44.2 \mathrm{kHz}\right.$, 30 seconds), the system exhibited an instantaneous high burst release resulting into an increase in [ETX] from 0.4 to $6.8 \mathrm{mg} \cdot \mathrm{mL}^{-1}$ in only 30 seconds. This highly rapid burst was explained by the opposite effects of the thermal expansion of the PVA and the thermal shrinkage of the F127 nanogels leading to de-structuring effects. These nanoplatforms were applied in vivo for anti-epilepsy applications and are detailed in Part 4.

Regarding potential toxicity or immunogenic issues that may be raised with the use of synthetic polymers $[207,208]$ hydrophilic natural polymers such as polysaccharides or proteins are choice candidates to form thermo-sensitive nanoplatforms [209] which can be further loaded with drugs and magnetic NPs. Hence, biocompatible magnetic hydrogels made of natural polymer derived from algae were developed by Ménager and co-workers.[210] In this work, magnetic alginate microbeads synthesized by a micro-emulsion process were loaded with $\mathrm{DOX}(\mathrm{DLC}=0.34 \%)$ and maghemite NPs (8 $\mathrm{nm}$ diameter) obtained by co-precipitation. The authors showed that the DOX amount released by AMF application (700 kHz, $26 \mathrm{mT}$, 2h) was highly increased compared to an external thermal treatment at $37^{\circ} \mathrm{C}$ (respectively ca. $60 \mathrm{vs} .25 .9 \mu \mathrm{g} \cdot \mathrm{mL}^{-1} \mathrm{DOX}$ released) and was negligible at $20^{\circ} \mathrm{C}$. Furthermore, the exposure of MCF-7 breast cancer cells during $2 \mathrm{~h}$ to the DOX loaded alginate microbeads upon AMF led to a very high decrease of the cell viability $(5.7 \%)$ compared to treatments with the same systems without AMF (63.3\%) or without DOX (59.4\%).

Multi-responsive glucose-, $\mathrm{pH}$ - and thermo-sensitive magnetic crosslinked nanogels were also recently designed by Duguet, Jerome et coll.,[211] In this work, poly(vinyl alcohol)-b-poly(N-vinylcaprolactam) PVAPNVCL micelles were first formed upon LCST and then the outer layer PVA was crosslinked with maghemite NPS bearing boronate functions through boronate/diol coupling reaction (Figure 6). This approach allowed encapsulation of a drug model Nile red (DLC= 10\%, DLE= $24 \%$ ) within the PNVCL hydrophobic core at pH7.4. The drug model was then released by different ways: at a lower $\mathrm{pH}=5.0$ mimicking endosomes or under glucose 
at 20-50 mM mimicking redox conditions of cytoplasm. Furthermore, the authors showed that AMF application $(\mathrm{f}=755 \mathrm{kHz}, \mathrm{B}=14 \mathrm{mT})$ combined with redox glucose stimuli $(20 \mathrm{mM})$ allowed accelerating the dye release in the solution.
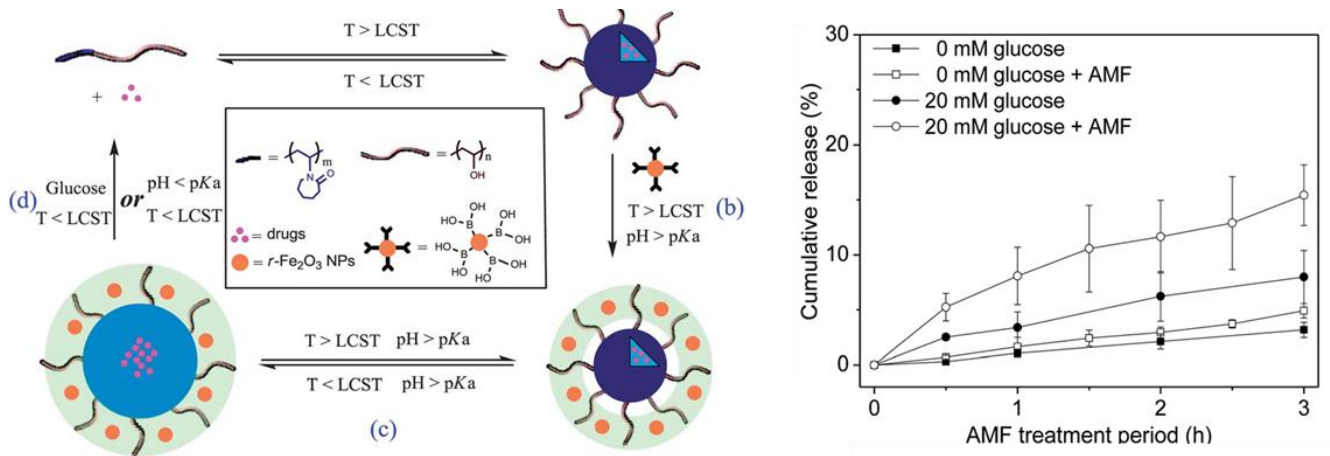

Figure 6. Scheme of the assembly of multi-responsive glucose-, $\mathrm{pH}$ - and thermo-sensitive magnetic crosslinked nanogels. At the right, cumulative release upon the simultaneous triggers: AMF and glucose at $20 \mathrm{mM}$.

Reproduced from ref. [211] with permission of The Royal Society of Chemistry.

\subsubsection{Magnetic PLGA-based NSs for hydrophobic drug loading}

As already mentioned for vesicles, Poly(D,L-lactide-co-glycolide) (PLGA)is particularly attractive to design nanocarrier systems because of its biocompatibility and biodegradability. Moreover, PLGA-based NSs are suitable nanoplatforms for the loading of hydrophobic drugs and are semi-crystalline. Kong et al. [105] formulated by a nanoprecipitation process PLGA NPs (80 nm size) coated with lipid-conjugated PEG and encapsulating both IONPs of $10 \mathrm{~nm}$ diameter (40\% IO payload) and the CPT drug (tunable range of DLC= 1-10 \%). Application of an AMF (100 kHz, 2×8min exposure separated by 4 min intervals) allowed a $60 \%$ and $100 \%$ cumulative CPT drug release respectively over $5 \mathrm{~h}$ and $46 \mathrm{~h}$. The mechanism of drug release was attributed to the heat induced-magnetic field that reached a $T$ above the $T_{m}$ of PLGA (ca. $45^{\circ} \mathrm{C}$ ). MTT assays performed on MT2 mouse breast cancer cells incubated with CPT-filled PLGA NPs resulted in a very high reduction in tumor cell viability upon AMF activation (ca. 65\% cell killing, with $2 \times 15$ min AMF separated with 5 min intervals) compared to the controls without AMF or without the CPT (ca. 10\% cell killing) (Figure 7.A).

In a recent work by Balasubramanian, Sakthikumar, and co-workers[212] two hydrophobic drugs, i.e. curcumin (Cur) (DLE= 71\%, DLC $1.5 \%$ calculated) and 5-FU (DLE= 63\%, DLC $3 \%$ calculated), were simultaneously co-loaded within PLGA NSs priory doped with IONPs (10\% wt). The PLGA magnetic NSs were further conjugated with two targeting ligands: folate and transferrin for a dual targeting strategy. These nanoplatforms showed a natural drug leakage of Cur and FU over time, which contribute to ca. 15-20\% release over $2 \mathrm{~h}$. However, the application of an AMF $\left(\mathrm{H}=18 \mathrm{kA} \cdot \mathrm{m}^{-1}\right.$ at $\left.\mathrm{f}=305 \mathrm{kHz}, 2 \mathrm{~h}\right)$ allowed to accelerate the release of both drugs $\geq 50 \%$ over the same periods. Cell viability experiments performed with MCF-7 and G1 cancer cell lines have shown that the combination of dual targeting/dual drug delivery and $\mathrm{MH}$ allowed to achieve a cell killing rate of 28 and $26 \%$ respectively.

Aside from the loading of classical antitumoral drugs, Tetrandrine (Tet), a potassium TASK3 channel inhibitor involved in the progression of various cancers (breast, colorectal, lung etc..) was efficiently loaded 
(DLC ca. 2\%, DLE ca. 65\%) in magnetic PLGA/IONP NSs (1-2\% wt) synthesized by an emulsion method [213]. The Tet kinetic release profiles were performed at $25^{\circ} \mathrm{C}, 37^{\circ} \mathrm{C}$ and $45^{\circ} \mathrm{C}$ showing an increase of the cumulative amount of drug released with T respectively at $37 \%, 48 \%$ and $60 \%$ over 24 hours. This increase was explained by the $T_{m}$ of PLGA which is around $44-48^{\circ} \mathrm{C}$. Upon heat induced AMF (216 kHz-147.6 kA.m ${ }^{-1}$ ) over a period of $340 \mathrm{~s}$, reaching an external $\mathrm{T}$ of $45^{\circ} \mathrm{C}$, the channel current in xenopus oocyte with overexpressed TASK 3 channel was monitored in response to the released drug. The data showed that the release of Tet from the Tetloaded IO-PLGA NSs ensured 25\% inhibition of the oocyte TASK 3 channel upon AMF application whereas $10 \%$ was measured in the absence of AMF. Furthermore, no change of the current was observed with PLGA-IO NPS without Tet inhibitor and upon AMF (Figure 7.B).

\subsubsection{Thermosensitive Magnetic micelles}

Among magnetic nanosystems involving the use of sophisticated designed polymers or co-polymers, magnetic micelles are particularly attractive systems as the controlled properties of the copolymers dictate finely the resulting properties of the core-shell magnetic micelles. However there are relatively fewer works dealing with the use of magnetic self-assembled copolymer micelles compared to previously described nanogels or NSs, and up to date there is no report on in vivo experiments, to our knowledge. This is probably due to the complexity to achieve the copolymer design and a controlled self-assembly. Nevertheless, such selfassembled magnetic nanosystems can afford a high level of precision in the thermal response.
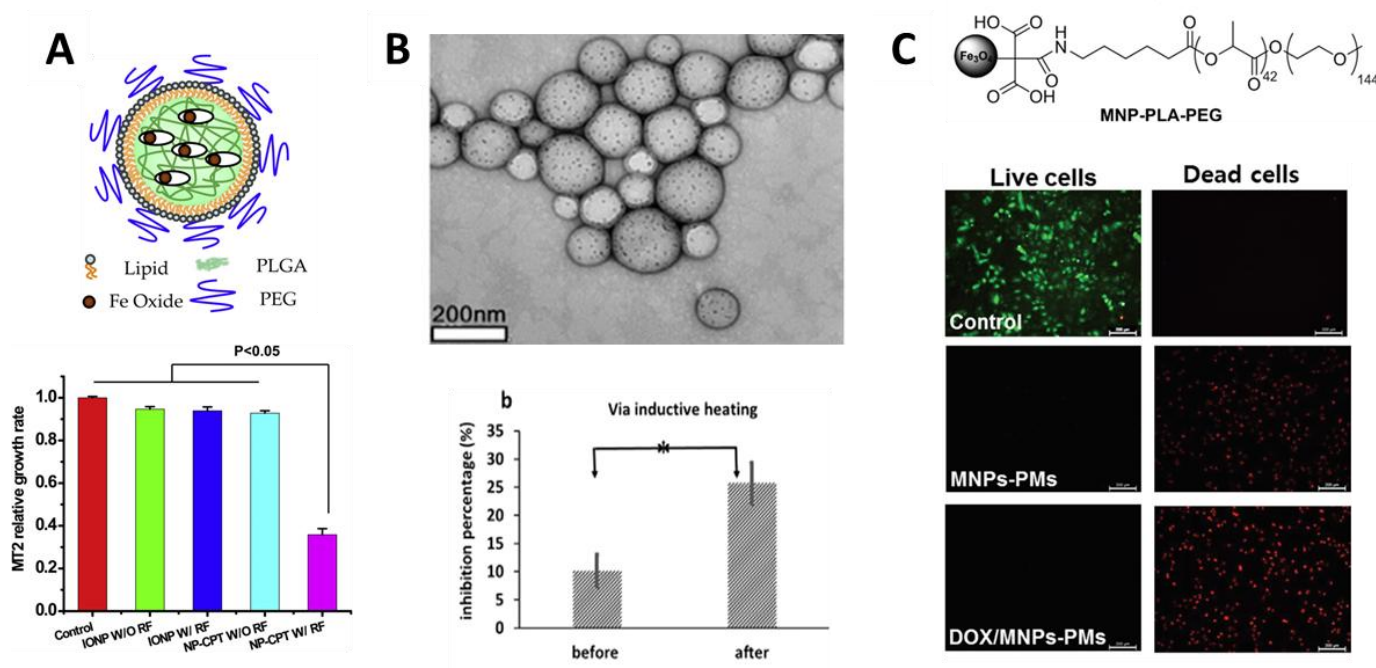

Figure 7. A. Scheme of the CPT-loaded magnetic PLGA-IONP coated with lipidic PEG and effect of MH with MBT2 cancer cells (below). Reprinted from ref. [105], Copyright 2013, with permission from Elsevier. B. TEM image of Tet loaded PLGA-IONPS and effect of AMF-induced inhibition of TAK3 channel of Xenopus oocytes. Reprinted from ref. [213], Copyright 2016, with permission from Elsevier. C. Scheme of MNP-PLA-PEG magnetic micelles and fluorescence live/dead cell assay. Reproduced from ref. [214] with permission of The Royal Society of Chemistry.

Rozkhova and co-workers [215] investigated the use of magnetic copolymer micelles made of poly $(\mathrm{N}$ isopropylacrylamide-co-acrylamide)-block-poly( $\varepsilon$-caprolactone) (P(NIPAAm-co-AAm)- $b$-PCL). The thermo- 
responsiveness of the random copolymer block was adjusted by copolymerizing acrylamide (Am) and NIPAAm groups to reach a LCST of $43{ }^{\circ} \mathrm{C}$ suitable for a thermal response in physiological conditions. The micelles were dually loaded with magnetic NPs $(11 \mathrm{~nm}$ ) formed by thermal decomposition and DOX (in its unprotonated state) at $1 \mathrm{mg} \cdot \mathrm{mL}^{-1}$, both confined in the hydrophobic PCL core of the micelles. Application of an AMF (330 kHz, 7.7 or $14 \mathrm{mT}$ according to the aimed temperature of respectively $43^{\circ} \mathrm{C}$ and $50^{\circ} \mathrm{C}, 10 \mathrm{~min}$ ) ensured a rapid burst release of DOX of $c a$. $20 \%$ of the initial payload whereas over this short period, the drug release was measured as negligible in the absence of AMF applied.

Very recently, Kim et al. [214] designed magnetic poly(ethylene)-b-poly(lactic acid) (PEG-PLA) micelles by conjugating a PEG-PLA block copolymer to an 10 core (Figure 7.C). Unprotonated DOX was loaded (DLC 11.4\%) inside the hydrophobic PLA moiety of the PEG-PLA copolymer and the drug loaded magnetic nanoplatform was submitted to $A M F\left(f=200 \mathrm{kHz}, \mathrm{H}=1.5 \mathrm{kA} \cdot \mathrm{m}^{-1}\right)$. The results showed that application of the AMF allowed reaching an amount of drug release up to $45 \%$ after $24 \mathrm{~h}$ whereas a natural leakage occurred over the same period up to $20 \%$ in the absence of applied AMF. The mechanism of drug release was attributed to a change in the PLA chain mobility occurring at a temperature range around the physiological T, as confirmed by DSC measurements with an endothermic melting peak observed between $40-56^{\circ} \mathrm{C}$ ascribed to a $T_{m}$ transition. Efficacy of the drug release was also assessed with cancer cells by incubating A549 cells with the DOX loaded MNP-PEG-PLA magnetic micelles. The cells were internalized with the magnetic micelles for $2 \mathrm{~h}$, washed and then were submitted to AMF $\left(200 \mathrm{kHz}, 1.5 \mathrm{kA} \cdot \mathrm{m}^{-1}\right)$. Results obtained showed that the combination of $\mathrm{MH}$ and DOX release from the magnetic micelles was more efficient to kill cancer cells (cell viability ca. 22\%) compared to the effect of MNP-PEG-PLA-DOX without AMF (ca. $60 \%$ cell viability) or with MNP-PEG-PLA without loaded DOX upon AMF (MH alone, ca. $46 \%$ cell viability).

\subsection{Magnetic inorganic nanocomposites}

Magnetic nanocomposites can be defined as inorganic matrixes encapsulating magnetic NPs. They are mainly made of silica, yet apatite or bioactive glasses can also be used and be doped to become magnetic. There are various possibilities of nanoconstruct/nanocomposites: core-shells, multicore structures, etc... There are different ways to release drugs from such inorganic matrix upon AMF. The drugs can be released eiter after an enhanced diffusion mechanism resulting from magnetothermal-induced deformation or cracks, or by the use of thermo-responsive gatekeepers judiciously located at the surface or extremities of the pores of mesoporous silica allowing to priory embedded drugs to diffuse out of the composite upon AMF application.

\subsubsection{Drug release via magneto-induced de-structuring}

First works dealing with magnetic silica nanocomposites releasing drugs upon AMF reported a mechanism of pores and cracks generation to release the drugs. Hence, magnetic silica composites were made via a one pot sol-gel process from iron salts and silica precursors.[167] Ibuprofen (IBU) was loaded during the sol-gel process $(\mathrm{DLC}=1 \%, \mathrm{DLE}=23 \%)$. Upon $30 \mathrm{~min}$. AMF exposure $\left(\mathrm{H}=2.5 \mathrm{kA} \cdot \mathrm{m}^{-1}, 50 \mathrm{kHz}\right)$, a burst release of IBU allowed reaching almost $c a$. $70 \%$ release whereas a negligible release was observed at externally controlled T of $50^{\circ} \mathrm{C}$ (ca. $10 \%$ release). Moreover, the release of IBU was performed by a pulsatile AMF mode ( $4 \times 5$ min) over several hours and the study showed slightly less ( $10 \%$ less) cumulative drug release compared with continuous 
AMF. Investigations of surface area, pore volume and pore size by BET analysis as a function of the time of AMF applied indicated that after 5 min AMF exposure, a recoverable change occurred whereas after 30 min AMF, an unrecoverable change with pore enlargement was measured. The temperature reached after 30 min AMF application was only measured at $34^{\circ} \mathrm{C}$ suggesting that local gradient $\mathrm{T}$ effects or magnetic actuation were responsible for the silica matrix de-structuration.

Conversely, $\mathrm{Hu}$, Liu, Chen et al. showed that the shell of the nanoplatforms could also be made of magnetic materials surrounding a silica core loaded with the drug.[168] Hence, in this work, a fluorescent molecule was loaded during the sol-gel process in PVP-modified silica core (15 nm) that was surrounded by an iron oxide shell ( $4 \mathrm{~nm}$ thickness) (Figure 8.A). Such original design ensured the rapid burst release of the fluorescent dye with an intensity depending on the application time : 30-180 seconds of the AMF applied $(P=15 W, f=50 \mathrm{kHz})$. The authors evidenced by high resolution (HR)-TEM and BET that short application times of AMF (60 s) gave rise to lattice deformation but not to pores or cracks, ensuring reversibility of the barrier shell opening whereas an irreversible degradation resulting in cracks of the 10 shells was demonstrated upon long times of AMF (20 min for shell disruption). The nanospheres were also internalized in HeLa cells and submitted to an $A M F$ treatment $(P=15 \mathrm{~W}, f=50 \mathrm{kHz} 30 \mathrm{~s})$. Fluorescence microscopy images of HeLa cells after $10 \mathrm{~h}$ incubation showed the green fluorescence of the dye released in the cytoplasm triggered by the AMF-induced shell opening. (Figure 8.A)

A
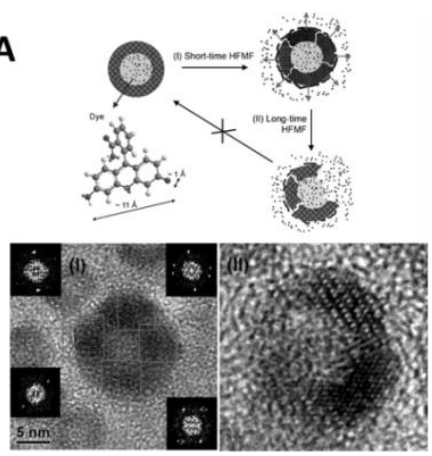

B

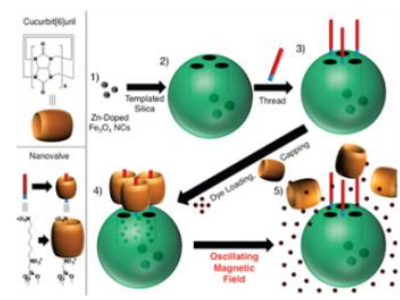

(a) Before HFMF Stimulus

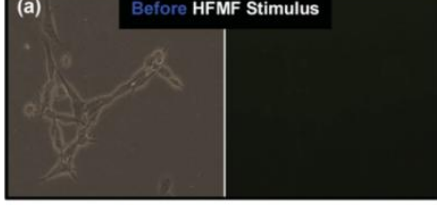

(b) After HFMF Stimulus
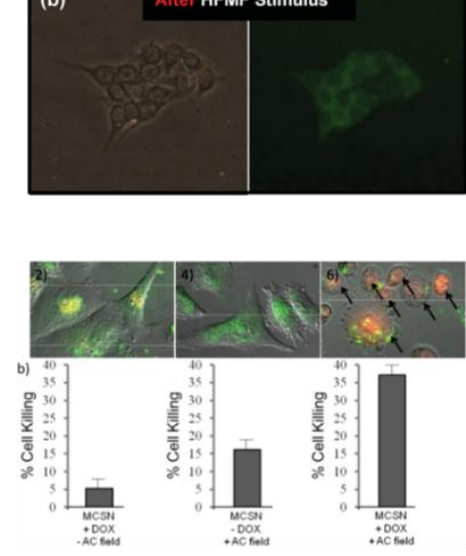

Figure 8. A. AMF effects on core-shell nanoplatforms made of a dye-loaded silica core surrounded by a magnetite shell. On the right: microscopy images show the dye delivery by AMF application. Reprinted from ref. [168] with permission of Wiley. B. Magnetic MS composites capped with cucurbituryl thermoresponsive gatekeepers. On the right: combined cell-killing effect of AMF-induced DOX delivery and MH. Reprinted from ref. [110] with permission. Copyright 2010, American Chemical Society.

Other works performed by the same authors involved the formation of silica shells around magnetic polymer-based cores as tight barriers for drug encapsulation. They designed PVA-coated self-assembled IO 
cores (SAIO of $5 \mathrm{~nm}$ core diameter) prepared by nanoemulsion surrounded by a thin silica shell of 4-5 $\mathrm{nm}$ $\left(\mathrm{SAIO} @ \mathrm{SiO}_{2}\right)$.[216] Ibubrofen as a model drug was loaded within the PVA matrix. In this work, the IBU release was achieved on 1-4 min treatment for both SAIO and SAIO@SiO 2 NPs at similar AMF field parameters $(\mathrm{H}=2.5$

$k A \cdot m^{-1}, f=50 \mathrm{kHz}$ ) that were used for the full IO@silica nanocomposites described above. The amount of drug

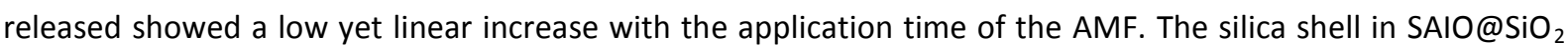
NPs was shown to limit importantly the burst release of IBU and to prevent the NP disassembly compared with the SAIO NPs alone. Study with HeLa cells showed a rapid intracellular uptake of the nanoplatforms as visualized by fluorescence microscopy, and MTT assays showed good cell viability at the tested doses. In another work by this group, yolk-shell capsules comprising IONPs and IBU emulsified with PVA/F68 (where Pluronic F68 is a PEO-PPO-PEO triblock copolymer) and coated with a thin silica shell were also designed.[217] The silica shell acted as a tight barrier without AMF applied and when AMF was applied $\left(\mathrm{f}=50 \mathrm{kHz}, \mathrm{H}=2.5 \mathrm{kA} \cdot \mathrm{m}^{1}\right.$ ) during 1-4 min, a burst release of IBU occurred. Indeed, upon AMF application, the local T reached the critical micelle temperature (hydrophilic-to-hydrophobic transition) of the PVA/F68 mixture $\left(47^{\circ} \mathrm{C}\right)$ which triggered a core size contraction as large as tenfold: such a significant volume phase thermal transition effect (VPTT) of the core led to the physical rupture of the silica capsules. These nanoplatforms were shown to be internalized efficiently in retinal pigment epithelium cells (ARPE 19).

\subsubsection{Magnetic silica composites : drug release via thermoresponsive gatekeepers}

Alternatively to non-porous silica, the use of mesoporous silica (MS) is a way to load very high amounts of a drug within magnetic porous nanocomposites. In this paragraph, the silica matrix is not affected by the AMF, but thermosensitive molecules or polymers ensure the thermal control of the MS silica pore opening by AMF application and consequent magnetic control the drug release,

The capping of magnetic MS with pseudorotaxanes as molecular caps is an elegant way of obtaining $\mathrm{pH}$-responsive gatekeepers and such host-guest interactions can also be disrupted by thermal effects. In a work by Stoddart, Cheon, Zinck et coll. [110], Zn-doped IO@MS modified with aminohexyl (AMTS) threads were loaded with $\mathrm{DOX}$ in $\mathrm{MeOH}(\mathrm{DLC}=4 \%)$ and complexed with cucurbituryl. Continuous release over 50 min or pulsatile release as well $(6 \times 1 \mathrm{~min})$ over $250 \mathrm{~min}$ upon $\mathrm{AMF}$ application $\left(\mathrm{H}=32.4 \mathrm{kA} \cdot \mathrm{m}^{-1}, \mathrm{f}=500 \mathrm{kHz}\right)$ allowed reaching a full release of DOX while the release was negligible in the absence of AMF. Moreover, tests on MDA MB 231 breast cancer cells showed that the combination of $\mathrm{MH}$ (5 min AC field exposure) and DOX delivery allowed reaching $37 \%$ cancer cell killing rate compared with $\mathrm{MH}$ alone at $16 \%$.(Figure 8.B) In another work, Baeza et al. achieved the simultaneous loading of small dye FITC and catalase enzyme by respectively impregnation in magnetic MS and immobilization within a PNIPAAM- $b$-PEI copolymer shell capping the MSNs@IONPs (200 nm size).[218] Upon AMF application ( $\left.\mathrm{H}=24 \mathrm{kA} \cdot \mathrm{m}^{-1}, \mathrm{f}=100 \mathrm{kHz}\right)$, both the protein release from the polymer shell and FITC release from the MS structure were achieved at a rate higher than $50 \%$ in $6 \mathrm{~h}$. This simultaneous release behavior was attributed to local PNIPAAM conformational change due to the local T change. The authors noticed that the enzymatic activity of the catalase showed only $10 \%$ loss which means that the local temperature sensed by the enzyme at the polymer coated silica surface should be lower that its temperature of denaturation $\mathrm{T}\left(60^{\circ} \mathrm{C}\right.$ for catalase). Other examples of thermally responsive gatekeepers at the 
surface of magnetic MS have been developed these last years. Ruiz Hernandez et al. [107] designed magnetic mesoporous silica gated with DNA double strands for the magnetothermal controlled release of fluorescein. Bringas et al. reported lipid bilayers as thermosensitive gatekeepers for the release of methylene blue as a drug model upon AMF.[219] Saint-Cricq et al. designed the functionalization of MS core-shells with a PEG spacer bearing a diazo bond that acts as an efficient thermo-degradable gatekeeper to release rhodamine upon AMF. [112] Recently, the use of tetradecanol as a phase changing wax $\left(T_{m}=39^{\circ} \mathrm{C}\right)$ was also shown efficient to cap the surface of PEGylated IO core-MS shell loaded with DOX (DLC=9.3\%, DLE $=37 \%$ ) and to ensure a zero premature release at $37^{\circ} \mathrm{C}$ in PBS over 96h.[176] Increasing the macroscopic $\mathrm{T}$ above $40^{\circ} \mathrm{C}$ allowed to trigger the diffusion of embedded drug release consequently to the phase change of the wax ( $37 \%$ release at $40^{\circ} \mathrm{C}$ in PBS over $96 \mathrm{~h}$ ). Test on melanoma cells MEC-5 demonstrated the in vitro efficient toxicity induced by the heat-triggered DOX release.

Finally, the study by Fontecave et al. [220] reports a model $\mathrm{MH}$-induced delivery system based on nanocapsules prepared by wrapping Pickering emulsion droplets with a MS shell. The chosen oil, the fatty diester dioctyl terephatalate (DOT), represented a pro-drug as DOT liberates aqueous terephtalate ions upon its ester bond cleavage. This Pickering emulsion being stabilized by caprylic acid-coated IONPs, these were ideally localized at the DOT-MS interface, the silica porosity being adjusted by a CTAB template added during the solgel step. Therefore water could penetrate through MS to the oil surface, where hydrolysis was catalyzed by local heating of the IONPs under AMF $\left(\mathrm{H}=24 \mathrm{kA} \cdot \mathrm{m}^{-1}\right.$ at $\left.900 \mathrm{kHz}\right)$, thereby releasing water-soluble terephthalate ions that could be titrated by UV-vis absorption (>30\% cumulative release after $225 \mathrm{~min}$ ).

\subsubsection{Other inorganic composites : glasses and hydroxyapatites NPs}

Recently, other types of nanocomposites have emerged as complementary systems releasing drugs upon AMF with new properties. For instance, fully biodegradable superparamagnetic iron-doped nanoapatite (FeHA) nanoneedles of 10-30 nm thickness, $70100 \mathrm{~nm}$ length were developed very recently by lafisco, Drouet et al.[221] DOX adsorption was performed on FeHA NPs at ca. $7 \mu \mathrm{mol}_{\mathrm{DOX}} \cdot \mathrm{m}^{-2}\left(\sim 4 \mathrm{mg} \cdot \mathrm{m}^{-2}, \mathrm{DLC}=44.9 \%\right)$. Application of a low-frequency pulsed electromagnetic field applied ( $B=2 \mathrm{mT}, f=75 \mathrm{~Hz}$ with pulses of $1.3 \mathrm{~ms}$ ) allowed to increase the DOX release from FeHA NPs from 3.7\% to 10\% DOX release over 6 days compared without AMF, and without any macroscopic heating of the solution. The release was explained by the enhanced desorption of DOX from the NPs mediated by the AMF triggered mechanical motion. Studies with cancer SAOS-2 cell lines showed a rapid cell uptake of the nanoneedles and cell viability assays (without AMF) showed efficiency of the FeHA NPs to kill cancer cells. In another recent work, the one pot sol-gel synthesis of polymer-siloxane-IO NPs hydrogels cross-linked by di-urea (Ureasil-PEO- $\gamma-\mathrm{Fe}_{2} \mathrm{O}_{3}$ nanocomposites) releasing sodium diclofenac (SDCF) as a model drug upon AMF was reported by Caetano, Menager et al. [222] SDCF release profiles achieved in PBS either at $37^{\circ} \mathrm{C}$ under AMF $\left(\mathrm{H}=14.9 \mathrm{kA} \cdot \mathrm{m}^{-1}, \mathrm{f}=420 \mathrm{kHz}\right)$ for 8 cycles of $45 \mathrm{~min}$ AMF or at $50^{\circ} \mathrm{C}$ externally applied T were very similar (ca. $70 \mu \mathrm{g} \cdot \mathrm{mL}^{-1} \mathrm{SDC}$ released over $8 \mathrm{~h}$ ) and moderately higher than at $37^{\circ} \mathrm{C}$ without applied AMF (ca. $55 \mu \mathrm{g} \cdot \mathrm{mL}^{-1}$ ). Mechanism of drug release was attributed to the melting of the crystalline PEO at around $38^{\circ} \mathrm{C}$ which triggered drug diffusion out of the network. 
Summary table of AMF induced drug release in vitro results.

\begin{tabular}{|c|c|c|c|c|c|c|c|}
\hline REF & $\begin{array}{l}\text { NANOPLATFORM } \\
\text { Carrier type }\end{array}$ & $\begin{array}{l}\text { DRUG } \\
\text { LOADING }\end{array}$ & $\begin{array}{l}\text { Magnetic Field } \\
\text { and Frequency }\end{array}$ & Time & Mechanism & $\begin{array}{l}\text { Cancer cell } \\
\text { line }\end{array}$ & $\begin{array}{l}\text { Cell viability } \\
\text { Reduction }\end{array}$ \\
\hline \multicolumn{8}{|c|}{ MAGNETIC CORE/ SHELL NANOSYSTEMS } \\
\hline [186] & $\begin{array}{l}\mathrm{Fe}_{3} \mathrm{O}_{4} @ P S M A \text { grafted } \\
\text { with polyA15 } \\
22 \mathrm{~nm} \text { core }\end{array}$ & $\begin{array}{l}5-\mathrm{FU} \\
5425 \\
\text { molecules/NP }\end{array}$ & $\begin{array}{l}\mathrm{f}=1.3 \mathrm{MHz} \\
\mathrm{B}=41.3 \mathrm{mT} \\
\mathrm{H}=33 \mathrm{kA} \cdot \mathrm{m}^{-1}\end{array}$ & $15 \mathrm{~min}$ & $\begin{array}{l}\mathrm{H} \text {-bond } \\
\text { breaking }\end{array}$ & MBT-2 & $\begin{array}{l}50 \% \text { reduction } \\
\text { Anti-HER2 ligand }\end{array}$ \\
\hline [184] & $\begin{array}{l}\gamma-\mathrm{Fe}_{2} \mathrm{O}_{3}-\mathrm{MIP} \text { core } \\
\text { shells systems } \\
\text { poly(acrylamide) }\end{array}$ & $\begin{array}{l}\text { DOX } \\
35.6 \\
\mu \mathrm{mol} . \mathrm{g}^{-1}\end{array}$ & $\begin{array}{l}f=700 \mathrm{kHz} \\
B=25 \mathrm{mT} \\
\mathrm{H}=20 \mathrm{kA} \cdot \mathrm{m}^{-1}\end{array}$ & $1 \mathrm{~h} 30$ & $\begin{array}{l}\mathrm{H} \text { bond } \\
\text { breaking }\end{array}$ & PC 3 & $40 \%$ reduction \\
\hline [185] & $\begin{array}{l}\text { Mixed ferrite } \\
\mathrm{Zn}_{0.4} \mathrm{Fe}_{2.6} \mathrm{O}_{4}\end{array}$ & $\begin{array}{l}\text { Geldanamycin } \\
\text { as HSP inhibitor }\end{array}$ & $\begin{array}{l}f=500 \mathrm{kHz} \\
B=46.3 \mathrm{mT} \\
\mathrm{H}=37 \mathrm{kA} \cdot \mathrm{m}^{-1}\end{array}$ & $80 \mathrm{~min}$ & Diazo bond & $\begin{array}{l}\text { MDA-MB } \\
\text { (breast } \\
\text { cancer) }\end{array}$ & $\begin{array}{l}100 \% \text { reduction } \\
25 \% \mathrm{MH} \text { only. }\end{array}$ \\
\hline [187] & $\begin{array}{l}\text { C-coated Fe NPs } \\
\text { NPs 7-9 nm }\end{array}$ & $\begin{array}{l}\text { DOX or Erlotinib } \\
=0.07 \text { or } 0.11 \\
\text { mg Fe }\end{array}$ & $\begin{array}{l}f=350 \mathrm{kHz} \\
P=1.2 \mathrm{~kW}\end{array}$ & $10 \mathrm{~min}$ & $\begin{array}{l}\pi-\pi \text { bond } \\
\text { breaking }\end{array}$ & Panc1 & $\begin{array}{l}50 \% \text { reduction } \\
25 \% \mathrm{AMF}\end{array}$ \\
\hline \multicolumn{8}{|c|}{ MAGNETIC VESICLES } \\
\hline [137] & $\begin{array}{l}\text { Stealth and Folate-R } \\
\text { targeted TMLs with } \\
\text { hydrophilic IO NPs }\end{array}$ & $\begin{array}{l}\text { DOX } \\
\text { DLC=10\%, } \\
\text { DLE }=85 \%\end{array}$ & $\begin{array}{l}\mathrm{f}=290 \mathrm{kKz} \\
\mathrm{B}=15 \mathrm{mT} \\
\mathrm{H}=12 \mathrm{kA} \cdot \mathrm{m}^{-1}\end{array}$ & $60 \mathrm{~min}$ & $\begin{array}{l}\text { Membrane } \\
\text { permeation } \\
\text { at lipid } T_{m}\end{array}$ & $\begin{array}{l}\text { KB and } \\
\text { HeLa }\end{array}$ & $\begin{array}{l}93 \% \text { at } 30 \mu \mathrm{M} \text { DOX } \\
+\mathrm{AMF}\left(33.5^{\circ} \mathrm{C}\right) \\
\text { synergetic effect }\end{array}$ \\
\hline [194] & $\begin{array}{l}\text { MLs coated by } \\
\text { carboxymethyl } \\
\text { dextran (CMD) with } 6 \\
\text { wt.\% citrated IONPs }\end{array}$ & $\begin{array}{l}\text { DOX } \\
\text { DLE = 97\% }\end{array}$ & $\begin{array}{l}\text { Low } \mathrm{f}=50 \mathrm{~Hz} \\
\mathrm{~B}=15 / 30 / 50 \mathrm{mT} \\
\mathrm{H}=12 / 24 / 40 \\
\mathrm{kA} \cdot \mathrm{m}^{-1}\end{array}$ & $\begin{array}{l}10,20, \text { or } \\
30 \mathrm{~min}\end{array}$ & $\begin{array}{l}\text { Non- } \\
\text { thermosensiti } \\
\text { ve lipid }\end{array}$ & $\begin{array}{l}\text { Human } \\
\text { neurobasto } \\
\text { ma SHSY5Y }\end{array}$ & \\
\hline $\begin{array}{l}\text { [102] } \\
]\end{array}$ & $\begin{array}{l}\text { Polymersomes with } \\
\text { surfactant-coated } \\
\text { IONPs in hydrophobic } \\
\text { membrane ( } 30 \% \text { wt.) }\end{array}$ & $\begin{array}{l}\text { DOX } \\
D L E=28 \% \\
D L C=5.6 \%\end{array}$ & $\begin{array}{l}\mathrm{f}=750 \mathrm{kHz} \\
\mathrm{B}=14 \mathrm{mT} \\
\mathrm{H}=11.2 \mathrm{kA} \cdot \mathrm{m}^{-1}\end{array}$ & $\begin{array}{l}10 \text { min } \\
3 \times / \text { day } \\
\text { every } 2 \mathrm{~h} \\
3 \text { days }\end{array}$ & $\begin{array}{l}\text { Membrane } \\
\text { permeation } \\
\text { at polymer } \mathrm{T}_{\mathrm{m}} \\
\text { (PTMC) }\end{array}$ & HeLa & $\begin{array}{l}\text { MH+DOX ca. } 45 \% \\
\text { No } \mathrm{MH} \text { ca. } 30 \% \\
\text { MH ca. } 5 \%\end{array}$ \\
\hline [144] & $\begin{array}{l}\text { Polymersomes with } \\
\text { polyelectrolyte gel } \\
\text { layers / citrated IONPs }\end{array}$ & $\begin{array}{l}\text { IONPS + DOX } \\
\text { DLE }=73.3 \% \\
\text { DLC }=9.3 \%\end{array}$ & $\begin{array}{l}\mathrm{f}=37 \mathrm{kHz} \\
\mathrm{B}=3.1 \mathrm{mT} \\
\mathrm{H}=2.5 \mathrm{kA} \cdot \mathrm{m}^{-1}\end{array}$ & $20 \mathrm{~min}$ & $\begin{array}{l}\text { Membrane } \\
\text { permeation } \\
\mathrm{T}_{\mathrm{m}} \text { (distearin) }\end{array}$ & HeLa & $\begin{array}{l}20 \% \text { survival after } \\
\mathrm{MH} \text { vs. } 45 \% \text { at same } \\
{[\mathrm{DOX}]=10 \mu \mathrm{M}}\end{array}$ \\
\hline [203] & $\begin{array}{l}\text { DEC capsules } \\
\text { PVA shells } \\
\text { IO NPs } \\
150 \mathrm{~nm}\end{array}$ & $\begin{array}{l}\text { DOX, DLE/DLC= } \\
60 / 2.4 \% \\
\text { PTX, DLE/DLC= } \\
90 / 3.6 \%\end{array}$ & $\begin{array}{l}\mathrm{f}=50 \mathrm{kHz} \\
\mathrm{B}=12.8 \mathrm{mT} \\
\mathrm{H}=16 \mathrm{kA} \cdot \mathrm{m}^{-1}\end{array}$ & $2.5 \mathrm{~min}$ & $\begin{array}{l}\text { Membrane } \\
\text { permeation }\end{array}$ & $\begin{array}{l}\text { HeLa and } \\
\text { MCF-7 }\end{array}$ & $\begin{array}{l}98 \% \text { AMF } \\
90 \% \text { no AMF } \\
\text { Targeting with } \\
\text { IVO24 }\end{array}$ \\
\hline [103] & $\begin{array}{l}\text { DEC capsules } \\
\text { PS- } b \text {-PAA/PVA }\end{array}$ & $\begin{array}{l}\text { DNAFITC } \\
\text { payloads }\end{array}$ & $\begin{array}{l}\mathrm{f}=50 \mathrm{kHz} \\
\mathrm{B}=2.5 \mathrm{mT} \\
\mathrm{H}=2 \mathrm{kA} \cdot \mathrm{m}^{-1}\end{array}$ & $2 \mathrm{~min}$. & $\begin{array}{l}\text { Membrane } \\
\text { permeation }\end{array}$ & HeLa & $\begin{array}{l}\text { DNA }^{\mathrm{FITC}} \text { release in } \\
\text { cells induced by } \\
\text { AMF }\end{array}$ \\
\hline \multicolumn{8}{|c|}{ MAGNETIC NANOSPHERES } \\
\hline [210] & $\begin{array}{l}\text { Magnetic alginate } \\
\text { microbeads }\end{array}$ & $\begin{array}{l}\text { DOX loading } \\
\text { DLC }=0.34 \%\end{array}$ & $\begin{array}{l}\mathrm{f}=700 \mathrm{kHz} \\
\mathrm{B}=10 \mathrm{mT} \\
\mathrm{H}=8 \mathrm{kA} \cdot \mathrm{m}^{-1}\end{array}$ & $2 \mathrm{~h}$ & $\begin{array}{l}\text { Gel } \\
\text { permeation }\end{array}$ & $\begin{array}{l}\text { MCF- } 7 \mathrm{~h} \\
\text { breast }\end{array}$ & $\begin{array}{l}\text { Cell viabilities } \\
\text { DOX + AMF (5.7\%) } \\
\text { Dox (63.3\%) } \\
\text { AMF }(59.4 \%)\end{array}$ \\
\hline [105] & $\begin{array}{l}\text { PLGA-lipid-PEG NPs } \\
80 \mathrm{~nm} \text { encapsulating } \\
\text { IO NPs } 10 \mathrm{~nm}\end{array}$ & $\begin{array}{l}\text { CPT tunable } \\
\text { loading } \\
\text { DLC }=1-10 \%\end{array}$ & $100 \mathrm{kHz}$ & $2 * 15 \min$ & $\begin{array}{l}\text { PLGA } \\
T_{g} \text { at } 45^{\circ} \mathrm{C}\end{array}$ & $\begin{array}{l}\mathrm{MT2} \\
\text { mouse } \\
\text { breast }\end{array}$ & $\begin{array}{l}\text { AMF+CPT } 65 \% \\
\text { AMF or CPT } 10 \%\end{array}$ \\
\hline [212] & $\begin{array}{l}\text { PLGA NPs } \\
\text { encapsulated with IO } \\
\text { NPs ( } 10 \% \text { wt) }\end{array}$ & $\begin{array}{l}\text { CUR, DLE } 71 \% \text {, } \\
\text { DLC 1.5\% } \\
\text { 5-FU, DLE 63\%, } \\
\text { DLC 3 \% }\end{array}$ & $\begin{array}{l}\mathrm{f}=305 \mathrm{kHz} \\
\mathrm{B}=22.5 \mathrm{mT} \\
\mathrm{H}=18 \mathrm{kA} \cdot \mathrm{m}^{-1}\end{array}$ & $2 \mathrm{~h}$ & $\begin{array}{l}\text { PLGA } \\
\mathrm{T}_{\mathrm{g}} \text { at } 45^{\circ} \mathrm{C}\end{array}$ & $\begin{array}{l}\text { MCF-7 and } \\
\text { G1-cells }\end{array}$ & $\begin{array}{l}\text { Cell viabilities } \\
28 \% \text { MCF-7 } \\
26 \% \mathrm{G} 1 \\
\text { Dual targeting F+T }\end{array}$ \\
\hline [213] & $\begin{array}{l}\text { PLGA- IO } \\
200 \mathrm{~nm}\end{array}$ & $\begin{array}{l}\text { Tet : (a TASK3 } \\
\text { channel } \\
\text { inhibitor) } \\
\text { DLC ca. } 2 \% \\
\text { DLE ca. } 65 \%\end{array}$ & $\begin{array}{l}\mathrm{f}=216 \mathrm{kHz} \\
\mathrm{B}=184.5 \mathrm{mT} \\
\mathrm{H}=147.6 \mathrm{kA} \cdot \mathrm{m}^{-1}\end{array}$ & $340 \mathrm{~s}$ & $\begin{array}{l}\text { PLGA } T_{g} \text { of } \\
44-48^{\circ} \mathrm{C}\end{array}$ & $\begin{array}{l}\text { Xenopus } \\
\text { oocyte with } \\
\text { over- } \\
\text { expressed } \\
\text { TASK } 3\end{array}$ & $\begin{array}{l}25 \% \text { channel } \\
\text { current inhibition } \\
\text { upon AMF }\end{array}$ \\
\hline [214] & $\begin{array}{l}\text { Magnetic PEG-PLA } \\
\text { micelles covalently } \\
\text { conjugated with MNPS }\end{array}$ & $\begin{array}{l}\text { DOX loading } \\
\text { DLC } 11.4 \% \\
\text { IO payload } 4 \% \\
\end{array}$ & $\begin{array}{l}\mathrm{f}=200 \mathrm{kHz} \\
\mathrm{B}=1.9 \mathrm{mT} \\
\mathrm{H}=1.5 \mathrm{kA} \cdot \mathrm{m}^{-1}\end{array}$ & & $\begin{array}{l}\text { Tc at } 37^{\circ} \mathrm{C} \\
T_{m} 40-56^{\circ} \mathrm{C}\end{array}$ & A549 & $\begin{array}{l}\text { Synergistic effect of } \\
\text { DOX+AMF applied }\end{array}$ \\
\hline \multicolumn{8}{|c|}{ MAGNETIC SILICA NANOCOMPOSITES } \\
\hline [168] & $\begin{array}{l}\text { PVP- silica core } \\
@ \text { @IO shell } \\
\text { Size = } 15-23 \text { nm }\end{array}$ & $\begin{array}{l}\text { Fluorescent dye } \\
\text { loaded in silica } \\
\text { core }\end{array}$ & $\begin{array}{l}f=50 \mathrm{kHz} \\
P=15 \mathrm{~W}\end{array}$ & $30 \mathrm{~s}$ & $\begin{array}{l}\text { Reversible } \\
\text { opening of } \\
\text { the IO shells }\end{array}$ & HeLa & $\begin{array}{l}\text { Fluorescence of } \\
\text { cells upon AMF }\end{array}$ \\
\hline [110] & $\begin{array}{l}\text { Zn doped IO@MS } \\
\text { + cucurbituryl (Curb) } \\
\text { Cap }\end{array}$ & $\begin{array}{l}\text { DOX } \\
D L C=4 \%\end{array}$ & $\begin{array}{l}\mathrm{f}=500 \mathrm{kHz} \\
\mathrm{B}=40 \mathrm{mT} \\
\mathrm{H}=32 \mathrm{kA} \cdot \mathrm{m}^{-1}\end{array}$ & $5 \mathrm{~min}$ & $\begin{array}{l}\text { Thermo- } \\
\text { sensitive } \\
\text { pseudo- } \\
\text { rotaxane }\end{array}$ & $\begin{array}{l}\text { Breast } \\
\text { MDA MB } \\
231\end{array}$ & $\begin{array}{l}\mathrm{MH}+\mathrm{DOX} \\
=37 \% \text { killing } \\
\mathrm{MH}=16 \% \text { killing }\end{array}$ \\
\hline
\end{tabular}




\section{In vivo advances with magnetically drug releasing platforms: an update of the latest results}

In this part, the recent in vivo advances over these 6 last years of AMF-drug releasing magnetic platforms are reviewed. Magnetic nanoplatforms and DDS are currently tested in clinical trials and some are on the market. However to date, to the authors' knowledge, there is not yet any drug delivery platform activated by AMF in clinical trials or on the market.

Magneto-liposomes were the first magnetic nanoplatforms to be used in vivo for magneto-thermal drug release. In 2010, Yoshida et al. [223] designed docetaxel loaded magneto-liposomes (DMLs) encapsulating magnetite NPs $(9 \mathrm{~nm})$. Mice bearing xenograft MKN45 gastric cancer cell models were injected with DMLs (100 $\mu \mathrm{L}$ of $\mathrm{DML}$ dose at $187 \mathrm{mg} \cdot \mathrm{mL}^{-1}$ magnetite and a range of [56.8-568.5] $\mathrm{\mu g} \cdot \mathrm{mL}^{-1}$ Docetaxel) and submitted to AMF $\left(6.36 \mathrm{kA} \cdot \mathrm{m}^{-1}, 478 \mathrm{kHz}\right)$ over $35 \mathrm{~min}$. Over a 28 day study, the authors showed a highly important tumor reduction from day 10 whereas the other treatments (ML upon AMF, DML without AMF, free docetaxel and PBS as a saline control) did not prevent the tumor growth. In another study, Wang et al.[224] designed thermosensitive magneto-liposomes loaded with $\mathrm{Mn}_{0.5} \mathrm{Zn}_{0.5} \mathrm{Fe}_{2} \mathrm{O}_{4}$ and arsenic $\mathrm{As}_{2} \mathrm{O}_{3}$ as a chemotherapy agent. The MLs were injected in the feeding artery of human hepatoma cell tumor model created in the rabbit liver. The animals were submitted to an AMF $(230 \mathrm{kHz}, \mathrm{I}=30 \mathrm{~A}, 30 \mathrm{~min}$, at different days: 3,6,9) and the combined effect of $\mathrm{MH}+\mathrm{AMF}$ drug delivery showed over a 14 day study a higher tumor volume inhibition (85\%) as compared with MLs not-loaded with drug upon AMF (53\%) or MLs loaded with $\mathrm{As}_{2} \mathrm{O}_{3}$ without AMF (45\%). Magnetic NP chains bound to thermosensitive liposomes (TSLs) loaded with DOX were also recently used as magnetic actuators for drug delivery.[143] The authors ascribed the DOX release with these original nanoconstructs to mechanical oscillation rather than to a thermal effect (also because the frequency of the AMF was low). They were intravenously injected (at $0.5 \mathrm{mg} \cdot \mathrm{kg}^{-1} \mathrm{DOX}$ ) in rat bearing MAT B III breast tumor models and after nanochain accumulation in the tumor (at $\mathrm{t}=24 \mathrm{~h}$ post-injection), the tumor size evolution was followed over 17 days upon application of AMF vs. controls. AMF application (10 kHz, 3-5 W, 60 min allowed to limit the tumor growth when rats were injected with DOX-loaded nanochains whereas no tumor growth inhibition was obtained with the nanochains in the absence of AMF or with AMF in the absence of nanochains. Further, a second AMF treatment was shown highly efficient to shrink importantly the tumor size compared with a single treatment. In this study, the evaluation of apoptosis by quantitative histological analysis allowed confirming the beneficial effect of DOX delivery combined with AMF.

Polymer-based capsules or NPs were demonstrated also to be particularly efficient nano-platforms for AMF-induced drug release in vivo. As seen in paragraph 3.2.3, Hu et al.[203] prepared highly performant w/o/w magnetic DEC PVA capsules for MH, dual chemotherapy (DOX and PTX) and cell targeting (with IVO 24 tumor targeting peptide). Mice bearing MCF-7 breast carcinoma tumor models were injected intra-tumoraly (100 $\mathrm{LL}$ saline solution at $2 \mathrm{wt}$. $\% \mathrm{DEC})$ and submitted to AMF (50 kHz, $\left.8 \mathrm{kA} \cdot \mathrm{m}^{-1}, 10 \mathrm{~min}\right)$ at $\mathrm{t}=24 \mathrm{~h}$ postinjection. Study of the tumor growth over 30 days showed impressive tumor suppression by the combination of hyperthermia, dual chemotherapy and IVO24 cell targeting in comparison with treatments without AMF or dual chemotherapy (Figure 9.A). The same group designed also an efficient drug releasing magnetic polymeric 
NPs promising for anti-epileptic applications, based on thermosensitive F127 triblock/PVA polymer gels as described in paragraph 3.3.1 [206] The ETX-loaded magnetic F127/PVA nanogels were injected intravenously in Long-Evans rat models and submitted to AMF $\left(2.5 \mathrm{kA} \cdot \mathrm{m}^{-1}, 44.2 \mathrm{kHz}, 15\right.$ seconds) after magnetic targeting of the NPs towards the rat brain. The reduction of epileptic episodes measured by electrophysiological recording was demonstrated through the decrease of the spike-wave discharges (SPD) over 2 hours, upon the AMF-induced burst release of ETX whereas free ETX administered (1h) or ETX-loaded PVA nanogels were shown not efficient (Figure 9.B). Other types of polymer based-nanoplatforms that have emerged for in vivo applications are supramolecular magnetic nanogels (denoted SMNPs) made of Zn-dopped nanoferrites and polymers (PAMAM, PEG and PEI) self-assembled via adamantane/cyclodextrine specific interactions and loaded with DOX (via Hbonds and $\pi-\pi$ stacking).[225] Mice bearing DLD1 xenograft colon cancer model were injected intravenously with the SMNPs (150 $\mu \mathrm{g} \cdot \mathrm{kg}^{-1}$ SMNPs, $\left.2.8 \mu \mathrm{g} \cdot \mathrm{kg}^{-1} \mathrm{DOX}\right)$ and submitted to AMF (500 kHz, $\left.37.4 \mathrm{kA} \cdot \mathrm{m}^{-1}, 10 \mathrm{~min}\right)$. Study of the tumor growth over 15 days showed after a single injection (day 0 ) the efficient tumor inhibition up to 8 days compared to other treatments without AMF or without loaded DOX where the tumor was shown to continuously grow (Figure 9.C). AMF treatment after two injections (day and day 7) allowed suppressing completely the tumor over the 15 days.

Since 2013, core-shell magnetic nanoplatforms have been also developed for in vivo applications. Hence, the 5-FU loaded core-shell $\mathrm{Fe}_{3} \mathrm{O}_{4} / \mathrm{PSMA} / \mathrm{PolyA}_{15} \mathrm{NPs}[186]$ grafted with anti-HER2 antibody as described in paragraph 3.1.2 were applied in vivo in mice bearing mouse bladder-cancer cell line (MBT-2). In a first study, the NPs were injected intra-tumorally at $50 \mu \mathrm{g}$ dose/tumor $(\times 3)$ in small and large tumors and submitted to AMF $\left(\mathrm{H}=33 \mathrm{kA} \times \mathrm{m}^{-1}, \mathrm{f}=1.3 \mathrm{MHz}, 15 \mathrm{~min}\right.$ at day 1$)$. Results in small tumors showed tumor suppression for both MNPs with and without loaded FU upon AMF. However for large tumors, the 5-FU loaded core-shell NPs were found to importantly reduce the tumor size compared with PBS solution and NPs without 5FU upon AFM. In a second study, the NPs were also administered by tail-vein systemic injection (100 $\mu \mathrm{g}$ NPs, $1 \times 4$ days) and submitted to AMF $24 \mathrm{~h}$ after each injection. Tumor growth study over 20 days evidenced full in vivo tumor suppression from day 16 with 5-FU loaded core-shell NPs whereas other treatments without AMF applied or with free chemotherapeutics did not lead to important tumor growth rate reduction (Fig 9.D).

Core-shell $\mathrm{Zn}_{0.4} \mathrm{Fe}_{2.6} \mathrm{O}$ MNPs grafted with the HSP inhibitor Geldanamycin, as described in the paragraph 3.1.3 were also applied for in vivo therapy.[185] NPs were injected intra-tumorally in mice bearing xenograft breast cancer (MDA-MB-231) (50 $\mu \mathrm{g}$ directly injected into the tumor $\left(100 \mathrm{~mm}^{3}\right)$ and submitted to AMF treatment $\left(\mathrm{H}=37.4 \mathrm{kA} \cdot \mathrm{m}^{-1}, \mathrm{f}=500 \mathrm{kHz}, 30 \mathrm{~min}\right)$. AMF application ensured the $\mathrm{T}$ rise up to $43^{\circ} \mathrm{C}$ in vivo. Study of the tumor growth over 14 days showed a full in vivo tumor suppression at day 8 compared with MNPs without grafted inhibitor (Fig 9.E). Very recently, core-shell nanoplatforms with a very straightforward design but a promising efficiency were reported for AMF-induced drug release. Jeon et al. [226] loaded DOX by simple electrostatic

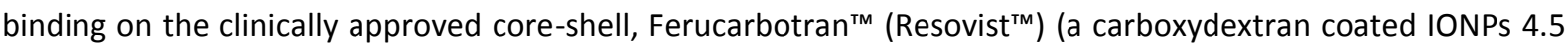
$\mathrm{nm}$ used for MRI applications). The authors injected the DOX-loaded NPs ([Fe] at $111.6 \mathrm{mg} \cdot \mathrm{kg}^{-1}$, and DOX at 4 $\mathrm{mg} \cdot \mathrm{kg}^{-1}$, intra-tumoral injection) in mice bearing a hepatocellular carcinoma (HCC) model and applied an AMF (155 Oe, $100 \mathrm{kHz}, 25$ minutes). The study over 14 days showed a therapeutic efficacy of the combined therapy 
measured by bioluminescence imaging (BLI). Histological analysis demonstrated that combination of the treatment AMF+NP/DOX allowed more apoptosis rate (39\%) compared with treatments using MNPs upon AMF (25\%) or Free DOX (23\%).

A

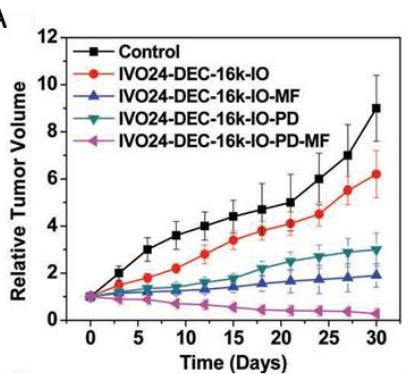

B

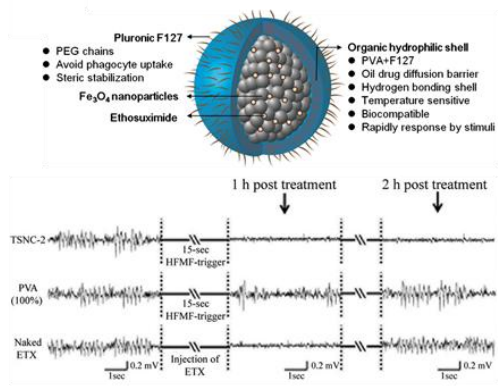

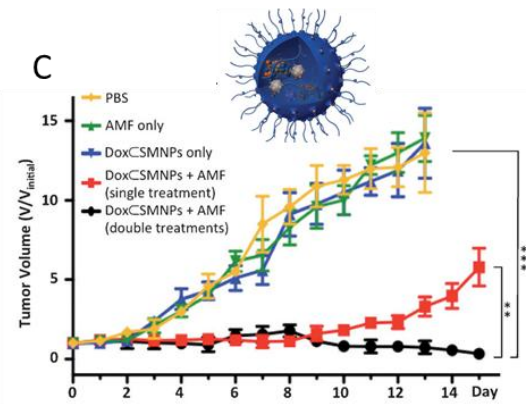

F

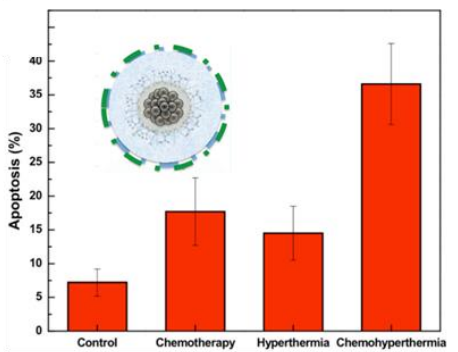

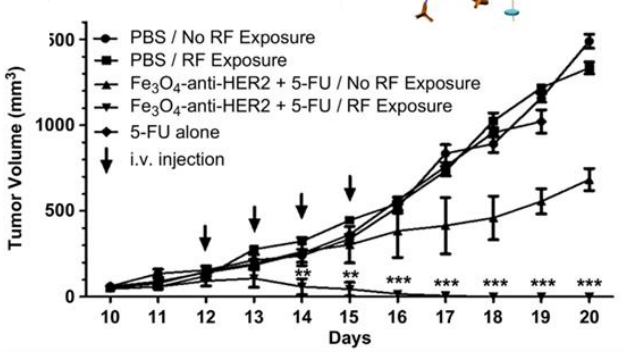

$\mathrm{E}$

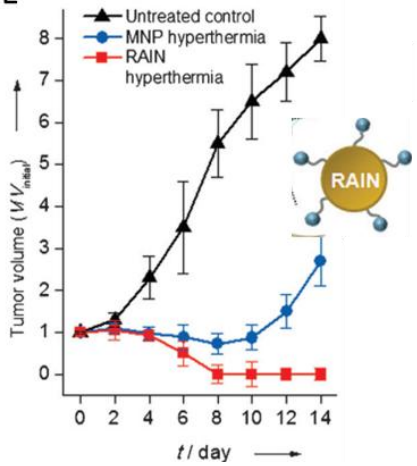

Figure 9. A. Evolution of the tumor volume in mice after AMF treatment with A. cell targeted, DOX and PTX loaded magnetic DEC capsules (IVO24-DEC-16k-IO-PD-MF). Reprinted from ref. [203] with permission of Wiley.

B. Electrophysiological diagrams recording the SPD of rats after AMF-induced delivery of ETX. Reproduced from ref. [206] with permission of The Royal Society of Chemistry. C-E. Evolution of the tumor volume after AMF treatment with: (C) supramolecular assembled magnetic-polymer NPs. Reprinted from ref. [225] with permission of Wiley; (D) core-shell IO bound with 5-FU drugs. Reprinted from ref. [186], Copyright 2013, with permission from Elsevier; (E) core-shell releasing geldanamycin HSP inhibitor. Reprinted from ref. [185] with permission of Wiley; (F) Evolution of apoptosis cell rate in tumor injected with MMSNs-HPC loaded with geldanmycine. All these studies were compared with control treatments: without AMF and/or NPs without GEM drug and/or with free GEM. Reprinted from ref.[227] with permission of Wiley.

Recently, in 2014, magnetic nanoclusters emerged as interesting magnetic nanoplatforms for in vivo AMF-induced chemothermotherapy. More precisely, Kim et al.,[227] designed MMSNs made of USPIO (7 nm) nanoclusters capped with MS shells used for the loading of the chemotherapeutic gemcitabine. The MMSNs were further coated with thermoresponsive hydroxypropyl cellulose (HPC) polymer of LCST $=45^{\circ} \mathrm{C}$ acting as a gatekeeper for the thermally controlled diffusion of the embedded drugs. The MMSNS were injected $\left(5 \mathrm{mg} \cdot \mathrm{mL}^{-}\right.$ ${ }^{1} 100 \mu \mathrm{L}$, intra-tumoral injection) in PANC-1 cells xenografts pancreas tumor models in nude mice. AMF (199 $\mathrm{kHz}, \mathrm{B}=17.5 \mathrm{mT}, 30 \mathrm{~min}$ ) was applied to the mice and the apoptosis rate of the tumor cells were measured 2 hours later after AMF treatment. The results showed that GEM-loaded MMSNS were more effective (38\% cell 
Summary table AMF induced drug release In vivo

\begin{tabular}{|c|c|c|c|c|c|c|c|}
\hline $\begin{array}{l}\text { YEAR } \\
\text { REF. }\end{array}$ & $\begin{array}{l}\text { Magnetic } \\
\text { NANO- } \\
\text { PLATFORM }\end{array}$ & $\begin{array}{l}\text { Therapeutics } \\
\text { Biological } \\
\text { activity }\end{array}$ & $\begin{array}{l}\text { Dose } \mathrm{mg} \cdot \mathrm{kg}^{-1} \\
\text { Administration } \\
\text { route }\end{array}$ & $\begin{array}{l}\text { Parameters of } \\
\text { the MAGNETIC } \\
\text { FIELD }\end{array}$ & Tumor model & Time & $\begin{array}{l}\text { Potency } \\
\text { Results }\end{array}$ \\
\hline $\begin{array}{l}2014 \\
{[226]}\end{array}$ & $\begin{array}{l}\text { CORE-SHELL } \\
\text { Ferucarbotran } \\
\text { (Resovist) }\end{array}$ & $\begin{array}{l}\text { DOX } \\
\text { Chemotherapy }\end{array}$ & $\begin{array}{l}\mathrm{Fe} \\
111.6 \mathrm{mg} \cdot \mathrm{kg}^{-1} \\
\text { DOX } \\
4 \mathrm{mg} \cdot \mathrm{kg}^{-1} \\
\text { i.t. }\end{array}$ & $\begin{array}{l}f=100 \mathrm{kHz} \\
B=15.5 \mathrm{mT} \\
H=12.4 \mathrm{kA} \cdot \mathrm{m}^{-1} \\
25 \mathrm{~min}\end{array}$ & $\begin{array}{l}\text { HCC model in } \\
\text { mice expressing } \\
\text { luciferase }\end{array}$ & $\begin{array}{l}14 \\
\text { days }\end{array}$ & $\begin{array}{l}\text { Suppression of BLI } \\
\text { signal Tumor apoptosis } \\
\text { rate } \\
\text { MNP/DOX }=39 \% \\
\text { MNP }=25 \% \\
\text { DOX free }=23 \%\end{array}$ \\
\hline $\begin{array}{l}2014 \\
{[227]}\end{array}$ & $\begin{array}{l}\text { NC@MS@HPC } \\
\text { USPIO (7 nm) } \\
\text { nanoclusters }\end{array}$ & $\begin{array}{l}\text { Gemcitabine } \\
\text { Chemotherapy } \\
\text { DLE 66\% } \\
\text { DLC } 20 \% \text { wt }\end{array}$ & $\begin{array}{l}5 \mathrm{mg} \cdot \mathrm{mL}^{-1} \\
100 \mu \mathrm{L} \\
\text { i.t. }\end{array}$ & $\begin{array}{l}\mathrm{f}=199 \mathrm{kHz} \\
\mathrm{B}=17.5 \mathrm{mT} \\
\mathrm{H}=14 \mathrm{kA} \cdot \mathrm{m}^{-1} \\
30 \mathrm{~min} \\
\text { At } \mathrm{t}=2 \mathrm{~h} \text { inj. }\end{array}$ & $\begin{array}{l}\text { Pancreas } \\
\text { xenografts } \\
\text { tumor models } \\
\text { in nude mice }\end{array}$ & $2 \mathrm{~h}$ & $\begin{array}{l}\text { Tumor apoptosis } \\
\text { GEM+MHT } 38 \% \\
\text { GEM } 17.5 \% \\
\text { MHT } 14.7 \%\end{array}$ \\
\hline $\begin{array}{l}2014 \\
{[228]}\end{array}$ & $\begin{array}{l}\text { NC@Polymer } \\
\text { Fe304@Ppyr- } \\
\text { PEG-FA } \\
70 \mathrm{~nm}\end{array}$ & $\begin{array}{l}\text { DOX } \\
\text { Chemotherapy }\end{array}$ & $\begin{array}{l}\text { NPs } 5 \mathrm{mg} \cdot \mathrm{kg}^{-1} \\
\text { DOX } \\
0.13 \mathrm{mg} \cdot \mathrm{kg}^{-1} \\
\text { i.t. }\end{array}$ & $\begin{array}{l}\mathrm{f}=230 \mathrm{kHz} \\
\mathrm{B}=10 \mathrm{mT} \\
\mathrm{H}=8 \mathrm{kA} \cdot \mathrm{m}^{-1} \\
20 \mathrm{~min}\end{array}$ & $\begin{array}{l}\text { Subcutaneous } \\
\text { Xenograft } \\
\text { myeloma cell } \\
\text { line in mice }\end{array}$ & $\begin{array}{l}45 \\
\text { days }\end{array}$ & $\begin{array}{l}\text { Tumor suppression } \\
\text { after } 12 \text { days } \\
\text { Survival } 200 \text { days vs } \\
\text { controls no MHT, or no } \\
\text { DOX (100 days) }\end{array}$ \\
\hline $\begin{array}{l}2013 \\
{[185]}\end{array}$ & $\begin{array}{l}\text { CORE-SHELL } \\
\text { Zn0.4Fe2.6O } \\
15 \mathrm{~nm} \text { core }\end{array}$ & $\begin{array}{l}\text { Geldanamycin } \\
\text { (HSP inhibition) }\end{array}$ & $\begin{array}{l}50 \mu \mathrm{g} \\
\text { i.t. }(100 \mathrm{~mm} 3)\end{array}$ & $\begin{array}{l}\mathrm{f}=500 \mathrm{kHz} \\
\mathrm{B}=46.8 \mathrm{mT} \\
\mathrm{H}=37.4 \mathrm{kA} \cdot \mathrm{m}^{-1} \\
30 \mathrm{~min}\end{array}$ & $\begin{array}{l}\text { xenograft } \\
\text { breast cancer } \\
\text { MDA-MB-231 in } \\
\text { mice }\end{array}$ & $\begin{array}{l}14 \\
\text { days }\end{array}$ & $\begin{array}{l}\text { In vivo tumor } \\
\text { suppression } \\
\text { at day } 8\end{array}$ \\
\hline \multirow[t]{2}{*}{$\begin{array}{l}2013 \\
{[186]}\end{array}$} & \multirow{2}{*}{$\begin{array}{l}\text { CORE-SHELL } \\
\text { PSMA coated } \\
\text { Fe304 core } \\
\text { grafted with } \\
\text { polyA15 a } \\
\text { polynucleotide } \\
22 \text { nm Fe304 } \\
\text { core }\end{array}$} & \multirow[t]{2}{*}{$\begin{array}{l}\text { 5-FU bound } \\
\text { chemotherapy } \\
\text { anti-HER2 } \\
\text { antibody }\end{array}$} & $\begin{array}{l}1-50 \mu \mathrm{g} / \text { tumor } \\
(>\text { or }<50 \mathrm{~mm} 3) \\
\text { i.t. }\left({ }^{*} 3\right)\end{array}$ & $\begin{array}{l}\mathrm{f}=1.3 \mathrm{MHZ} \\
\mathrm{B}=41.3 \mathrm{mT} \\
\mathrm{H}=33 \mathrm{kA} \cdot \mathrm{m}^{-1} \\
15 \mathrm{~min} \text { at day } 1 \\
\text { for i.t. }\end{array}$ & $\begin{array}{l}\text { Mouse } \\
\text { bladder-cancer } \\
\text { cell line (MBT- } \\
\text { 2) }\end{array}$ & $\begin{array}{l}2 \\
\text { days }\end{array}$ & $\begin{array}{l}\text { For large tumors, } \\
\text { AMF+FU-NPS give } \\
\text { better results / AMF } \\
\text { NPs alone }\end{array}$ \\
\hline & & & $\begin{array}{l}\text { 2-tail-vein i.v. } \\
(100 \mu \mathrm{g} \text { NPs } \\
1 \times 4 \text { days })\end{array}$ & $\begin{array}{l}\text { idem } \\
15 \mathrm{~min} \\
24 \mathrm{~h} \text { after each } \\
\text { i.v. }\end{array}$ & idem & $\begin{array}{l}20 \\
\text { days }\end{array}$ & $\begin{array}{l}\text { Tumor suppression } \\
\text { at day } 16\end{array}$ \\
\hline $\begin{array}{l}2013 \\
{[225]}\end{array}$ & $\begin{array}{l}\text { NANOGEL } \\
\text { Supramolecular } \\
\text { magnetic } \\
\text { nanogel } \\
70-160 \mathrm{~nm}\end{array}$ & $\begin{array}{l}\text { DOX } \\
\text { Chemotherapy } \\
\text { H-bonds and pi } \\
\text { pi stacking }\end{array}$ & $\begin{array}{l}150 \mu \mathrm{g} \cdot \mathrm{kg}^{-1} \mathrm{NPs} \\
2.8 \mu \mathrm{g} \cdot \mathrm{kg}^{-1} \mathrm{DOX} \\
\text { i.v. injection }\end{array}$ & $\begin{array}{l}\mathrm{f}=500 \mathrm{kHz} \\
\mathrm{B}=46.3 \mathrm{mT} \\
\mathrm{H}=37 \mathrm{kA} \cdot \mathrm{m}^{-1} \\
10 \mathrm{~min} \\
\text { at } 36 \mathrm{~h} \text { inj. }\end{array}$ & $\begin{array}{l}\text { Colon DLD1 } \\
\text { cancer } \\
\text { xenografts } \\
\text { model on mices }\end{array}$ & $\begin{array}{l}15 \\
\text { days }\end{array}$ & $\begin{array}{l}\text { Tumor suppression over } \\
15 \text { days } \\
\text { With double injection }\end{array}$ \\
\hline $\begin{array}{l}2012 \\
{[206]}\end{array}$ & $\begin{array}{l}\text { NANOGEL } \\
\text { Magnetic PVA- } \\
\text { F127 }\end{array}$ & $\begin{array}{l}\text { ETX (Ca2+ } \\
\text { channel } \\
\text { blocker) } \\
\text { anti-epileptic }\end{array}$ & $\begin{array}{l}12 \mathrm{mg}_{\mathrm{Fe}} \cdot \mathrm{kg}^{-1} \\
\text { i.v. }\end{array}$ & $\begin{array}{l}\mathrm{f}=44.2 \mathrm{kHz} \\
\mathrm{B}=3.1 \mathrm{mT} \\
\mathrm{H}=2.5 \mathrm{kA} \cdot \mathrm{m}^{-1} \\
15 \mathrm{~s}\end{array}$ & $\begin{array}{l}\text { Long Evans rat } \\
\text { models }\end{array}$ & $2 \mathrm{~h}$ & $\begin{array}{l}\text { Decrease of the the } \\
\text { spike-wave discharge, } \\
\text { after the burst release } \\
\text { of ETX from the TSNCs }\end{array}$ \\
\hline $\begin{array}{l}2012 \\
{[203]}\end{array}$ & $\begin{array}{l}\text { DEC capsules } \\
\text { PVA shell +IO } \\
\text { NPs } 5 \mathrm{~nm} \\
150 \mathrm{~nm} \text { DEC }\end{array}$ & $\begin{array}{l}\text { DOX/PTX } \\
\text { Dual } \\
\text { Chemotherapy } \\
\text { IVO24 peptide } \\
\text { targeting }\end{array}$ & $\begin{array}{l}100 \mu \text { saline } \\
\text { solution at } 2 \text { wt } \\
\% \text { DEC } \\
\text { i.t. }\end{array}$ & $\begin{array}{l}f=50 \mathrm{kHz} \\
B=10 \mathrm{mT} \\
\mathrm{H}=8 \mathrm{kA} \cdot \mathrm{m}^{-1} \\
10 \mathrm{~min} \\
\text { at } \mathrm{t}=24 \mathrm{~h} \text { post } \\
\text { inj. }\end{array}$ & $\begin{array}{l}\text { MCF-7 breast } \\
\text { carcinoma } \\
\text { tumor model }\end{array}$ & $\begin{array}{l}30 \\
\text { days }\end{array}$ & $\begin{array}{l}\text { In vivo = tumor model } \\
\text { suppression when } \\
\text { PTX+DOX+AMF+IVO24 }\end{array}$ \\
\hline $\begin{array}{l}2012 \\
{[143]}\end{array}$ & $\begin{array}{l}\mathrm{ML}+\text { magnetic } \\
\mathrm{NP} \text { chains }\end{array}$ & $\begin{array}{l}\text { DOX } \\
\text { chemotherapy }\end{array}$ & $\begin{array}{l}0.5 \mathrm{mg} \cdot \mathrm{kg}^{-1} \mathrm{DOX} \\
\text { iv Injection at } \\
\text { day } 5 \text { and day } 7\end{array}$ & $\begin{array}{l}f=10 \mathrm{kHz} \\
P=3-5 \mathrm{~W} \\
60 \mathrm{~min} \\
\text { At } t=24 \mathrm{~h} \text { inj. }\end{array}$ & $\begin{array}{l}\text { MAT B III breast } \\
\text { tumor model, in } \\
\text { rat }\end{array}$ & $\begin{array}{l}17 \\
\text { days }\end{array}$ & $\begin{array}{l}\text { Full tumor growth } \\
\text { inhibition after two } \\
\text { AMF treatments }\end{array}$ \\
\hline $\begin{array}{l}2011 \\
{[224]}\end{array}$ & $\begin{array}{l}\text { TMLs } \\
\text { Mn0.5Zn0.5 } \\
\text { Fe204 }\end{array}$ & $\begin{array}{l}\text { AS203 } \\
\text { chemotherapy }\end{array}$ & $\begin{array}{l}\mathrm{n} / \mathrm{a} \\
\text { Injection in } \\
\text { tumor feeding } \\
\text { artey }\end{array}$ & $\begin{array}{l}\mathrm{f}=230 \mathrm{kHz} \\
\mathrm{l}=30 \mathrm{~A} \\
30 \mathrm{~min} \\
\text { At days : } 3,6,9\end{array}$ & $\begin{array}{l}\text { human } \\
\text { hepatoma cells, } \\
\text { VX2 in rabbit } \\
\text { liver lobe }\end{array}$ & $\begin{array}{l}14 \\
\text { days }\end{array}$ & $\begin{array}{l}\text { Tumor inhibition } \\
85 \% \text { combined effect } \\
53 \% \text { MHT alone } \\
45 \% \text { TSL AS203 alone }\end{array}$ \\
\hline $\begin{array}{l}2010 \\
{[223]}\end{array}$ & $\begin{array}{l}\text { TMLs } \\
\text { loaded with } \\
\text { magnetite } 9 \mathrm{~nm}\end{array}$ & $\begin{array}{l}\text { Docetaxel } \\
\text { chemotherapy }\end{array}$ & $\begin{array}{l}100 \mu \mathrm{L} \text { of DML } \\
187 \mathrm{mg} \cdot \mathrm{ml}^{-1} \\
\text { (magnetite) } \\
{[56.8-568.5 \text { ) }} \\
\mu \mathrm{g} \cdot \mathrm{mL}^{-1} \\
\text { (Docetaxel) }\end{array}$ & $\begin{array}{l}\mathrm{f}=478 \mathrm{kHz} \\
\mathrm{B}=8 \mathrm{mT} \\
\mathrm{H}=6.4 \mathrm{kA} \cdot \mathrm{m}^{-1} \\
\mathrm{P}=1 \mathrm{~kW} \\
35 \mathrm{~min} .\end{array}$ & $\begin{array}{l}\text { Xenogratf } \\
\text { MKN45 gastric } \\
\text { cancer cells in } \\
\text { mice }\end{array}$ & $\begin{array}{l}28 \\
\text { days }\end{array}$ & $\begin{array}{l}\text { Tumor suppression at } \\
\text { day } 10\end{array}$ \\
\hline
\end{tabular}


apoptotic rate) compared with free GEM treatment alone (17.5\%) and $\mathrm{MH}$ alone (14.7\%). (Fig 9.F). In an another work by Hayashi et al. [228], magnetite clusters formed in situ in a polymer matrix by iron salt reduction, were covered with poly(pyrrole) polymer having $T_{g}$ of $c a .44^{\circ} \mathrm{C}$, and loaded with DOX via $\pi-\pi$ stacking interactions. The NPs were further covered by PEG and folic acid for cancer cell targeting. The magnetic polymer coated NCs were injected (NPs $5 \mathrm{mg} \cdot \mathrm{kg}^{-1}$, DOX $0.13 \mathrm{mg} \cdot \mathrm{kg}^{-1}$, intratumoral injection) in subcutaneous xenograft myeloma cell line in mice.

An AMF (230 kHz, $\left.8 \mathrm{kA} \cdot \mathrm{m}^{-1}, 20 \mathrm{~min}\right)$ was submitted to the mice and a 45 days study showed that the combination of $\mathrm{MH}$ and chemotherapy ensured full tumor suppression after 12 days whereas MH (NPs without DOX) or free DOX injection exhibited only tumor inhibition but not curing. Furthermore, the survival study demonstrated a 200 days (at least) survival time with the combined treatment compared with the $\mathrm{MH}$ treatment alone or free DOX (100 days survival).

Also of high interest regarding the use of photosensitizing agents, in 2015, Di Corato et al. [135] showed synergetic effects of magnetically-induce release and photodynamic therapy (PDT) with TMLs embedding a photosensitizer (M-THPC sold under brand name Foscan) in their membrane and encapsulating ultra-high concentration of citrated hydrophilic IONPs in their aqueous compartment: prepared by the RPE method, such ultra-magnetic liposomes (UML) can reach a SAR as high as $438 \mathrm{~W} \cdot \mathrm{g}^{-1}$ at $\mathrm{f}=700 \mathrm{kHz}$ and $\mathrm{B}=33.8$ $\mathrm{mT} / \mathrm{H}=27 \mathrm{kA} \cdot \mathrm{m}^{-1}$ ) as described previously. [134] Contrary to pure PDT (10 s laser irradiation corresponding to $10 \mathrm{~J} \cdot \mathrm{cm}^{-2}$ ) or pure AMF application (30 min at $\mathrm{f}=111 \mathrm{kHz}$ and $\mathrm{B}=30 \mathrm{mT} / \mathrm{H}=24 \mathrm{kA} \cdot \mathrm{m}^{-1}$ ), their combined application every day led to complete regression after 4 days of subcutaneous carcinoma A431 tumors in mice.

\section{Conclusions and Perspectives}

This review evidences that a lot of research efforts are currently devoted to the optimization of nanoplatforms that allow delivering an anticancer or inflammatory drug locally upon external AMF stimulation. The published in vitro and in vivo experiments demonstrated the high potential of such nanoplatforms to deliver locally drugs and to affect the cell vialibility (in vitro) or inhibit tumor growth (in vivo). The studies further evidence that the drug release in most of cases is not solely responsible from the observed cytotoxic effects but also that the AMF treatment inducing temperature increase, at least locally, contributes to the therapeutic treatment. Such strategy is favored also by a lot of works aiming at improving the design of the magnetic NPs in order to obtain efficient heating agents at lower injected dose and efficient polymer based systems able to load high drug amounts and to release the drug only locally and in a continuous or sustainable way, without uncontrollable instantaneous/burst release.

One may observe two main strategies: i) encapsulation of drug in polymeric or inorganic matrixes with drug either loaded in the systems by weak interactions within the matrix or ii) drug strongly bonded to the systems by labile groups. The weak interactions or bonds are then externally controlled by AMF application. A great attention in all these systems is paid to the release mechanism and also to the efficiency when applying either a pulsed or a continuous AMF. The studies described in this review showed that such strategy is very promising and that the systems are mature for preclinical in vivo studies in research laboratories, which are prerequisite to envision clinical studies by pharmaceutical companies. 
However to date, there are different challenges to overcome until such an approach is able to reach the clinics. First and probably most important aspect to mention is the safety issue. Such nanoplatforms (made of inorganic nanoparticles, polymers, surfactants etc...) must be designed to have a high circulation time in the blood, avoid recognition by the macrophages and be efficiently bio-eliminated or metabolized after use. Moreover, besides the usual cell toxicity in vitro, there are various types of other toxicity in vitro and in vivo that should be more deeply investigated in the future such as: genotoxicity, hematolytic effects, and immunogenicity, with the aim to prevent potential risks of undesirable side effects. Other toxicity effects such as generation of radical oxygen species (ROS) or toxicity coming from the degraded nanoplatforms in the body would be also of high interest to investigate. The development of fully degradable nanoplatforms made of bioerodible components which can be metabolized or easily bio-eliminated by the body seems to be a relevant research topic to investigate. Another key aspect regarding safety issues is controlling the thermal dose as the local and uncontrolled overheating may induce tissue necrosis. Recent researches for instance were devoted to develop self-regulated nanoheaters which display a change in their magnetic phase when a critical temperature is reached which stops and hence regulates the heat transfer.

Another challenge to mention is the scaling-up in view of the industrialization of the nanoplatform fabrication process also respecting "good medical practice" (GMP) conditions in order to be authorized by the regulation agencies as medicines or at least as medical devices on the pharmaceutical market. Large scale and cost-effective procedures are to be well-thought from the genesis of the research work to envision technology transfer. Simplified procedures with a limited number of steps associated with the use of cost-affordable materials would be thus largely preferable compared to sophisticated procedures involving multistep synthesis of costly products. For instance, since this last decade, there have been important developments towards "onepot strategies" (polymerization induced self-assembly, in situ sol-gel/polymerization, etc...) allowing the design of polymer thin films or self-assembled nanoplatforms according to robust and cost-effective procedures.

At last, with the aim to improve the efficacy of the treatment, especially for anticancer therapies, it is now well-reported that combining a cocktail of various medicines may achieve a synergistic effect that helps to eradicate more efficiently tumor tissues and/or metastasis, and/or to fight against tumor cell resistance. Novel approaches consisting in the design of multi-modal systems ensuring a multimodal therapy that can be followed by clinical (multi-modal) bio-imaging would be of high interest. For instance, these last years, there have been some developments towards the design of innovative nano-systems made of carbon-based materials or gold NPs and iron oxide NPs which allow to envision the in vivo combination of various modalities : magnetic manipulation, radiation therapies $(\mathrm{MH}$, focused ultrasound, photo-thermal or photodynamic therapy...), imaging (MRI, ultra-sonography, X-ray, PET, SPECT...) and additionally drug release. In such strategies too, challenges mentioned in the above paragraph regarding potential toxicity and bio-elimination issues would as well to be overcome.

Acknowledgements. The authors thank COST Action RADIOMAG (TD1402), supported by COST (European Cooperation in Science and Technology). D. M. thanks the University of Strasbourg for financial support from 
IDEX-Attractivité framework. O.S. thanks the Agence Nationale de la Recherche (grant ANR-13-BS08-0017 MagnetoChemoBlast).

\section{References}

[1] B. Sumer, J. Gao, Theranostic nanomedicine for cancer, (2008). http://www.futuremedicine.com/doi/abs/10.2217/17435889.3.2.137 (accessed October 25, 2016).

[2] T. Lammers, S. Aime, W.E. Hennink, G. Storm, F. Kiessling, Theranostic nanomedicine, Acc. Chem. Res. 44 (2011) 1029-1038.

[3] K. Cho, X.U. Wang, S. Nie, D.M. Shin, others, Therapeutic nanoparticles for drug delivery in cancer, Clin. Cancer Res. 14 (2008) 1310-1316.

[4] K.A. Whitehead, R. Langer, D.G. Anderson, Knocking down barriers: advances in siRNA delivery, Nat. Rev. Drug Discov. 8 (2009) 129-138. doi:10.1038/nrd2742.

[5] S.S. Lucky, K.C. Soo, Y. Zhang, Nanoparticles in photodynamic therapy, Chem. Rev. 115 (2015) 1990-2042.

[6] X. Huang, P.K. Jain, I.H. El-Sayed, M.A. El-Sayed, Plasmonic photothermal therapy (PPTT) using gold nanoparticles, Lasers Med. Sci. 23 (2008) 217-228.

[7] A. Jordan, R. Scholz, P. Wust, H. Fähling, R. Felix, Magnetic fluid hyperthermia (MFH): Cancer treatment with AC magnetic field induced excitation of biocompatible superparamagnetic nanoparticles, J. Magn. Magn. Mater. 201 (1999) 413-419.

[8] H. Meng, M. Liong, T. Xia, Z. Li, Z. Ji, J.I. Zink, A.E. Nel, Engineered design of mesoporous silica nanoparticles to deliver doxorubicin and P-glycoprotein siRNA to overcome drug resistance in a cancer cell line, ACS Nano. 4 (2010) 4539-4550.

[9] C. Zhu, S. Jung, S. Luo, F. Meng, X. Zhu, T.G. Park, Z. Zhong, Co-delivery of siRNA and paclitaxel into cancer cells by biodegradable cationic micelles based on PDMAEMA-PCL-PDMAEMA triblock copolymers, Biomaterials. 31 (2010) 2408-2416.

[10] S. Mitragotri, J. Lahann, Physical approaches to biomaterial design, Nat. Mater. 8 (2009) 15-23. doi:10.1038/nmat2344.

[11] Y. Yan, G.K. Such, A.P.R. Johnston, J.P. Best, F. Caruso, Engineering Particles for Therapeutic Delivery: Prospects and Challenges, ACS Nano. 6 (2012) 3663-3669. doi:10.1021/nn3016162.

[12] R.A. Petros, J.M. DeSimone, Strategies in the design of nanoparticles for therapeutic applications, Nat. Rev. Drug Discov. 9 (2010) 615-627.

[13] K. Ulbrich, K. Holá, V. Šubr, A. Bakandritsos, J. Tuček, R. Zbořil, Targeted Drug Delivery with Polymers and Magnetic Nanoparticles: Covalent and Noncovalent Approaches, Release Control, and Clinical Studies, Chem. Rev. 116 (2016) 5338-5431.

[14] S. Mura, J. Nicolas, P. Couvreur, Stimuli-responsive nanocarriers for drug delivery, Nat. Mater. 12 (2013) 991-1003. doi:10.1038/nmat3776.

[15] M.A.C. Stuart, W.T. Huck, J. Genzer, M. Müller, C. Ober, M. Stamm, G.B. Sukhorukov, I. Szleifer, V.V. Tsukruk, M. Urban, others, Emerging applications of stimuli-responsive polymer materials, Nat. Mater. 9 (2010) 101-113.

[16] S. Ganta, H. Devalapally, A. Shahiwala, M. Amiji, A review of stimuli-responsive nanocarriers for drug and gene delivery, J. Controlled Release. 126 (2008) 187-204. doi:10.1016/j.jconrel.2007.12.017.

[17] Y. Zhang, J. Yu, H.N. Bomba, Y. Zhu, Z. Gu, Mechanical Force-Triggered Drug Delivery, Chem. Rev. (2016). http://pubs.acs.org/doi/abs/10.1021/acs.chemrev.6b00369 (accessed October 11, 2016).

[18] J. Barthes, D. Mertz, C. Bach, M.-H. Metz-Boutigue, B. Senger, J.-C. Voegel, P. Schaaf, P. Lavalle, Stretch-induced biodegradation of polyelectrolyte multilayer films for drug release, Langmuir. 28 (2012) 13550-13554. 
[19] C. Vogt, D. Mertz, K. Benmlih, J. Hemmerle, J.-C. Voegel, P. Schaaf, P. Lavalle, Layer-by-layer enzymatic platform for stretched-induced reactive release, ACS Macro Lett. 1 (2012) 797-801.

[20] R. Hergt, S. Dutz, M. Zeisberger, Validity limits of the Néel relaxation model of magnetic nanoparticles for hyperthermia, Nanotechnology. 21 (2009) 15706.

[21] I.M. Obaidat, B. Issa, Y. Haik, Magnetic properties of magnetic nanoparticles for efficient hyperthermia, Nanomaterials. 5 (2015) 63-89.

[22] S. Dutz, R. Hergt, Magnetic nanoparticle heating and heat transfer on a microscale: basic principles, realities and physical limitations of hyperthermia for tumour therapy, Int. J. Hyperthermia. 29 (2013) 790-800.

[23] S. Laurent, S. Dutz, U.O. Häfeli, M. Mahmoudi, Magnetic fluid hyperthermia: focus on superparamagnetic iron oxide nanoparticles, Adv. Colloid Interface Sci. 166 (2011) 8-23.

[24] B. Kozissnik, A.C. Bohorquez, J. Dobson, C. Rinaldi, Magnetic fluid hyperthermia: Advances, challenges, and opportunity, Int. J. Hyperthermia. 29 (2013) 706-714.

[25] B.P. Timko, T. Dvir, D.S. Kohane, Remotely triggerable drug delivery systems, Adv. Mater. 22 (2010) 4925-4943.

[26] C.S. Brazel, Magnetothermally-responsive nanomaterials: combining magnetic nanostructures and thermally-sensitive polymers for triggered drug release, Pharm. Res. 26 (2009) 644-656.

[27] J. Thévenot, H. Oliveira, O. Sandre, S. Lecommandoux, Magnetic responsive polymer composite materials, Chem. Soc. Rev. 42 (2013) 7099-7116.

[28] J. Liu, C. Detrembleur, S. Mornet, C. Jérôme, E. Duguet, Design of hybrid nanovehicles for remotely triggered drug release: an overview, J. Mater. Chem. B. 3 (2015) 6117-6147. doi:10.1039/C5TB00664C.

[29] A. Hervault, N.T.K. Thanh, Magnetic nanoparticle-based therapeutic agents for thermochemotherapy treatment of cancer, Nanoscale. 6 (2014) 11553-11573.

[30] C.S. Kumar, F. Mohammad, Magnetic nanomaterials for hyperthermia-based therapy and controlled drug delivery, Adv. Drug Deliv. Rev. 63 (2011) 789-808.

[31] E.A. Périgo, G. Hemery, O. Sandre, D. Ortega, E. Garaio, F. Plazaola, F.J. Teran, Fundamentals and advances in magnetic hyperthermia, Appl. Phys. Rev. 2 (2015) 41302.

[32] N. Lee, D. Yoo, D. Ling, M.H. Cho, T. Hyeon, J. Cheon, Iron oxide based nanoparticles for multimodal imaging and magnetoresponsive therapy, Chem. Rev. 115 (2015) 10637-10689.

[33] M. Bikram, J.L. West, Thermo-responsive systems for controlled drug delivery, Expert Opin. Drug Deliv. 5 (2008) 1077-1091.

[34] M.A. Ward, T.K. Georgiou, Thermoresponsive polymers for biomedical applications, Polymers. 3 (2011) 1215-1242.

[35] A. Trabolsi, T. Skorjanc, F. Benyettou, J.-C. Olsen, Design of organic macrocycle-modified ironoxide nanoparticles for drug delivery, Chem. - Eur. J. (2017) n/a-n/a. doi:10.1002/chem.201605246.

[36] H.B. Na, I.C. Song, T. Hyeon, Inorganic Nanoparticles for MRI Contrast Agents, Adv. Mater. 21 (2009) 2133-2148. doi:10.1002/adma.200802366.

[37] S. Laurent, D. Forge, M. Port, A. Roch, C. Robic, L. Vander Elst, R.N. Muller, Magnetic iron oxide nanoparticles: synthesis, stabilization, vectorization, physicochemical characterizations, and biological applications, Chem. Rev. 108 (2008) 2064-2110.

[38] K. Maier-Hauff, R. Rothe, R. Scholz, U. Gneveckow, P. Wust, B. Thiesen, A. Feussner, A. von Deimling, N. Waldoefner, R. Felix, others, Intracranial thermotherapy using magnetic nanoparticles combined with external beam radiotherapy: results of a feasibility study on patients with glioblastoma multiforme, J. Neurooncol. 81 (2007) 53-60.

[39] K. Maier-Hauff, F. Ulrich, D. Nestler, H. Niehoff, P. Wust, B. Thiesen, H. Orawa, V. Budach, A. Jordan, Efficacy and safety of intratumoral thermotherapy using magnetic iron-oxide nanoparticles combined with external beam radiotherapy on patients with recurrent glioblastoma multiforme, J. Neurooncol. 103 (2011) 317-324.

[40] MagForce AG - Home, (n.d.). http://www.magforce.de/en/home.html (accessed October 25, 2016). 
[41] B. Thiesen, A. Jordan, Clinical applications of magnetic nanoparticles for hyperthermia, Int. J. Hyperthermia. 24 (2008) 467-474.

[42] G.F. Goya, L. Asín, M.R. Ibarra, Cell death induced by AC magnetic fields and magnetic nanoparticles: Current state and perspectives, Int. J. Hyperthermia. 29 (2013) 810-818.

[43] A.E. Deatsch, B.A. Evans, Heating efficiency in magnetic nanoparticle hyperthermia, J. Magn. Magn. Mater. 354 (2014) 163-172.

[44] J. Kolosnjaj-Tabi, R. Di Corato, L. Lartigue, I. Marangon, P. Guardia, A.K. Silva, N. Luciani, O. Clément, P. Flaud, J.V. Singh, others, Heat-generating iron oxide nanocubes: subtle "destructurators" of the tumoral microenvironment, ACS Nano. 8 (2014) 4268-4283.

[45] J.-H. Lee, J. Jang, J. Choi, S.H. Moon, S. Noh, J. Kim, J.-G. Kim, I.-S. Kim, K.I. Park, J. Cheon, Exchange-coupled magnetic nanoparticles for efficient heat induction, Nat. Nanotechnol. 6 (2011) 418-422.

[46] R. Hergt, S. Dutz, R. Müller, M. Zeisberger, Magnetic particle hyperthermia: nanoparticle magnetism and materials development for cancer therapy, J. Phys. Condens. Matter. 18 (2006) S2919. doi:10.1088/0953-8984/18/38/S26.

[47] G. Glöckl, R. Hergt, M. Zeisberger, S. Dutz, S. Nagel, W. Weitschies, The effect of field parameters, nanoparticle properties and immobilization on the specific heating power in magnetic particle hyperthermia, J. Phys. Condens. Matter. 18 (2006) S2935. doi:10.1088/0953$8984 / 18 / 38 / S 27$.

[48] Simple models for dynamic hysteresis loop calculations of magnetic single-domain nanoparticles: Application to magnetic hyperthermia optimization, J. Appl. Phys. 109 (2011) 83921. doi:10.1063/1.3551582.

[49] F. Gazeau, M. Lévy, C. Wilhelm, Optimizing magnetic nanoparticle design for nanothermotherapy, (2008). http://www.futuremedicine.com/doi/abs/10.2217/17435889.3.6.831 (accessed October 25, 2016).

[50] C. Blanco-Andujar, A. Walter, G. Cotin, C. Bordeianu, D. Mertz, D. Felder-Flesch, S. Begin-Colin, Design of iron oxide-based nanoparticles for MRI and magnetic hyperthermia, Nanomed. 11 (2016) 1889-1910.

[51] R.E. Rosensweig, Heating magnetic fluid with alternating magnetic field, J. Magn. Magn. Mater. 252 (2002) 370-374. doi:10.1016/S0304-8853(02)00706-0.

[52] R. Hergt, S. Dutz, Magnetic particle hyperthermia-biophysical limitations of a visionary tumour therapy, J. Magn. Magn. Mater. 311 (2007) 187-192.

[53] P. Guardia, R. Di Corato, L. Lartigue, C. Wilhelm, A. Espinosa, M. Garcia-Hernandez, F. Gazeau, L. Manna, T. Pellegrino, Water-soluble iron oxide nanocubes with high values of specific absorption rate for cancer cell hyperthermia treatment, ACS Nano. 6 (2012) 3080-3091.

[54] T.J. Daou, G. Pourroy, S. Begin-Colin, J.M. Greneche, C. Ulhaq-Bouillet, P. Legaré, P. Bernhardt, C. Leuvrey, G. Rogez, Hydrothermal synthesis of monodisperse magnetite nanoparticles, Chem. Mater. 18 (2006) 4399-4404.

[55] J. Santoyo Salazar, L. Perez, O. de Abril, L. Truong Phuoc, D. Ihiawakrim, M. Vazquez, J.-M. Greneche, S. Begin-Colin, G. Pourroy, Magnetic iron oxide nanoparticles in 10- $40 \mathrm{~nm}$ range: Composition in terms of magnetite/maghemite ratio and effect on the magnetic properties, Chem. Mater. 23 (2011) 1379-1386.

[56] B. Basly, G. Popa, S. Fleutot, B.P. Pichon, A. Garofalo, C. Ghobril, C. Billotey, A. Berniard, P. Bonazza, H. Martinez, others, Effect of the nanoparticle synthesis method on dendronized iron oxides as MRI contrast agents, Dalton Trans. 42 (2013) 2146-2157.

[57] E. Alphandery, S. Faure, O. Seksek, F. Guyot, I. Chebbi, Chains of magnetosomes extracted from AMB-1 magnetotactic bacteria for application in alternative magnetic field cancer therapy, ACS Nano. 5 (2011) 6279-6296.

[58] R. Hergt, R. Hiergeist, M. Zeisberger, D. Schüler, U. Heyen, I. Hilger, W.A. Kaiser, Magnetic properties of bacterial magnetosomes as potential diagnostic and therapeutic tools, J. Magn. Magn. Mater. 293 (2005) 80-86. 
[59] W. Baaziz, B.P. Pichon, C. Lefevre, C. Ulhaq-Bouillet, J.-M. Greneche, M. Toumi, T. Mhiri, S. Bégin-Colin, High Exchange Bias in Fe3- $804 @$ CoO Core Shell Nanoparticles Synthesized by a One-Pot Seed-Mediated Growth Method, J. Phys. Chem. C. 117 (2013) 11436-11443.

[60] X. Liu, B.P. Pichon, C. Ulhaq, C. Lefèvre, J.-M. Grenèche, D. Bégin, S. Bégin-Colin, Systematic Study of Exchange Coupling in Core-Shell Fe3- $004 @$ CoO Nanoparticles, Chem. Mater. 27 (2015) 4073-4081.

[61] A. Sathya, P. Guardia, R. Brescia, N. Silvestri, G. Pugliese, S. Nitti, L. Manna, T. Pellegrino, Co x Fe3-x 04 Nanocubes for Theranostic Applications: Effect of Cobalt Content and Particle Size, Chem. Mater. 28 (2016) 1769-1780.

[62] C. Martinez-Boubeta, K. Simeonidis, A. Makridis, M. Angelakeris, O. Iglesias, P. Guardia, A. Cabot, L. Yedra, S. Estradé, F. Peiró, others, Learning from nature to improve the heat generation of iron-oxide nanoparticles for magnetic hyperthermia applications, Sci. Rep. 3 (2013). http://www.nature.com/srep/2013/130411/srep01652/full/srep01652.html?WT.ec_id=SREP692-20130501 (accessed October 27, 2016).

[63] P. Hugounenq, M. Levy, D. Alloyeau, L. Lartigue, E. Dubois, V. Cabuil, C. Ricolleau, S. Roux, C. Wilhelm, F. Gazeau, others, Iron oxide monocrystalline nanoflowers for highly efficient magnetic hyperthermia, J. Phys. Chem. C. 116 (2012) 15702-15712.

[64] L. Lartigue, P. Hugounenq, D. Alloyeau, S.P. Clarke, M. Lévy, J.-C. Bacri, R. Bazzi, D.F. Brougham, C. Wilhelm, F. Gazeau, Cooperative organization in iron oxide multi-core nanoparticles potentiates their efficiency as heating mediators and MRI contrast agents, ACS Nano. 6 (2012) 10935-10949.

[65] A. Kostopoulou, K. Brintakis, M. Vasilakaki, K.N. Trohidou, A.P. Douvalis, A. Lascialfari, L. Manna, A. Lappas, Assembly-mediated interplay of dipolar interactions and surface spin disorder in colloidal maghemite nanoclusters, Nanoscale. 6 (2014) 3764-3776.

[66] C.L. Dennis, A.J. Jackson, J.A. Borchers, P.J. Hoopes, R. Strawbridge, A.R. Foreman, J. Van Lierop, C. Grüttner, R. Ivkov, Nearly complete regression of tumors via collective behavior of magnetic nanoparticles in hyperthermia, Nanotechnology. 20 (2009) 395103.

[67] C.L. Dennis, A.J. Jackson, J.A. Borchers, R. Ivkov, A.R. Foreman, J.W. Lau, E. Goernitz, C. Gruettner, The influence of collective behavior on the magnetic and heating properties of iron oxide nanoparticles, J. Appl. Phys. 103 (2008) 07A319.

[68] B. Mehdaoui, R.P. Tan, A. Meffre, J. Carrey, S. Lachaize, B. Chaudret, M. Respaud, Increase of magnetic hyperthermia efficiency due to dipolar interactions in low-anisotropy magnetic nanoparticles: Theoretical and experimental results, Phys. Rev. B. 87 (2013) 174419.

[69] F. Burrows, C. Parker, R.F.L. Evans, Y. Hancock, O. Hovorka, R.W. Chantrell, Energy losses in interacting fine-particle magnetic composites, J. Phys. Appl. Phys. 43 (2010) 474010.

[70] P. De la Presa, Y. Luengo, M. Multigner, R. Costo, M.P. Morales, G. Rivero, A. Hernando, Study of heating efficiency as a function of concentration, size, and applied field in $\gamma$-Fe2O3 nanoparticles, J. Phys. Chem. C. 116 (2012) 25602-25610.

[71] D. Serantes, K. Simeonidis, M. Angelakeris, O. Chubykalo-Fesenko, M. Marciello, M.D.P. Morales, D. Baldomir, C. Martinez-Boubeta, Multiplying magnetic hyperthermia response by nanoparticle assembling, J. Phys. Chem. C. 118 (2014) 5927-5934.

[72] A. Walter, C. Billotey, A. Garofalo, C. Ulhaq-Bouillet, C. Lefèvre, J. Taleb, S. Laurent, L. Vander Elst, R.N. Muller, L. Lartigue, F. Gazeau, D. Felder-Flesch, S. Begin-Colin, Mastering the Shape and Composition of Dendronized Iron Oxide Nanoparticles To Tailor Magnetic Resonance Imaging and Hyperthermia, Chem. Mater. 26 (2014) 5252-5264. doi:10.1021/cm5019025.

[73] H.G. Schild, Poly(N-isopropylacrylamide): experiment, theory and application, Prog. Polym. Sci. 17 (1992) 163-249. doi:10.1016/0079-6700(92)90023-R.

[74] E.E. Makhaeva, L.T.M. Thanh, S.G. Starodoubtsev, A.R. Khokhlov, Thermoshrinking behavior of poly (vinylcaprolactam) gels in aqueous solution, Macromol. Chem. Phys. 197 (1996) 19731982. 
[75] B. Jeong, S.W. Kim, Y.H. Bae, Thermosensitive sol-gel reversible hydrogels, Adv. Drug Deliv. Rev. 54 (2002) 37-51.

[76] L. Klouda, A.G. Mikos, Thermoresponsive hydrogels in biomedical applications, Eur. J. Pharm. Biopharm. 68 (2008) 34-45.

[77] S.G. Hirsch, R.J. Spontak, Temperature-dependent property development in hydrogels derived from hydroxypropylcellulose, Polymer. 43 (2002) 123-129.

[78] A.K. Gaharwar, J.E. Wong, D. Müller-Schulte, D. Bahadur, W. Richtering, Magnetic nanoparticles encapsulated within a thermoresponsive polymer, J. Nanosci. Nanotechnol. 9 (2009) 53555361.

[79] J.A. Mackay, A. Chilkoti, Temperature sensitive peptides: Engineering hyperthermia-directed therapeutics, Int. J. Hyperthermia. 24 (2008) 483-495. doi:10.1080/02656730802149570.

[80] S.R. MacEwan, A. Chilkoti, Applications of elastin-like polypeptides in drug delivery, J. Controlled Release. 190 (2014) 314-330. doi:10.1016/j.jconrel.2014.06.028.

[81] A. Dabbagh, B.J.J. Abdullah, H. Abdullah, M. Hamdi, N.H.A. Kasim, Triggering Mechanisms of Thermosensitive Nanoparticles Under Hyperthermia Condition, J. Pharm. Sci. 104 (2015) 24142428.

[82] K. Matyjaszewski, J. Xia, Atom transfer radical polymerization, Chem. Rev. 101 (2001) 29212990.

[83] K. Matyjaszewski, Atom transfer radical polymerization (ATRP): current status and future perspectives, Macromolecules. 45 (2012) 4015-4039.

[84] N.E. Kamber, W. Jeong, R.M. Waymouth, R.C. Pratt, B.G. Lohmeijer, J.L. Hedrick, Organocatalytic ring-opening polymerization, Chem. Rev. 107 (2007) 5813-5840.

[85] A.-C. Albertsson, I.K. Varma, Recent developments in ring opening polymerization of lactones for biomedical applications, Biomacromolecules. 4 (2003) 1466-1486.

[86] R.T. Mayadunne, J. Jeffery, G. Moad, E. Rizzardo, Living free radical polymerization with reversible addition-fragmentation chain transfer (RAFT polymerization): approaches to star polymers, Macromolecules. 36 (2003) 1505-1513.

[87] C.L. McCormick, A.B. Lowe, Aqueous RAFT polymerization: recent developments in synthesis of functional water-soluble (co) polymers with controlled structures, Acc. Chem. Res. 37 (2004) 312-325.

[88] S. Louguet, B. Rousseau, R. Epherre, N. Guidolin, G. Goglio, S. Mornet, E. Duguet, S. Lecommandoux, C. Schatz, Thermoresponsive polymer brush-functionalized magnetic manganite nanoparticles for remotely triggered drug release, Polym. Chem. 3 (2012) 14081417.

[89] N.Ž. Knežević, E. Ruiz-Hernández, W.E. Hennink, M. Vallet-Regí, Magnetic mesoporous silicabased core/shell nanoparticles for biomedical applications, RSC Adv. 3 (2013) 9584-9593. doi:10.1039/C3RA23127E.

[90] C. Liu, J. Guo, W. Yang, J. Hu, C. Wang, S. Fu, Magnetic mesoporous silica microspheres with thermo-sensitive polymer shell for controlled drug release, J. Mater. Chem. 19 (2009) 47644770. doi:10.1039/B902985K.

[91] E. Guisasola, A. Baeza, M. Talelli, D. Arcos, M. Vallet-Regí, Design of thermoresponsive polymeric gates with opposite controlled release behaviors, RSC Adv. 6 (2016) 42510-42516.

[92] J. Rubio-Retama, N.E. Zafeiropoulos, C. Serafinelli, R. Rojas-Reyna, B. Voit, E. Lopez Cabarcos, $M$. Stamm, Synthesis and characterization of thermosensitive PNIPAM microgels covered with superparamagnetic $\gamma$-Fe2O3 nanoparticles, Langmuir. 23 (2007) 10280-10285.

[93] Osmotically driven drug delivery through remote-controlled magnetic nanocomposite membranes, Biomicrofluidics. 9 (2015) 54113. doi:10.1063/1.4931954.

[94] M.B. Yatvin, J.N. Weinstein, W.H. Dennis, R. Blumenthal, Design of liposomes for enhanced local release of drugs by hyperthermia, Science. 202 (1978) 1290-1293.

[95] J.N. Weinstein, R.L. Magin, M.B. Yatvin, D.S. Zaharko, Liposomes and local hyperthermia: selective delivery of methotrexate to heated tumors, Science. 204 (1979) 188-191. doi:10.1126/science.432641. 
[96] K. Maruyama, S. Unezaki, N. Takahashi, M. Iwatsuru, Enhanced delivery of doxorubicin to tumor by long-circulating thermosensitive liposomes and local hyperthermia, Biochim. Biophys. Acta BBA-Biomembr. 1149 (1993) 209-216.

[97] D. Needham, M.W. Dewhirst, The development and testing of a new temperature-sensitive drug delivery system for the treatment of solid tumors, Adv. Drug Deliv. Rev. 53 (2001) 285305.

[98] L.H. Lindner, M.E. Eichhorn, H. Eibl, N. Teichert, M. Schmitt-Sody, R.D. Issels, M. Dellian, Novel temperature-sensitive liposomes with prolonged circulation time, Clin. Cancer Res. 10 (2004) 2168-2178.

[99] Q. Chen, A. Krol, A. Wright, D. Needham, M.W. Dewhirst, F. Yuan, Tumor microvascular permeability is a key determinant for antivascular effects of doxorubicin encapsulated in a temperature sensitive liposome, Int. J. Hyperthermia. 24 (2008) 475-482.

[100] T.M. Zagar, Z. Vujaskovic, S. Formenti, H. Rugo, F. Muggia, B. O'Connor, R. Myerson, P. Stauffer, I.-C. Hsu, C. Diederich, others, Two phase I dose-escalation/pharmacokinetics studies of low temperature liposomal doxorubicin (LTLD) and mild local hyperthermia in heavily pretreated patients with local regionally recurrent breast cancer, Int. J. Hyperthermia. 30 (2014) 285-294.

[101] C. Sanson, O. Diou, J. Thévenot, E. Ibarboure, A. Soum, A. Brûlet, S. Miraux, E. Thiaudière, S. Tan, A. Brisson, V. Dupuis, O. Sandre, S. Lecommandoux, Doxorubicin Loaded Magnetic Polymersomes: Theranostic Nanocarriers for MR Imaging and Magneto-Chemotherapy, ACS Nano. 5 (2011) 1122-1140. doi:10.1021/nn102762f.

[102] H. Oliveira, E. Pérez-Andrés, J. Thevenot, O. Sandre, E. Berra, S. Lecommandoux, Magnetic field triggered drug release from polymersomes for cancer therapeutics, J. Controlled Release. 169 (2013) 165-170.

[103] S.-H. Hu, S.-Y. Chen, X. Gao, Multifunctional Nanocapsules for Simultaneous Encapsulation of Hydrophilic and Hydrophobic Compounds and On-Demand Release, ACS Nano. 6 (2012) 25582565. doi:10.1021/nn205023w.

[104] W.-L. Chiang, C.-J. Ke, Z.-X. Liao, S.-Y. Chen, F.-R. Chen, C.-Y. Tsai, Y. Xia, H.-W. Sung, Pulsatile Drug Release from PLGA Hollow Microspheres by Controlling the Permeability of Their Walls with a Magnetic Field, Small. 8 (2012) 3584-3588. doi:10.1002/smll.201201743.

[105] S.D. Kong, M. Sartor, C.-M.J. Hu, W. Zhang, L. Zhang, S. Jin, Magnetic field activated lipidpolymer hybrid nanoparticles for stimuli-responsive drug release, Acta Biomater. 9 (2013) 5447-5452.

[106] A.M. Derfus, G. von Maltzahn, T.J. Harris, T. Duza, K.S. Vecchio, E. Ruoslahti, S.N. Bhatia, Remotely Triggered Release from Magnetic Nanoparticles, Adv. Mater. 19 (2007) 3932-3936. doi:10.1002/adma.200700091.

[107] E. Ruiz-Hernandez, A. Baeza, M. Vallet-Regí, Smart drug delivery through DNA/magnetic nanoparticle gates, ACS Nano. 5 (2011) 1259-1266.

[108] M. Banchelli, S. Nappini, C. Montis, M. Bonini, P. Canton, D. Berti, P. Baglioni, Magnetic nanoparticle clusters as actuators of ssDNA release, Phys. Chem. Chem. Phys. 16 (2014) 1002310031.

[109] J.T. Dias, M. Moros, P. del Pino, S. Rivera, V. Grazú, J.M. de la Fuente, DNA as a molecular local thermal probe for the analysis of magnetic hyperthermia, Angew. Chem. 125 (2013) 1174011743.

[110] C.R. Thomas, D.P. Ferris, J.-H. Lee, E. Choi, M.H. Cho, E.S. Kim, J.F. Stoddart, J.-S. Shin, J. Cheon, J.I. Zink, Noninvasive remote-controlled release of drug molecules in vitro using magnetic actuation of mechanized nanoparticles, J. Am. Chem. Soc. 132 (2010) 10623-10625.

[111] A. Riedinger, P. Guardia, A. Curcio, M.A. Garcia, R. Cingolani, L. Manna, T. Pellegrino, Subnanometer local temperature probing and remotely controlled drug release based on azofunctionalized iron oxide nanoparticles, Nano Lett. 13 (2013) 2399-2406.

[112] P. Saint-Cricq, S. Deshayes, J.I. Zink, A.M. Kasko, Magnetic field activated drug delivery using thermodegradable azo-functionalised PEG-coated core-shell mesoporous silica nanoparticles, Nanoscale. 7 (2015) 13168-13172. 
[113] T.T. N'Guyen, H.T. Duong, J. Basuki, V. Montembault, S. Pascual, C. Guibert, J. Fresnais, C. Boyer, M.R. Whittaker, T.P. Davis, others, Functional Iron Oxide Magnetic Nanoparticles with Hyperthermia-Induced Drug Release Ability by Using a Combination of Orthogonal Click Reactions, Angew. Chem. Int. Ed. 52 (2013) 14152-14156.

[114] S. Yamashita, H. Fukushima, Y. Niidome, T. Mori, Y. Katayama, T. Niidome, Controlled-release system mediated by a retro Diels-Alder reaction induced by the photothermal effect of gold nanorods, Langmuir. 27 (2011) 14621-14626.

[115] Functionalized Nanoparticles for Magnetically-Guided, Heat-Induced Drug Delivery (12087) | Flintbox, (n.d.). http://www.flintbox.com/public/project/26926 (accessed October 10, 2016).

[116] J. Liu, C. Detrembleur, A. Debuigne, M.-C. De Pauw-Gillet, S. Mornet, L. Vander Elst, S. Laurent, C. Labrugère, E. Duguet, C. Jérôme, Poly (acrylic acid)-block-poly (vinyl alcohol) anchored maghemite nanoparticles designed for multi-stimuli triggered drug release, Nanoscale. 5 (2013) 11464-11477.

[117] T.J. Daou, J.M. Grenèche, G. Pourroy, S. Buathong, A. Derory, C. Ulhaq-Bouillet, B. Donnio, D. Guillon, S. Begin-Colin, Coupling Agent Effect on Magnetic Properties of Functionalized Magnetite-Based Nanoparticles, Chem. Mater. 20 (2008) 5869-5875. doi:10.1021/cm801405n.

[118] T.J. Daou, G. Pourroy, J.M. Greneche, A. Bertin, D. Felder-Flesch, S. Begin-Colin, Water soluble dendronized iron oxide nanoparticles, Dalton Trans. (2009) 4442-4449. doi:10.1039/B823187G.

[119] M. Liong, H. Shao, J.B. Haun, H. Lee, R. Weissleder, Carboxymethylated polyvinyl alcohol stabilizes doped ferrofluids for biological applications, Adv. Mater. 22 (2010) 5168-5172.

[120] R. De Palma, S. Peeters, M.J. Van Bael, H. Van den Rul, K. Bonroy, W. Laureyn, J. Mullens, G. Borghs, G. Maes, Silane ligand exchange to make hydrophobic superparamagnetic nanoparticles water-dispersible, Chem. Mater. 19 (2007) 1821-1831.

[121] G. Hemery, E. Garanger, S. Lecommandoux, A.D. Wong, E.R. Gillies, B. Pedrono, T. Bayle, D. Jacob, $\mathrm{O}$. Sandre, Thermosensitive polymer-grafted iron oxide nanoparticles studied by in situ dynamic light backscattering under magnetic hyperthermia, J. Phys. Appl. Phys. 48 (2015) 494001.

[122] A. Hervault, A.E. Dunn, M. Lim, C. Boyer, D. Mott, S. Maenosono, N.T. Thanh, Doxorubicin loaded dual $\mathrm{pH}$-and thermo-responsive magnetic nanocarrier for combined magnetic hyperthermia and targeted controlled drug delivery applications, Nanoscale. (2016). http://pubs.rsc.org/is/content/articlehtml/2016/nr/c5nr07773g (accessed October 10, 2016).

[123] X.-Y. Wang, D. Mertz, C. Blanco-Andujar, A. Bora, M. Ménard, F. Meyer, C. Giraudeau, S. BéginColin, Optimizing the silanization of thermally-decomposed iron oxide nanoparticles for efficient aqueous phase transfer and MRI applications, RSC Adv. 6 (2016) 93784-93793. doi:10.1039/C6RA18360C.

[124] T. Lam, P.K. Avti, P. Pouliot, J.-C. Tardif, É. Rhéaume, F. Lesage, A. Kakkar, Surface engineering of SPIONs: role of phosphonate ligand multivalency in tailoring their efficacy, Nanotechnology. 27 (2016) 415602.

[125] C. Ghobril, G. Popa, A. Parat, C. Billotey, J. Taleb, P. Bonazza, S. Begin-Colin, D. Felder-Flesch, A bisphosphonate tweezers and clickable PEGylated PAMAM dendrons for the preparation of functional iron oxide nanoparticles displaying renal and hepatobiliary elimination, Chem. Commun. 49 (2013) 9158-9160.

[126] T. Blin, A. Kakinen, E.H. Pilkington, A. Ivask, F. Ding, J.F. Quinn, M.R. Whittaker, P.C. Ke, T.P. Davis, Synthesis and in vitro properties of iron oxide nanoparticles grafted with brushed phosphorylcholine and polyethylene glycol, Polym. Chem. 7 (2016) 1931-1944.

[127] R. Barbey, L. Lavanant, D. Paripovic, N. Schüwer, C. Sugnaux, S. Tugulu, H.-A. Klok, Polymer brushes via surface-initiated controlled radical polymerization: synthesis, characterization, properties, and applications, Chem. Rev. 109 (2009) 5437-5527.

[128] D. Mertz, C.J. Ochs, Z. Zhu, L. Lee, S.N. Guntari, G.K. Such, T.K. Goh, L.A. Connal, A. Blencowe, G.G. Qiao, others, ATRP-mediated continuous assembly of polymers for the preparation of nanoscale films, Chem. Commun. 47 (2011) 12601-12603. 
[129] T.K. Goh, S.N. Guntari, C.J. Ochs, A. Blencowe, D. Mertz, L.A. Connal, G.K. Such, G.G. Qiao, F. Caruso, Nanoengineered Films via Surface-Confined Continuous Assembly of Polymers, Small. 7 (2011) 2863-2867.

[130] J.O. Zoppe, N.C. Ataman, P. Mocny, J. Wang, J. Moraes, H.-A. Klok, Surface-Initiated Controlled Radical Polymerization: State-of-the-Art, Opportunities, and Challenges in Surface and Interface Engineering with Polymer Brushes, Chem. Rev. 117 (2017) 1105-1318. doi:10.1021/acs.chemrev.6b00314.

[131] A. Yao, Q. Chen, F. Ai, D. Wang, W. Huang, Preparation and characterization of temperatureresponsive magnetic composite particles for multi-modal cancer therapy, J. Mater. Sci. Mater. Med. 22 (2011) 2239. doi:10.1007/s10856-011-4413-5.

[132] M. Rahimi, A. Wadajkar, K. Subramanian, M. Yousef, W. Cui, J.-T. Hsieh, K.T. Nguyen, In vitro evaluation of novel polymer-coated magnetic nanoparticles for controlled drug delivery, Nanomedicine Nanotechnol. Biol. Med. 6 (2010) 672-680. doi:10.1016/j.nano.2010.01.012.

[133] L. Zhu, Z. Huo, L. Wang, X. Tong, Y. Xiao, K. Ni, Targeted delivery of methotrexate to skeletal muscular tissue by thermosensitive magnetoliposomes, Int. J. Pharm. 370 (2009) 136-143.

[134] G. Béalle, R. Di Corato, J. Kolosnjaj-Tabi, V. Dupuis, O. Clément, F. Gazeau, C. Wilhelm, C. Ménager, Ultra magnetic liposomes for MR imaging, targeting, and hyperthermia, Langmuir. 28 (2012) 11834-11842.

[135] R. Di Corato, G. Béalle, J. Kolosnjaj-Tabi, A. Espinosa, O. Clement, A.K. Silva, C. Menager, C. Wilhelm, Combining magnetic hyperthermia and photodynamic therapy for tumor ablation with photoresponsive magnetic liposomes, ACS Nano. 9 (2015) 2904-2916.

[136] M.-S. Martina, J.-P. Fortin, C. Ménager, O. Clément, G. Barratt, C. Grabielle-Madelmont, F. Gazeau, V. Cabuil, S. Lesieur, Generation of superparamagnetic liposomes revealed as highly efficient MRI contrast agents for in vivo imaging, J. Am. Chem. Soc. 127 (2005) 10676-10685.

[137] P. Pradhan, J. Giri, F. Rieken, C. Koch, O. Mykhaylyk, M. Döblinger, R. Banerjee, D. Bahadur, C. Plank, Targeted temperature sensitive magnetic liposomes for thermo-chemotherapy, J. Controlled Release. 142 (2010) 108-121.

[138] Y. Chen, A. Bose, G.D. Bothun, Controlled release from bilayer-decorated magnetoliposomes via electromagnetic heating, ACS Nano. 4 (2010) 3215-3221.

[139] K. Katagiri, Y. Imai, K. Koumoto, T. Kaiden, K. Kono, S. Aoshima, Magnetoresponsive OnDemand Release of Hybrid Liposomes Formed from Fe3O4 Nanoparticles and Thermosensitive Block Copolymers, Small. 7 (2011) 1683-1689. doi:10.1002/smll.201002180.

[140] E. Amstad, J. Kohlbrecher, E. Müller, T. Schweizer, M. Textor, E. Reimhult, Triggered release from liposomes through magnetic actuation of iron oxide nanoparticle containing membranes, Nano Lett. 11 (2011) 1664-1670.

[141] S. Nappini, M. Bonini, F. Ridi, P. Baglioni, Structure and permeability of magnetoliposomes loaded with hydrophobic magnetic nanoparticles in the presence of a low frequency magnetic field, Soft Matter. 7 (2011) 4801-4811. doi:10.1039/COSM01264E.

[142] G. Haran, R. Cohen, L.K. Bar, Y. Barenholz, Transmembrane ammonium sulfate gradients in liposomes produce efficient and stable entrapment of amphipathic weak bases, Biochim. Biophys. Acta BBA - Biomembr. 1151 (1993) 201-215. doi:10.1016/0005-2736(93)90105-9.

[143] P.M. Peiris, L. Bauer, R. Toy, E. Tran, J. Pansky, E. Doolittle, E. Schmidt, E. Hayden, A. Mayer, R.A. Keri, M.A. Griswold, E. Karathanasis, Enhanced Delivery of Chemotherapy to Tumors Using a Multicomponent Nanochain with Radio-Frequency-Tunable Drug Release, ACS Nano. 6 (2012) 4157-4168. doi:10.1021/nn300652p.

[144] W.-H. Chiang, W.-C. Huang, C.-W. Chang, M.-Y. Shen, Z.-F. Shih, Y.-F. Huang, S.-C. Lin, H.-C. Chiu, Functionalized polymersomes with outlayered polyelectrolyte gels for potential tumor-targeted delivery of multimodal therapies and MR imaging, J. Controlled Release. 168 (2013) 280-288. doi:10.1016/j.jconrel.2013.03.029.

[145] T.-Y. Liu, K.-H. Liu, D.-M. Liu, S.-Y. Chen, I.-W. Chen, Temperature-Sensitive Nanocapsules for Controlled Drug Release Caused by Magnetically Triggered Structural Disruption, Adv. Funct. Mater. 19 (2009) 616-623. 
[146] M.B. Bannwarth, S. Ebert, M. Lauck, U. Ziener, S. Tomcin, G. Jakob, K. Münnemann, V. Mailänder, A. Musyanovych, K. Landfester, Tailor-Made Nanocontainers for Combined Magnetic-Field-Induced Release and MRI, Macromol. Biosci. 14 (2014) 1205-1214.

[147] S.-H. Hu, C.-H. Tsai, C.-F. Liao, D.-M. Liu, S.-Y. Chen, Controlled rupture of magnetic polyelectrolyte microcapsules for drug delivery, Langmuir. 24 (2008) 11811-11818.

[148] A.Z. Abbasi, L. Gutiérrez, L.L. del Mercato, F. Herranz, O. Chubykalo-Fesenko, S. VeintemillasVerdaguer, W.J. Parak, M.P. Morales, J.M. González, A. Hernando, others, Magnetic capsules for NMR imaging: effect of magnetic nanoparticles spatial distribution and aggregation, J. Phys. Chem. C. 115 (2011) 6257-6264.

[149] K. Katagiri, M. Nakamura, K. Koumoto, Magnetoresponsive smart capsules formed with polyelectrolytes, lipid bilayers and magnetic nanoparticles, ACS Appl. Mater. Interfaces. 2 (2010) 768-773.

[150] M. Nakamura, K. Katagiri, K. Koumoto, Preparation of hybrid hollow capsules formed with Fe 3 $\mathrm{O} 4$ and polyelectrolytes via the layer-by-layer assembly and the aqueous solution process, J. Colloid Interface Sci. 341 (2010) 64-68.

[151] A.N. Zelikin, J.F. Quinn, F. Caruso, Disulfide cross-linked polymer capsules: en route to biodeconstructible systems, Biomacromolecules. 7 (2006) 27-30.

[152] G.K. Such, E. Tjipto, A. Postma, A.P. Johnston, F. Caruso, Ultrathin, responsive polymer click capsules, Nano Lett. 7 (2007) 1706-1710.

[153] J. Cui, Y. Yan, G.K. Such, K. Liang, C.J. Ochs, A. Postma, F. Caruso, Immobilization and intracellular delivery of an anticancer drug using mussel-inspired polydopamine capsules, Biomacromolecules. 13 (2012) 2225-2228.

[154] D. Mertz, P. Tan, Y. Wang, T.K. Goh, A. Blencowe, F. Caruso, Bromoisobutyramide as an Intermolecular Surface Binder for the Preparation of Free-standing Biopolymer Assemblies, Adv. Mater. 23 (2011) 5668-5673.

[155] D. Mertz, H. Wu, J.S. Wong, J. Cui, P. Tan, R. Alles, F. Caruso, Ultrathin, bioresponsive and drugfunctionalized protein capsules, J. Mater. Chem. 22 (2012) 21434-21442.

[156] D. Mertz, J. Cui, Y. Yan, G. Devlin, C. Chaubaroux, A. Dochter, R. Alles, P. Lavalle, J.C. Voegel, A. Blencowe, others, Protein capsules assembled via isobutyramide grafts: sequential growth, biofunctionalization, and cellular uptake, ACS Nano. 6 (2012) 7584-7594.

[157] D. Mertz, C. Affolter-Zbaraszczuk, J. Barthès, J. Cui, F. Caruso, T.F. Baumert, J.-C. Voegel, J. Ogier, F. Meyer, Templated assembly of albumin-based nanoparticles for simultaneous gene silencing and magnetic resonance imaging, Nanoscale. 6 (2014) 11676-11680.

[158] K. Kataoka, T. Matsumoto, M. Yokoyama, T. Okano, Y. Sakurai, S. Fukushima, K. Okamoto, G.S. Kwon, Doxorubicin-loaded poly (ethylene glycol)-poly ( $\beta$-benzyl-I-aspartate) copolymer micelles: their pharmaceutical characteristics and biological significance, J. Controlled Release. 64 (2000) 143-153.

[159] F. Kohori, K. Sakai, T. Aoyagi, M. Yokoyama, Y. Sakurai, T. Okano, Preparation and characterization of thermally responsive block copolymer micelles comprising poly ( $\mathrm{N}$ isopropylacrylamide-b-DL-lactide), J. Controlled Release. 55 (1998) 87-98.

[160] J.E. Chung, M. Yokoyama, M. Yamato, T. Aoyagi, Y. Sakurai, T. Okano, Thermo-responsive drug delivery from polymeric micelles constructed using block copolymers of poly ( $\mathrm{N}$ isopropylacrylamide) and poly (butylmethacrylate), J. Controlled Release. 62 (1999) 115-127.

[161] F. Kohori, K. Sakai, T. Aoyagi, M. Yokoyama, M. Yamato, Y. Sakurai, T. Okano, Control of adriamycin cytotoxic activity using thermally responsive polymeric micelles composed of poly (N-isopropylacrylamide-co-N, N-dimethylacrylamide)-b-poly (D, L-lactide), Colloids Surf. B Biointerfaces. 16 (1999) 195-205.

[162] D. Neradovic, O. Soga, C.F. Van Nostrum, W.E. Hennink, The effect of the processing and formulation parameters on the size of nanoparticles based on block copolymers of poly (ethylene glycol) and poly ( $\mathrm{N}$-isopropylacrylamide) with and without hydrolytically sensitive groups, Biomaterials. 25 (2004) 2409-2418. 
[163] H. Ai, C. Flask, B. Weinberg, X.-T. Shuai, M.D. Pagel, D. Farrell, J. Duerk, J. Gao, MagnetiteLoaded Polymeric Micelles as Ultrasensitive Magnetic-Resonance Probes, Adv. Mater. 17 (2005) 1949-1952.

[164] S. Lecommandoux, O. Sandre, F. Chécot, J. Rodriguez-Hernandez, R. Perzynski, Magnetic nanocomposite micelles and vesicles, Adv. Mater. 17 (2005) 712-718.

[165] W. Agut, D. Taton, A. Brûlet, O. Sandre, S. Lecommandoux, Depletion induced vesicle-to-micelle transition from self-assembled rod-coil diblock copolymers with spherical magnetic nanoparticles, Soft Matter. 7 (2011) 9744-9750.

[166] C. Barbe, J. Bartlett, L. Kong, K. Finnie, H.Q. Lin, M. Larkin, S. Calleja, A. Bush, G. Calleja, Silica particles: a novel drug-delivery system, Adv. Mater. 16 (2004) 1959-1966.

[167] S.-H. Hu, T.-Y. Liu, H.-Y. Huang, D.-M. Liu, S.-Y. Chen, Magnetic-sensitive silica nanospheres for controlled drug release, Langmuir. 24 (2008) 239-244.

[168] S.-H. Hu, S.-Y. Chen, D.-M. Liu, C.-S. Hsiao, Core/Single-Crystal-Shell Nanospheres for Controlled Drug Release via a Magnetically Triggered Rupturing Mechanism, Adv. Mater. 20 (2008) 26902695.

[169] Z. Li, J.C. Barnes, A. Bosoy, J.F. Stoddart, J.I. Zink, Mesoporous silica nanoparticles in biomedical applications, Chem. Soc. Rev. 41 (2012) 2590-2605. doi:10.1039/C1CS15246G.

[170] P. Yang, S. Gai, J. Lin, Functionalized mesoporous silica materials for controlled drug delivery, Chem. Soc. Rev. 41 (2012) 3679-3698. doi:10.1039/C2CS15308D.

[171] F. Tang, L. Li, D. Chen, Mesoporous silica nanoparticles: synthesis, biocompatibility and drug delivery, Adv. Mater. 24 (2012) 1504-1534.

[172] Y. Wang, H. Gu, Core-Shell-Type Magnetic Mesoporous Silica Nanocomposites for Bioimaging and Therapeutic Agent Delivery, Adv. Mater. 27 (2015) 576-585. doi:10.1002/adma.201401124.

[173] J. Kim, H.S. Kim, N. Lee, T. Kim, H. Kim, T. Yu, I.C. Song, W.K. Moon, T. Hyeon, Multifunctional uniform nanoparticles composed of a magnetite nanocrystal core and a mesoporous silica shell for magnetic resonance and fluorescence imaging and for drug delivery, Angew. Chem. Int. Ed. 47 (2008) 8438-8441.

[174] F. Ye, S. Laurent, A. Fornara, L. Astolfi, J. Qin, A. Roch, A. Martini, M.S. Toprak, R.N. Muller, M. Muhammed, Uniform mesoporous silica coated iron oxide nanoparticles as a highly efficient, nontoxic MRI T2 contrast agent with tunable proton relaxivities, Contrast Media Mol. Imaging. 7 (2012) 460-468.

[175] J. Shen, Q. He, Y. Gao, J. Shi, Y. Li, Mesoporous silica nanoparticles loading doxorubicin reverse multidrug resistance: performance and mechanism, Nanoscale. 3 (2011) 4314-4322. doi:10.1039/C1NR10580A.

[176] J. Liu, C. Detrembleur, M.-C. De Pauw-Gillet, S. Mornet, L. Vander Elst, S. Laurent, C. Jérôme, E. Duguet, Heat-triggered drug release systems based on mesoporous silica nanoparticles filled with a maghemite core and phase-change molecules as gatekeepers, J. Mater. Chem. B. 2 (2014) 59-70.

[177] J. Lu, M. Liong, J.I. Zink, F. Tamanoi, Mesoporous silica nanoparticles as a delivery system for hydrophobic anticancer drugs, Small. 3 (2007) 1341-1346.

[178] M. Liong, J. Lu, M. Kovochich, T. Xia, S.G. Ruehm, A.E. Nel, F. Tamanoi, J.I. Zink, Multifunctional inorganic nanoparticles for imaging, targeting, and drug delivery, ACS Nano. 2 (2008) 889-896.

[179] L. Yuan, Q. Tang, D. Yang, J.Z. Zhang, F. Zhang, J. Hu, Preparation of pH-responsive mesoporous silica nanoparticles and their application in controlled drug delivery, J. Phys. Chem. C. 115 (2011) 9926-9932.

[180] N.Ž. Knežević, I.I. Slowing, V.S.-Y. Lin, Tuning the release of anticancer drugs from magnetic iron oxide/mesoporous silica core/shell nanoparticles, ChemPlusChem. 77 (2012) 48-55.

[181] U. Bhardwaj, D.J. Burgess, A novel USP apparatus 4 based release testing method for dispersed systems, Int. J. Pharm. 388 (2010) 287-294.

[182] P. Costa, J.M.S. Lobo, Modeling and comparison of dissolution profiles, Eur. J. Pharm. Sci. 13 (2001) 123-133. 
[183] H. Kakwere, M.P. Leal, M.E. Materia, A. Curcio, P. Guardia, D. Niculaes, R. Marotta, A. Falqui, T. Pellegrino, Functionalization of strongly interacting magnetic nanocubes with (thermo) responsive coating and their application in hyperthermia and heat-triggered drug delivery, ACS Appl. Mater. Interfaces. 7 (2015) 10132-10145.

[184] N. Griffete, J. Fresnais, A. Espinosa, C. Wilhelm, A. Bée, C. Ménager, Design of magnetic molecularly imprinted polymer nanoparticles for controlled release of doxorubicin under an alternative magnetic field in athermal conditions, Nanoscale. 7 (2015) 18891-18896.

[185] D. Yoo, H. Jeong, S.-H. Noh, J.-H. Lee, J. Cheon, Magnetically Triggered Dual Functional Nanoparticles for Resistance-Free Apoptotic Hyperthermia, Angew. Chem. Int. Ed. 52 (2013) 13047-13051.

[186] T.-J. Li, C.-C. Huang, P.-W. Ruan, K.-Y. Chuang, K.-J. Huang, D.-B. Shieh, C.-S. Yeh, In vivo anticancer efficacy of magnetite nanocrystal-based system using locoregional hyperthermia combined with 5-fluorouracil chemotherapy, Biomaterials. 34 (2013) 7873-7883.

[187] Y. Xu, A. Karmakar, W.E. Heberlein, T. Mustafa, A.R. Biris, A.S. Biris, Multifunctional magnetic nanoparticles for synergistic enhancement of cancer treatment by combinatorial radio frequency thermolysis and drug delivery, Adv. Healthc. Mater. 1 (2012) 493-501.

[188] M.W. Dewhirst, C.D. Landon, C.L. Hofmann, P.R. Stauffer, Novel approaches to treatment of hepatocellular carcinoma and hepatic metastases using thermal ablation and thermosensitive liposomes, Surg. Oncol. Clin. N. Am. 22 (2013) 545-561.

[189] M. Babincova, P. Čičmanec, V. Altanerova, Č. Altaner, P. Babinec, AC-magnetic field controlled drug release from magnetoliposomes: design of a method for site-specific chemotherapy, Bioelectrochemistry. 55 (2002) 17-19.

[190] M. De Cuyper, M. Joniau, Magnetoliposomes, Eur. Biophys. J. 15 (1988) 311-319.

[191] M. De Cuyper, S. Valtonen, Investigation of the spontaneous transferability of a phospholipidpoly (ethylene glycol)-biotin derivative from small unilamellar phospholipid vesicles to magnetoliposomes, J. Magn. Magn. Mater. 225 (2001) 89-94.

[192] L.D. Mayer, L.C. Tai, M.B. Bally, G.N. Mitilenes, R.S. Ginsberg, P.R. Cullis, Characterization of liposomal systems containing doxorubicin entrapped in response to $\mathrm{pH}$ gradients, Biochim. Biophys. Acta BBA-Biomembr. 1025 (1990) 143-151.

[193] J. Hanuš, M. Ullrich, J. Dohnal, M. Singh, F. Štěpánek, Remotely controlled diffusion from magnetic liposome microgels, Langmuir. 29 (2013) 4381-4387.

[194] H. Guo, W. Chen, X. Sun, Y.-N. Liu, J. Li, J. Wang, Theranostic magnetoliposomes coated by carboxymethyl dextran with controlled release by low-frequency alternating magnetic field, Carbohydr. Polym. 118 (2015) 209-217.

[195] B.M. Discher, Y.-Y. Won, D.S. Ege, J.C. Lee, F.S. Bates, D.E. Discher, D.A. Hammer, Polymersomes: tough vesicles made from diblock copolymers, Science. 284 (1999) 1143-1146.

[196] H. Bermudez, A.K. Brannan, D.A. Hammer, F.S. Bates, D.E. Discher, Molecular weight dependence of polymersome membrane structure, elasticity, and stability, Macromolecules. 35 (2002) 8203-8208.

[197] M. Krack, H. Hohenberg, A. Kornowski, P. Lindner, H. Weller, S. Förster, Nanoparticle-loaded magnetophoretic vesicles, J. Am. Chem. Soc. 130 (2008) 7315-7320.

[198] R.J. Hickey, A.S. Haynes, J.M. Kikkawa, S.-J. Park, Controlling the self-assembly structure of magnetic nanoparticles and amphiphilic block-copolymers: from micelles to vesicles, J. Am. Chem. Soc. 133 (2011) 1517-1525.

[199] T. Ren, Q. Liu, H. Lu, H. Liu, X. Zhang, J. Du, Multifunctional polymer vesicles for ultrasensitive magnetic resonance imaging and drug delivery, J. Mater. Chem. 22 (2012) 12329-12338.

[200] B. Karagoz, J. Yeow, L. Esser, S.M. Prakash, R.P. Kuchel, T.P. Davis, C. Boyer, An efficient and highly versatile synthetic route to prepare iron oxide nanoparticles/nanocomposites with tunable morphologies, Langmuir. 30 (2014) 10493-10502.

[201] D. Bacinello, E. Garanger, D. Taton, K.C. Tam, S. Lecommandoux, Tailored drug-release from multi-functional polymer-peptide hybrid vesicles, Eur. Polym. J. 62 (2015) 363-373. 
[202] L. Pourtau, H. Oliveira, J. Thevenot, Y. Wan, A.R. Brisson, O. Sandre, S. Miraux, E. Thiaudiere, S. Lecommandoux, Antibody-functionalized magnetic polymersomes: in vivo targeting and imaging of bone metastases using high resolution MRI, Adv. Healthc. Mater. 2 (2013) 14201424.

[203] S.-H. Hu, B.-J. Liao, C.-S. Chiang, P.-J. Chen, I.-W. Chen, S.-Y. Chen, Core-Shell Nanocapsules Stabilized by Single-Component Polymer and Nanoparticles for MagnetoChemotherapy/Hyperthermia with Multiple Drugs, Adv. Mater. 24 (2012) 3627-3632.

[204] S. Carregal-Romero, P. Guardia, X. Yu, R. Hartmann, T. Pellegrino, W.J. Parak, Magnetically triggered release of molecular cargo from iron oxide nanoparticle loaded microcapsules, Nanoscale. 7 (2015) 570-576.

[205] T.-Y. Liu, S.-H. Hu, K.-H. Liu, R.-S. Shaiu, D.-M. Liu, S.-Y. Chen, Instantaneous drug delivery of magnetic/thermally sensitive nanospheres by a high-frequency magnetic field, Langmuir. 24 (2008) 13306-13311.

[206] H.-Y. Huang, S.-H. Hu, C.-S. Chian, S.-Y. Chen, H.-Y. Lai, Y.-Y. Chen, Self-assembling PVA-F127 thermosensitive nanocarriers with highly sensitive magnetically-triggered drug release for epilepsy therapy in vivo, J. Mater. Chem. 22 (2012) 8566-8573.

[207] R. Duncan, Polymer therapeutics as nanomedicines: new perspectives, Curr. Opin. Biotechnol. 22 (2011) 492-501.

[208] R. Duncan, M.J. Vicent, Polymer therapeutics-prospects for 21st century: the end of the beginning, Adv. Drug Deliv. Rev. 65 (2013) 60-70.

[209] L. Zhu, J. Ma, N. Jia, Y. Zhao, H. Shen, Chitosan-coated magnetic nanoparticles as carriers of 5fluorouracil: preparation, characterization and cytotoxicity studies, Colloids Surf. B Biointerfaces. 68 (2009) 1-6.

[210] S. Brulé, M. Levy, C. Wilhelm, D. Letourneur, F. Gazeau, C. Ménager, C. Le Visage, Doxorubicin release triggered by alginate embedded magnetic nanoheaters: a combined therapy, Adv. Mater. 23 (2011) 787-790.

[211] J. Liu, C. Detrembleur, A. Debuigne, M.-C. De Pauw-Gillet, S. Mornet, L. Vander Elst, S. Laurent, E. Duguet, C. Jérôme, Glucose-, pH-and thermo-responsive nanogels crosslinked by functional superparamagnetic maghemite nanoparticles as innovative drug delivery systems, J. Mater. Chem. B. 2 (2014) 1009-1023.

[212] A.R.G. Sivakumar Balasubramanian, Y. Nagaoka, S. Iwai, M. Suzuki, V. Kizhikkilot, Y. Yoshida, T. Maekawa, S.D. Nair, Curcumin and 5-fluorouracil-loaded, folate-and transferrin-decorated polymeric magnetic nanoformulation: a synergistic cancer therapeutic approach, accelerated by magnetic hyperthermia, Int. J. Nanomedicine. 9 (2014) 437.

[213] C. Shi, C. Thum, Q. Zhang, W. Tu, B. Pelaz, W.J. Parak, Y. Zhang, M. Schneider, Inhibition of the cancer-associated TASK 3 channels by magnetically induced thermal release of Tetrandrine from a polymeric drug carrier, J. Controlled Release. 237 (2016) 50-60.

[214] H.-C. Kim, E. Kim, S.W. Jeong, T.-L. Ha, S.-I. Park, S.G. Lee, S.J. Lee, S.W. Lee, Magnetic nanoparticle-conjugated polymeric micelles for combined hyperthermia and chemotherapy, Nanoscale. 7 (2015) 16470-16480.

[215] D.-H. Kim, E.A. Vitol, J. Liu, S. Balasubramanian, D.J. Gosztola, E.E. Cohen, V. Novosad, E.A. Rozhkova, Stimuli-responsive magnetic nanomicelles as multifunctional heat and cargo delivery vehicles, Langmuir. 29 (2013) 7425-7432.

[216] S.-H. Hu, D.-M. Liu, W.-L. Tung, C.-F. Liao, S.-Y. Chen, Surfactant-Free, Self-Assembled PVA-Iron Oxide/Silica Core-Shell Nanocarriers for Highly Sensitive, Magnetically Controlled Drug Release and Ultrahigh Cancer Cell Uptake Efficiency, Adv. Funct. Mater. 18 (2008) 2946-2955.

[217] S.-H. Hu, Y.-Y. Chen, T.-C. Liu, T.-H. Tung, D.-M. Liu, S.-Y. Chen, Remotely nano-rupturable yolk/shell capsules for magnetically-triggered drug release, Chem. Commun. 47 (2011) 17761778 .

[218] A. Baeza, E. Guisasola, E. Ruiz-Hernández, M. Vallet-Regí, Magnetically triggered multidrug release by hybrid mesoporous silica nanoparticles, Chem. Mater. 24 (2012) 517-524. 
[219] E. Bringas, Ö. Köysüren, D.V. Quach, M. Mahmoudi, E. Aznar, J.D. Roehling, M.D. Marcos, R. Martínez-Máñez, P. Stroeve, Triggered release in lipid bilayer-capped mesoporous silica nanoparticles containing SPION using an alternating magnetic field, Chem. Commun. 48 (2012) 5647-5649.

[220] T. Fontecave, M. Bourbousson, C. Chaneac, C. Wilhelm, A. Espinosa, M.-A. Fortin, C. Sanchez, C. Boissiere, Multifunctional core-shell hybrid nano-composites made using Pickering emulsions: a new design for therapeutic vectors, New J. Chem. 40 (2016) 4436-4446.

[221] M. Iafisco, C. Drouet, A. Adamiano, P. Pascaud, M. Montesi, S. Panseri, S. Sarda, A. Tampieri, Superparamagnetic iron-doped nanocrystalline apatite as a delivery system for doxorubicin, J. Mater. Chem. B. 4 (2016) 57-70.

[222] B.L. Caetano, C. Guibert, R. Fini, J. Fresnais, S.H. Pulcinelli, C. Ménager, C.V. Santilli, Magnetic hyperthermia-induced drug release from ureasil-PEO- $\gamma$-Fe 203 nanocomposites, RSC Adv. 6 (2016) 63291-63295.

[223] M. Yoshida, Y. Watanabe, M. Sato, T. Maehara, H. Aono, T. Naohara, H. Hirazawa, A. Horiuchi, S. Yukumi, K. Sato, others, Feasibility of chemohyperthermia with docetaxel-embedded magnetoliposomes as minimally invasive local treatment for cancer, Int. J. Cancer. 126 (2010) 1955-1965.

[224] L. Wang, J. Zhang, Y. An, Z. Wang, J. Liu, Y. Li, D. Zhang, A study on the thermochemotherapy effect of nanosized As2O3/MZF thermosensitive magnetoliposomes on experimental hepatoma in vitro and in vivo, Nanotechnology. 22 (2011) 315102.

[225] J.-H. Lee, K.-J. Chen, S.-H. Noh, M.A. Garcia, H. Wang, W.-Y. Lin, H. Jeong, B.J. Kong, D.B. Stout, J. Cheon, others, On-demand drug release system for in vivo cancer treatment through selfassembled magnetic nanoparticles, Angew. Chem. 125 (2013) 4480-4484.

[226] M.J. Jeon, C.-H. Ahn, H. Kim, I.J. Chung, S. Jung, Y.-H. Kim, H. Youn, J.W. Chung, Y.I. Kim, The intratumoral administration of ferucarbotran conjugated with doxorubicin improved therapeutic effect by magnetic hyperthermia combined with pharmacotherapy in a hepatocellular carcinoma model, J. Exp. Clin. Cancer Res. 33 (2014) 1.

[227] D.-H. Kim, Y. Guo, Z. Zhang, D. Procissi, J. Nicolai, R.A. Omary, A.C. Larson, TemperatureSensitive Magnetic Drug Carriers for Concurrent Gemcitabine Chemohyperthermia, Adv. Healthc. Mater. 3 (2014) 714-724.

[228] K. Hayashi, M. Nakamura, H. Miki, S. Ozaki, M. Abe, T. Matsumoto, W. Sakamoto, T. Yogo, K. Ishimura, Magnetically responsive smart nanoparticles for cancer treatment with a combination of magnetic hyperthermia and remote-control drug release, Theranostics. 4 (2014) 834. 